Florida International University

FIU Digital Commons

FIU Electronic Theses and Dissertations

University Graduate School

6-12-2019

\title{
Persistence among Emerging Adults with Traumatic Brain Injury in Postsecondary Settings
}

Ardith A. Clayton-Wright

Florida International University, awrig038@fiu.edu

Follow this and additional works at: https://digitalcommons.fiu.edu/etd

Part of the Adult and Continuing Education Commons, Curriculum and Social Inquiry Commons, Educational Psychology Commons, Gender Equity in Education Commons, Higher Education Commons, Social and Behavioral Sciences Commons, Special Education and Teaching Commons, and the Teacher Education and Professional Development Commons

\section{Recommended Citation}

Clayton-Wright, Ardith A., "Persistence among Emerging Adults with Traumatic Brain Injury in Postsecondary Settings" (2019). FIU Electronic Theses and Dissertations. 4211.

https://digitalcommons.fiu.edu/etd/4211

This work is brought to you for free and open access by the University Graduate School at FIU Digital Commons. It has been accepted for inclusion in FIU Electronic Theses and Dissertations by an authorized administrator of FIU Digital Commons. For more information, please contact dcc@fiu.edu. 


\section{FLORIDA INTERNATIONAL UNIVERSITY}

Miami, Florida

\section{PERSISTENCE AMONG EMERGING ADULTS WITH TRAUMATIC BRAIN}

INJURY IN POSTSECONDARY SETTINGS

A dissertation submitted in partial fulfillment of the

requirements for the degree of

DOCTOR OF EDUCATION

in

ADULT EDUCATION AND HUMAN RESOURCE DEVELOPMENT

by

Ardith Clayton-Wright

2019 
To: Dean Michael R. Heithaus

College of Arts, Sciences and Education

This dissertation, written by Ardith Clayton-Wright, and entitled Persistence among Emerging Adults with Traumatic Brain Injury in Postsecondary Settings, having been approved in respect to style and intellectual content, is referred to you for judgment.

We have read this dissertation and recommend that it be approved.

$\begin{array}{r}\hline \text { Benjamin Baez } \\ \hline \text { Elizabeth Cramer } \\ \hline \text { Joanne Sanders-Reio } \\ \hline \text { Thomas G. Reio Jr., Major Professor }\end{array}$

Date of Defense: June 12, 2019

The dissertation of Ardith Clayton-Wright is approved.

Dean Michael R. Heithaus

College of Arts, Sciences and Education

Andrés G. Gil

Vice President for Research and Economic Development and Dean of the University Graduate School

Florida International University, 2019 
(C) Copyright 2019 by Ardith Clayton-Wright

All rights reserved 


\section{DEDICATION}

I dedicate this dissertation to my children, Alysia Zoe-Blanche Wright and James S. Wright II and in memory of Mrs. Dulcie Blanche McGill Clayton and Mrs. Aimee Yvonne Blake Smith Without their love, patience, support, and most of all of your prayers, the completion of this work would not have been possible. 


\section{ACKNOWLEDGMENTS}

I would first like to thank God for taking me this far, when I thought that I could not make it. I thank God for providing me with a beautiful family who have always been there for me. Alysia and James have been my inspiration and my source of motivation. My parents, Pastor and Mrs. Caleb Clayton, (my mother now deceased) never doubted my ability. Gratitude extends to my siblings and close friends with special note to, Jasmine Clayton Flynn, Dr. Judith Clayton Gomez, Dr. Orville Clayton, Dr. Hensworth Weaver, Dwight Nimblette, Danielle Redman, Dr. Ralford Jones, Dr. Devin Avery, Dr. Erskine Dottin and Dr. Mickey Weirner, for turning around and giving me a helping hand. A special thank you to my niece, Danielle Redman, who was my graphic artist. Thanks to my dissertation major professor, Dr. Thomas Reio, Jr., and committee members, Dr. Benjamin Baez, Dr. Elizabeth Cramer and Dr, Joanne Sanders-Reio. A special thank you to the staff of Florida International University Biostatistics office and my church family, Fort Lauderdale Seventh-day Adventist Church. 


\title{
ABSTRACT OF THE DISSERTATION
}

\section{PERSISTENCE AMONG EMERGING ADULTS WITH TRAUMATIC BRAIN INJURY IN POSTSECONDARY SETTINGS}

by

$$
\text { Ardith Clayton-Wright }
$$

Florida International University, 2019

\author{
Miami, Florida \\ Professor Thomas G. Reio, Jr., Major Professor
}

This longitudinal study sought to investigate the demographic and sociopsychological factors associated with predicting persistence in postsecondary education among emerging adults with traumatic brain injury. The predicting variables in this study were: (a) gender (sex), (b) socioeconomic status (SES), (c) employment, (d) years of education; (e) age at onset of injury, (f) existence of familial capital/parental involvement, and $(\mathrm{g})$ hours spent studying for a class.

Data were obtained from a secondary dataset collected by the Traumatic Brain Injury Model Systems National Data and Statistical Center longitudinal database. There were 2436 participants with TBI in the study. Ages ranged from 16 to 29 at injury, with a median age of 22 . Males $(75 \%, n=1,825)$ outnumbered females $(25.0 \%, n=608)$ in the sample by a factor of three to one.

Logistic regression analysis revealed that while there was not a significant relationship among gender and persistence among the emerging adults with TBI, there 
were significant negative relationships between socioeconomic status, age, and years of education at time of injury, hours worked, and persistence. In contrast, years of education at follow-up, time spent studying, and familial support were positively associated with persistence.

Additional research is needed to develop more refined measures of familial and social support to tease out these findings with samples beyond the U.S. Future research should also include self-regulation strategy measures to gain further indepth understanding of how studying is linked to persistence. Finally, hours working while attending school and time spent studying could be examined in conjunction with moderator variables to acquire new theoretical and empirical insights into persistence among emerging adults with TBI. Building upon the results, academic advisors and administrators could target hours worked, time spent studying and social integration as leverage points to improve the likelihood of persistence with the understudied group. 


\section{TABLE OF CONTENTS}

CHAPTER

PAGE

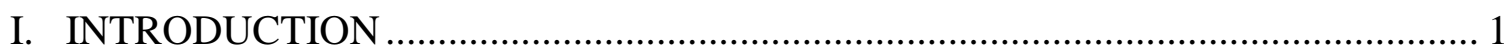

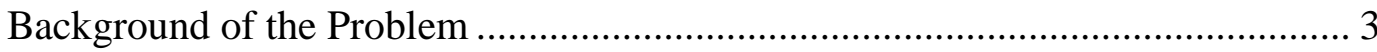

Problem Statement …………………………………............................... 7

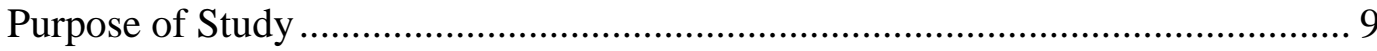

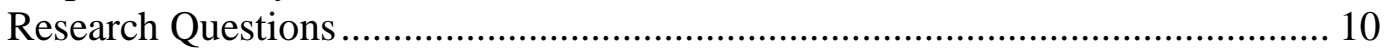

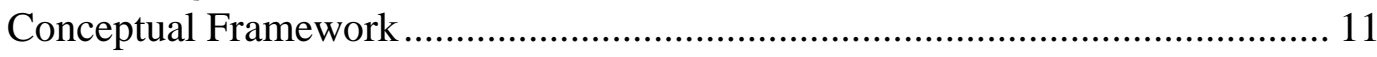

Significance of the Study ................................................................................ 17

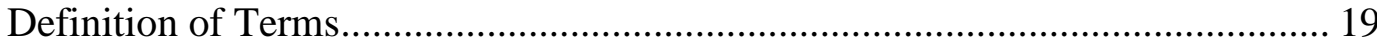

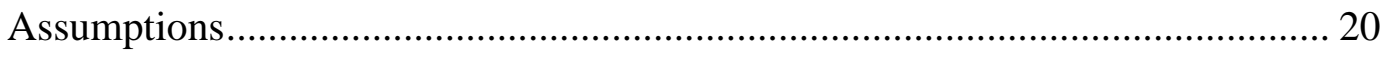

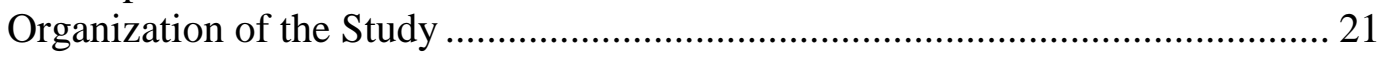

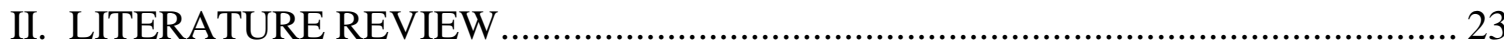

Traumatic Brain Injury in Emerging Adults ..................................................... 24

Conceptual Framework ...............................................28

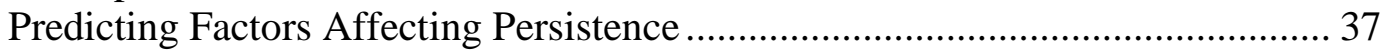

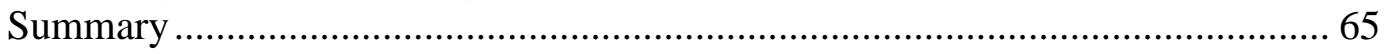

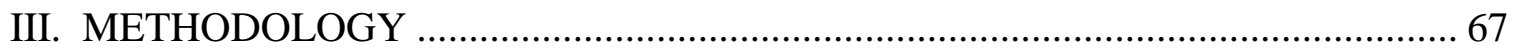

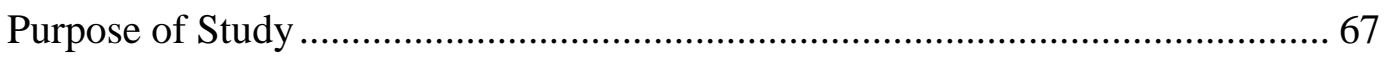

Research Questions and Hypotheses .............................................................. 68

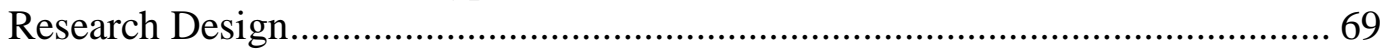

Population and Sample Size....................................................................... 71

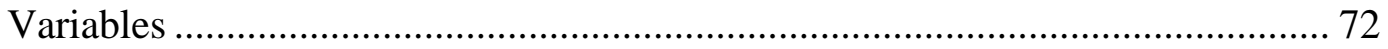

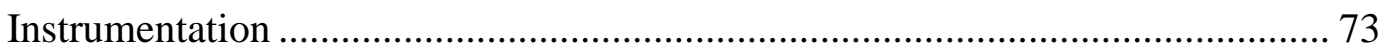

Data Collection Procedures............................................................................... 79

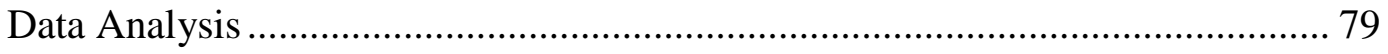

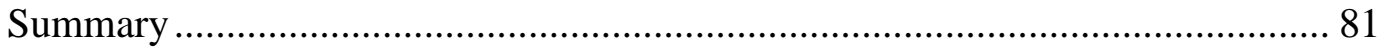

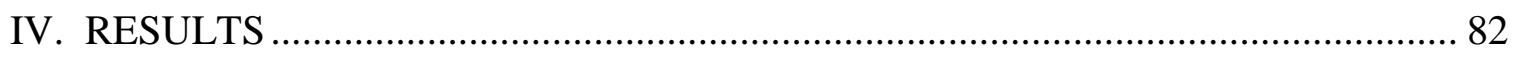

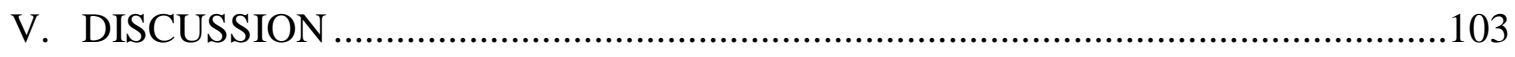

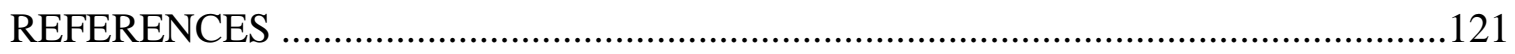

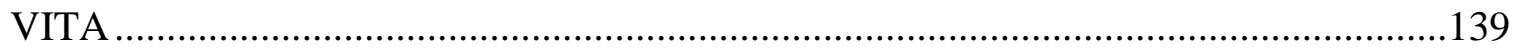




\section{LIST OF TABLES}

TABLE

PAGE

1. Description of Self-Motivated Participants .32

2 Multivariate Analysis of Covariance (MANCOVA) for Differences between High and Low Self-Efficacy Groups

3. Intercorrelations between GPA and Subscales of the MSLQ: Motivational Orientations, Cognitive MetaCognitive Strategies and Resource Management

4. Summary of Hierarchical Regression Analysis for Motivational Orientations .....36

5 Outcome of Longitudinal Study on Individuals with TBI and Individuals with Non-TBI

6. Stepwise Regression Analysis ................................................................65

7. Predicting Variables Description ...................................... 70

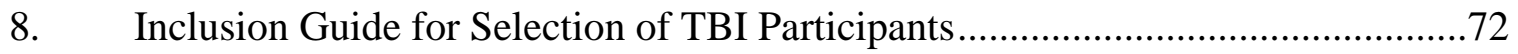

9. Measurement of Participants with Disability Attributes and Challenges ..............73

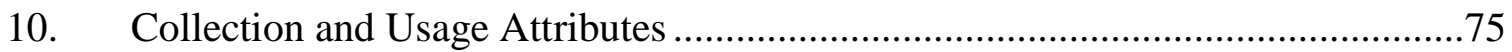

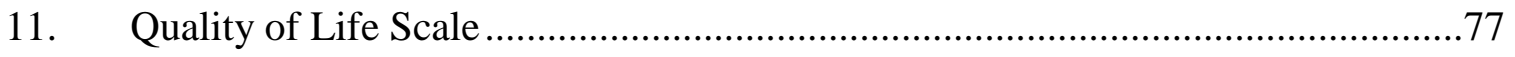

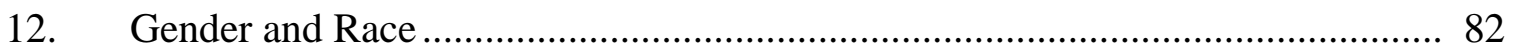

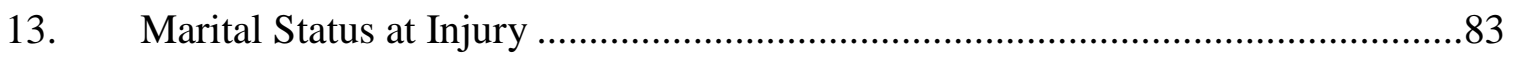

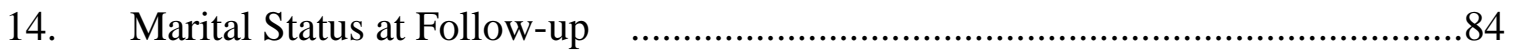

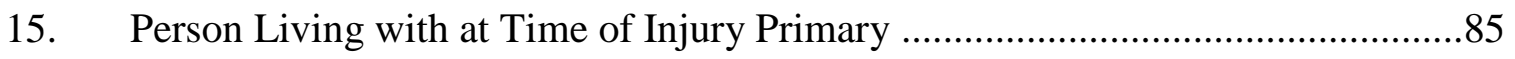

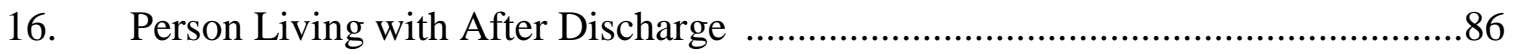

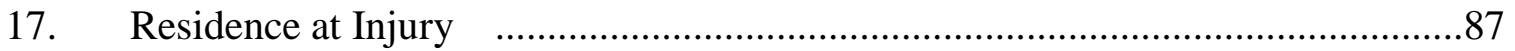

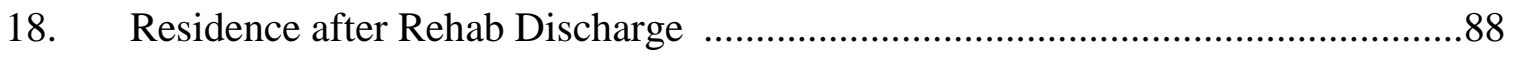

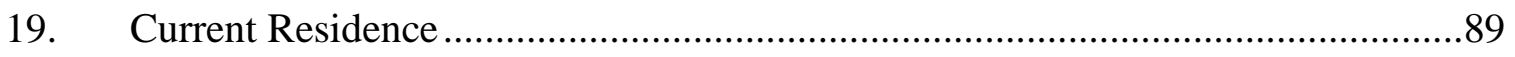

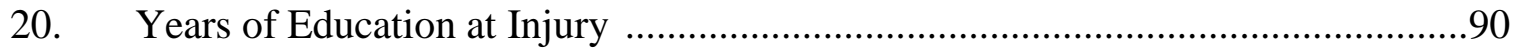

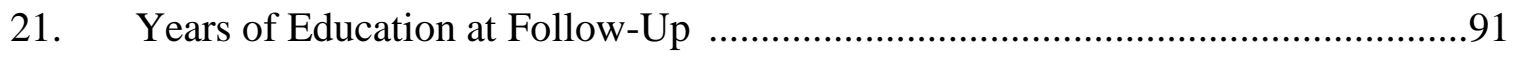




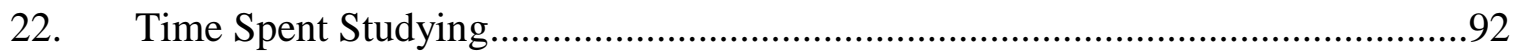

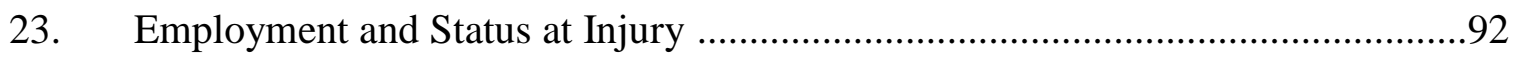

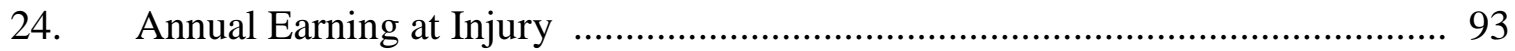

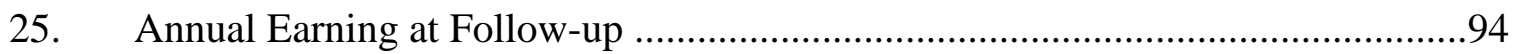

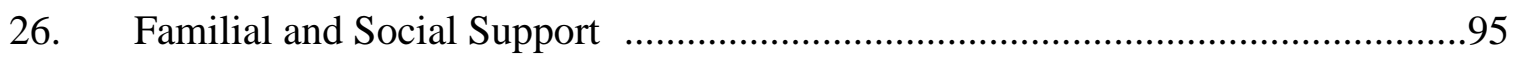

27. Coefficient for Logistic Regression Model for Research Question One ....... 97

28. School Participation by Time Spent Studying ...............................................98

29. Coefficient of Logistic Regression for Research Question 2 ...........................100

30. Summary of Hypothesis and Outcomes ..........................................................101 


\section{LIST OF FIGURES}

FIGURE

PAGE

1. Poor Academic Achievement as it is Linked to being an Emerging

Adult with Traumatic Brain Injury...............................................................

2. Model of Variables Linked to Persistence among Emerging Adults with TBI ....10

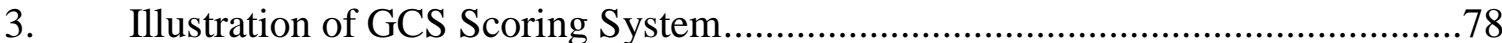




\section{CHAPTER I}

\section{INTRODUCTION}

The confidence and belief that success is conceivable is crucial for the existence of persistence (Crisp, Taggart, \& Nora, 2015). Persistence, as defined by Tinto (1993), is the ability to adjust to postsecondary education and the ability to perform academically by meeting many required minimal standards. Postsecondary education is the pursuit of higher education after the completion of high school (secondary) or general education diploma. In the present study, postsecondary education excludes vocational or trade schools. Persistence is motivation driven and is crafted by the student's major life experiences and intense desire to stay in college and graduate (Baran, \& Kiliç, 2015; Tinto, 2016). The intense desire that results in persistence is believed to be comprised of three components: (a) self-efficacy (Bandura, 2010, 2011)-belief of self's ability to succeed at a specific task or situation; (b) sense of belonging (Carey, 2016; Maslow, 1943; Nunez \& Sansone, 2016)-feeling as a part of a community, such as a school body; and (c) perceived value of the student's curriculum-perception of studies possessing adequate value and significance to deserve their time and effort (Goldrick-Rab, 2016; Tinto, 2016).

Researchers suggest that "emerging" adults (18-29 years of age) participating in postsecondary education seem to have greater difficulty with academic motivation (persistence) than their older counterparts (O’Neill \& Thomson, 2013). Emerging adult theory provides that this period of the lifespan is a distinct and identifiable period of demographic, subjective, and age specific foci (Arnett, 2014; Tanner \& Arnett, 2011). Arnett $(2000,2011,2014)$ defines the emerging adulthood period, typically between the 
ages of 18 to 29 , as the time from the end of adolescence to the young adulthood when, though not universally set, the responsibilities of a stable job, marriage and parenthood come in view. It is during the emerging adult period that the emerging adult spends significant time and energy thinking about themselves and exploring their identities (Arnett, 2014; Douglas, 2007). While spending time being curious and exploring new identities during the emerging adult period (Reio, Portes \& Nixon, 2014), it is not uncommon that postsecondary education persistence among emerging adults suffers, as decisions about where and what to do with one's life, are delayed or dropped altogether (Mason, 2016). Thinking about themselves and exploring their identities are of particular concern for emerging adults with traumatic brain injuries (TBI) because of their higher risk for postsecondary education dropout (Holland \& Schmidt, 2015).

Traumatic brain injury, one of the greatest causes of death and disability in the United States, contributes to a third of all injury deaths (Centers of Disease Control [CDC], 2017; Holland \& Schmidt, 2015). Closed-head brain injury resulting in TBI can occur from a bump, blow, or jolt to the head, or a penetrating head injury that interrupts the normal function of the brain (United States Department of Veteran Affairs, 2018). Traumatic brain injury affects all branches of life on multiple levels such as: physical, psychological, social, and spiritual, all of which have been linked to academic performance; more so, among emerging adults in postsecondary education because they are in a period of exploring their identities (Deidrick \& Farmer, 2005; Faul, Xu, Wald, \& Coronado, 2010; Mason, 2016).

The focus of the present study is the persistence of emerging adults with TBI in pursuing postsecondary education. The study focused on investigating the role of 
demographic and socio-psychological factors associated with predicting persistence in postsecondary education among emerging adults with traumatic brain injury. This chapter provides a background of the problem as well as the problem statement that is addressed in the study. The chapter also provides a detailed discussion of the purpose of the study and introduce the research questions posed. This chapter will also provide a discussion of the conceptual framework that will guide this study. This chapter will end with a list of term definitions and a summary.

\section{Background of the Problem}

Individuals with brain injury may manifest different problems depending on the region of the brain injury. The brain injury addressed in this project focuses on traumatic brain injury with damage to the cerebral cortex, specifically TBI. Globally, the World Health Organization (WHO) predicts that by 2020, TBI, a worldwide public health concern, will surpass many diseases as a major cause of death (Hyder et al., 2007). Approximately 5.3 million individuals are currently living with TBI in the U.S. (Centers for Disease Control [CDC], 2017). Every year approximately 1.7 million individuals sustain a TBI in the United States and of this number, 50,000 die, 230,000 are hospitalized, and 80,000 to 90,000 individuals experience the onset of long-term disability (CDC, 2017). Although 70 to $80 \%$ of all TBI cases are mild (mTBI) and most recover their cognitive abilities within three months; 15 to $22 \%$ of the TBI cases are presented with symptoms that persist (Faul et al., 2010; McMahon et al., 2014).

Even though the awareness of TBI in the U.S. dates back to as early as in the mid19th century, TBI continues to be of concern with the report of at least one TBI diagnosis every 19 seconds, of which adolescents and emerging adults take the lead (Faul et al., 
2010). Traumatic brain injury, which can range from a mild (mTBI) to severe condition, can completely disrupt the functioning of the brain, with the duration of TBI signs ranging from a few days, to a lifetime of disability.

Numerous studies, such as Helms and Libertz (2014), have been conducted on the causes of TBI and possible ways to prevent or reduce the risk, and methods to advance learning among the service (i.e., military) men and women participating in postsecondary education. Despite all these studies being conducted on TBI, there is still an urgent need for more studies addressing the emerging adult with TBI participating in postsecondary education and the challenges that they face, in addition to the factors that foster their persistence in achieving their postsecondary academic goals. The need has been magnified by the influx of military service personnel with "blast" TBI returning from the battlefield, with the intent to enter postsecondary learning institutions. With the passage of the 2008 Post-9/11 Veterans Education Assistance Act, also known as the GI Bill, there was a surge of more than 300,000 military emerging adults with TBI participating in postsecondary education (Barry, Whiteman, \& MacDermid Wadsworth, 2014; Dortch, 2014).

Understanding how emerging adults with TBI navigate and persist in postsecondary education is vital. Repeated failure of coursework, experiencing frequent feelings of self-doubt, questioning stares from class mates, repeated missed graduation deadlines, aging out of the system, and recurring financial aid issues are some of the challenges that confront the emerging adult with TBI who attempts to navigate college (Barry et al., 2012). 
Apart from investigating the role of persistence among emerging adults with TBI in postsecondary education, there is evidence of increasing gender gap among males and females in the postsecondary setting, where more females portray a higher rate of persistence of academic behavior than their male counterparts (Aud, Fox, \& KewalRamani 2010; Aud, KewalRamani, \& Frohlich, 2011; Goldin, Katz, \& Kuziemko, 2006). Indeed, females have surpassed males in postsecondary retention also known as postsecondary degree attainment (Chellman, Crook, Holod, Schwartz, \& Stiefel, 2011). The increased female participation in postsecondary education, is in contrast to pre-1982 where females trailed behind males in postsecondary education.

It is also interesting to note that socioeconomic status also plays a major role in the persistence level of students participating in postsecondary education (Fuller-Rowell, Evans, Paul, \& Curtis, 2015). Amato (1996) proposes that the higher the income level of parents, the greater the availability of parents' flexibility in assisting students (e.g., emerging adults with TBI) in goal setting and decision-making in postsecondary education (Amato, 1996). Fuller et al. (2015) noted that students, who spent a major portion of their adolescent life in poverty, or poverty compounded with a high level of chaos, demonstrated a lower level of academic persistence.

The effect of employment on academic achievement among emerging adults participating in postsecondary education remains unclear. Researchers have found a link between employment and sleep deprivation. For example, Laberge et al. (2011) and Martin, Hebert, Ledoux, Gaudreault, and Laberge (2012) noted that emerging adults participating in employment while pursuing postsecondary education often suffered from sleep deprivation. Sleep deprivation is often associated with adverse cognitive task 
effects, which includes memory functions (Drummond, Anderson, Straus, Vogel, \& Perez, 2012), which can impact academic performance and ultimately persistence in school.

Many studies associated employment as a negative predictor of poor academic performance, because of insufficient study time and increased fatigue coupled with sleep deprivation (Lammers, Onwuegbuzie, \& Slate, 2001; Miller, Danner, \& Staten, 2008; Staff, Schulenberg, \& Bachman, 2010; Steinberg, \& Cauffman 1996). Investigators such as Dundes and Marx (2006) and Manthei and Gilmore (2005) purported that working manageable hours between 10-19 hours per week resulted in higher grades among students as compared to students who were employed for $\geq 20$ hours per week, or were unemployed. Later studies supported Dundes and Marx' (2006) in claiming that intensive employment of $>20$ hours per week was related to poor academic performance because students were unable to put in the requisite hours of study to master course materials and pass their classes (Lammers et al., 2001; Miller et al., 2008; Staff et al., 2010).

Familial support (e.g., family members and carers) and socioeconomic status play a significant role in academic performance of postsecondary students (Baoyan \& Minggang, 2015; Carey, 2016; Khattab, 2015). Parental involvement is an essential factor in the existence of persistence among emerging adults with TBI participating in postsecondary education. Parental involvement is directly related to the quality of life (QoL) of the emerging adults with TBI as was noted by Chevignard et al., (2016) and Degeneffe and Tucker (2014). Moreover, parents of children who sustained TBI from an early age (i.e, early onset TBI) have reported increased accounts of children suffering 
from anxiety, as compared to children or adults who sustained injury at an older age (Karver et al., 2012). Additional research is needed to determine the impact of age at onset of injury on academic persistence.

The present study seeks to explore how predictor variables such as (a) gender (sex), (b) socioeconomic status (SES), (c) employment, (d) years of education, (e) age at onset of injury, (f) existence of familial capital (support), (g) anxiety, and (h) hours spent studying for a class relate to persistence among emerging adults with TBI, a largely underserved population, in postsecondary education.

\section{Problem Statement}

Little is known of the contributing factors influencing persistence in the academic performance of emerging adults with TBI engaged in postsecondary education. The limited knowledge surrounding the population is currently attributed to the lack of

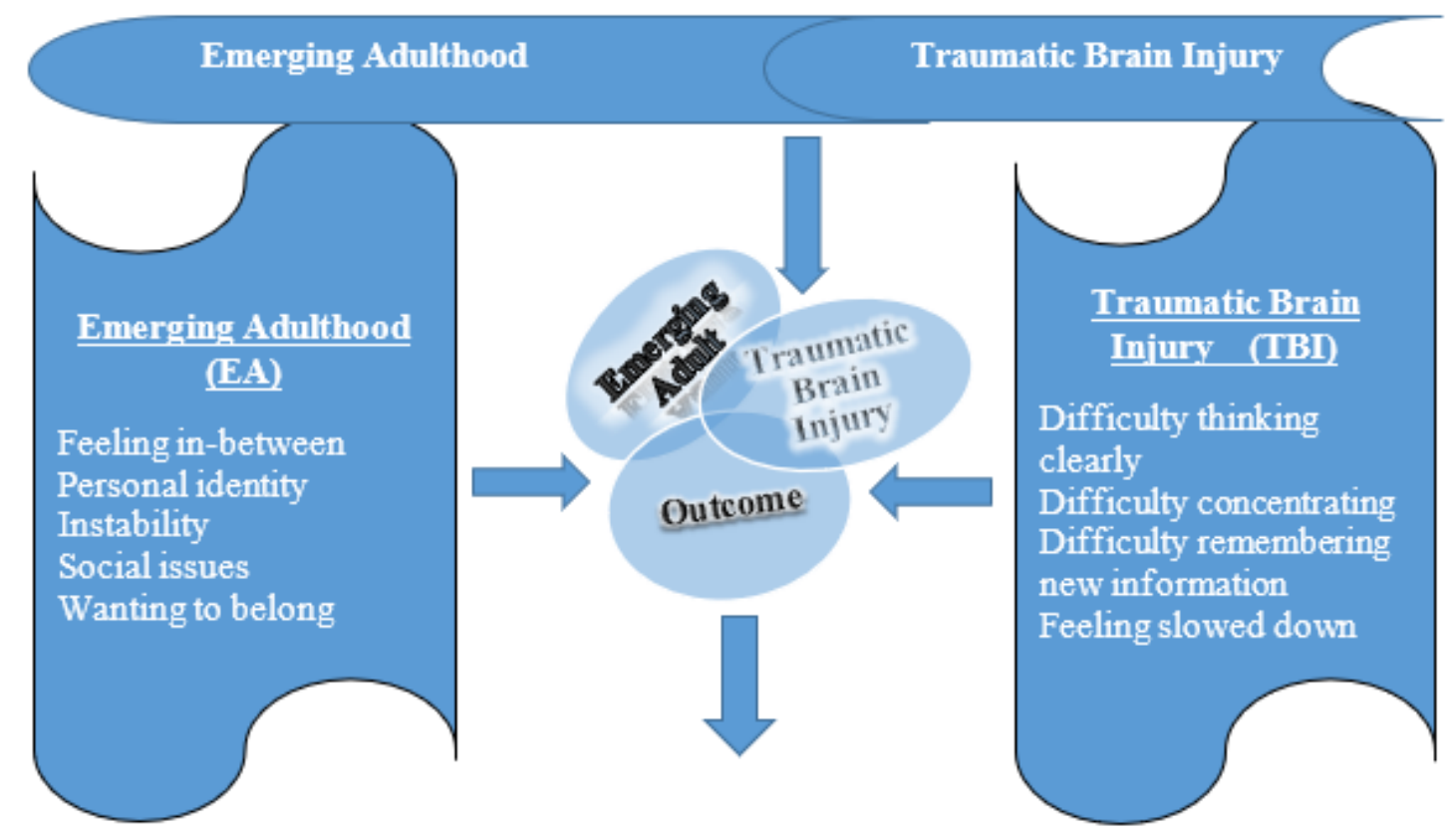

Figure 1. Poor Academic Achievement as it is Linked to being an Emerging Adult with Traumatic Brain Injury. 
available research addressing the existence of challenges faced by the emerging adults with TBI who are participating in postsecondary education. The presence of TBI and the emerging adulthood physiognomies, also referred to as features, have tremendous potential impact on academic performance, as illustrated in Figure 1. Characteristics of TBI affecting academic performance (Centers of Disease Control and Prevention [CDC], 2017) are: (a) impaired cognition, (b) language difficulty, (c) memory loss, (d) attention deficit, (e) reasoning difficulty, (f) abstract thinking impairment, (g) poor judgment, (h) impaired problem-solving, (i) impaired sensory, perceptual, and motor skills, (j) psychosocial behavior; (k) impaired physical functions; (l) information processing; and (m) impaired speech.

While several studies have been conducted regarding young children with TBI and their recovery phases (e.g., Brown, Whittingham, Sofronoff, \& Boyd, 2013; Karver et al., 2012; Khattab, 2015), few studies have been published on the role of persistence among emerging adults with TBI who are participating in postsecondary education. Traumatic brain injury has continued to exist among emerging adult civilians; however, it took the increased inflow of military servicemen to postsecondary settings to rekindle the increased awareness of the need for further studies surrounding the emerging adult with TBI participating in postsecondary education.

Compounding the challenges of the postsecondary-bound emerging adult with TBI, the disability is referred to as the invisible and silent epidemic disability (Amen et al., 2015). The difficulty of emerging adults with TBI is also aggravated with the labeling of poorly performing students who present inappropriate behavioral problems (Amen et al., 2015). The intrinsic need of emerging adults to blend in and function as their peers 
do intensifies the social exclusion that is often times noted among the emerging adults with TBI.

Persistence is a function of being able to adjust to postsecondary education and succeed academically by meeting a number of required minimal standards (Tinto, 1993). Identified predicting factors that can influence postsecondary education persistence among emerging adults with TBI are: (a) gender (sex), (b) socioeconomic status (SES), (c) employment, (d) years of education, (e) age at onset of injury, (f) existence of familial capital (e.g., family support), (g) anxiety, and (h) hours spent studying for a class (Chiang, Guo, Huang, Lee, \& Fan, 2016). For the purpose of the current study, lack of persistence is referred to dropping out from postsecondary education during the specified period of study assigned to the research. Therefore, the study addresses the gap in literature which has yet to investigate persistence among emerging adults with TBI in postsecondary education. Moreover, the study investigates the extent to which demographic and socio-psychological factors predict persistence among emerging adults with TBI in postsecondary education.

\section{Purpose of Study}

The purpose of the study is to investigate the association between demographic and socio-psychological factors and persistence in postsecondary education among emerging adults with traumatic brain injury. Each of the demographic and sociopsychological variables have been linked to persistence per se, but the combination of variables has not been studied with regards to persistence among students with TBI in the emerging adulthood period (ages 18-29; Arnett, 2014). The predicting variables employed in the current study are: (a) gender (sex), (b) socioeconomic status (SES), (c) 
employment, (d) years of education; (e) age at onset of injury, (f) existence of familial capital/parental involvement, and (g) hours spent studying for a class.

Being cognizant of promising research variables that forecast persistence among emerging adults with TBI is critical to understanding persistence within this underserved group in the postsecondary education setting. Figure 2 depicts the variables linked to persistence identified in this research.

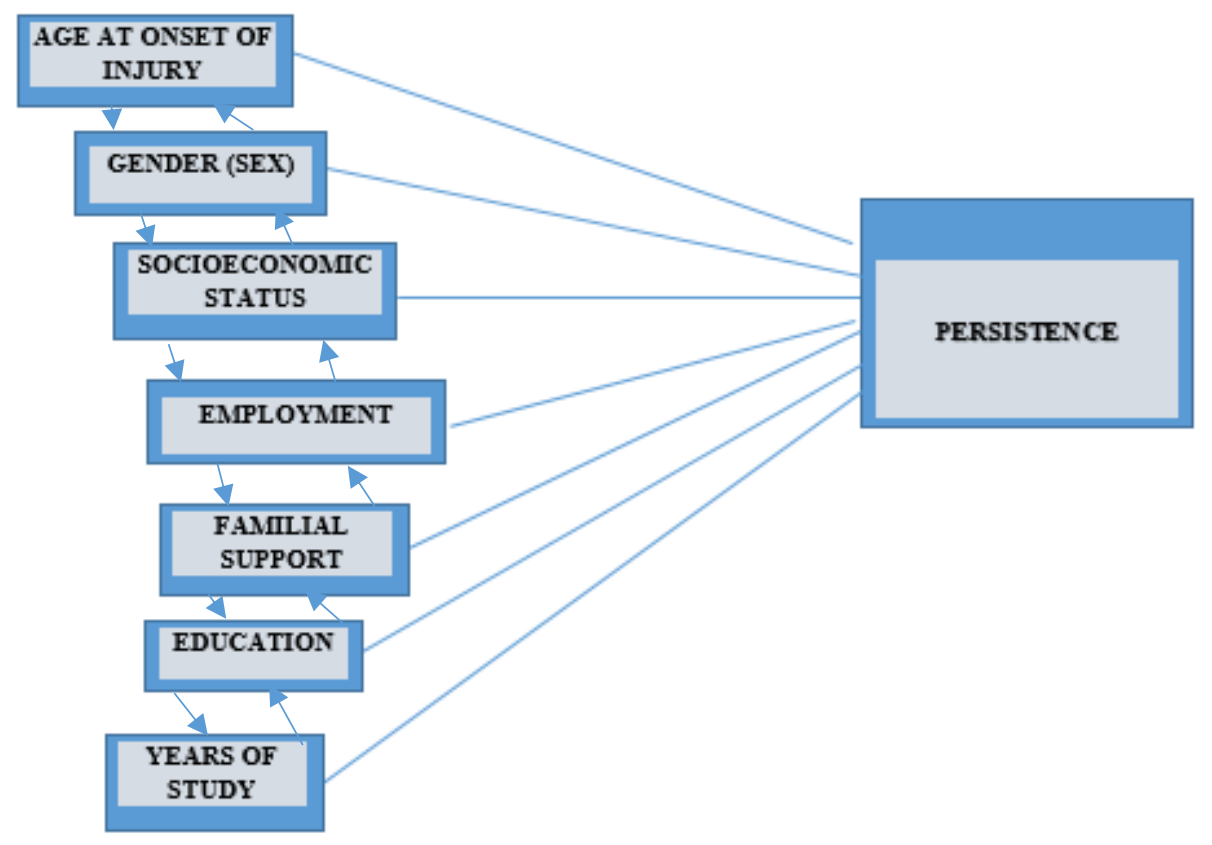

Figure 2. Model of Variables Linked to Persistence among Emerging Adults with TBI.

\section{Research Questions}

The following research questions and accompanying hypotheses will guide the study:

RQ1: Is there a relationship among gender, socioeconomic status, time spent studying, age at onset of injury, employment, years of education and persistence in postsecondary education among emerging adults with TBI? 
$\mathrm{H}_{1}$ : There is a significant relationship among gender (sex), socioeconomic status, time spent studying, age at onset of injury, employment, and years of education (independent variables) and persistence among emerging adults with TBI in postsecondary education.

$\mathrm{H}_{01}$ : There is no significant relationship among gender, socioeconomic status, time spent studying, age at onset of injury, employment, and years of education (independent variables) and persistence among emerging adults with TBI in postsecondary education.

RQ2: Is there a relationship between familial support and persistence in postsecondary education among emerging adults with traumatic brain injury?

$\mathrm{H}_{2}$ : There is a significant relationship between familial support and persistence among emerging adults with TBI in postsecondary education.

$\mathrm{H}_{02}$ : There is no significant relationship between familial support and persistence among emerging adults with TBI in postsecondary education.

\section{Conceptual Framework}

Many researchers have echoed their concerns about the limited body of knowledge regarding the academic performance and functionality of emerging adults with TBI participating in postsecondary education (Scott et al., 2015; Rosema et al., 2014; Williamson et al., 2016). Consequently, a review of the literature was conducted. With the researcher's intent of exploring new constructs that may disclose new meanings and understandings of emerging adults with TBI attending college, a combination of 
emerging adulthood theory (Arnett, 2014) and persistence theory (Tinto, 1993) was utilized as the overarching framework for guiding this study.

\section{Emerging Adulthood}

Arnett's (2000) emerging adulthood theory posits that there is a distinct new period of the lifespan (at least in Western cultures) that encompasses ages 18-29 years-ofage. The theory is built upon Erikson's (1968) psychosocial (prolonged period of adolescence where commitments and experimentations are explored in the search for an identity), Levinson's (1978) phases of life (early adulthood corresponds to the novice phase where the individual seeks to progress into an adult's world and build a stable life), and Keniston's (1971) theory of youth (youth is a period of continued role experimentation). In emerging adulthood theory, the period of the lifespan (18-29 years) is unique in at least three unique ways. First, demographically speaking, emerging adulthood for those in industrialized nations is characterized by demographic changes where marriage and parenthood are delayed until the lates 20 s and beyond. Residential status is explored greatly in that it is common for emerging adults to move back and forth from independent living to home again; thus, emerging adults tend to be semiautonomous. In addition, two thirds experiment with periods of cohabitation with a romantic partner. Further, participation in postsecondary education for emerging adults has increased to over $60 \%$, although participation is nonlinear; that is, emerging adults frequently work while going to school. Thus, instability during this time is high and does not abate until the transition to young adulthood in the later twenties (Arnett, 2014). Second, emerging adulthood is distinct subjectively in that emerging adults do not see themselves as being fully adult. In general, when queried, emerging adults would say 
they feel they have reached adulthood in some ways, but in other ways not (Arnett, 2000). Emerging adults tend to attribute being able to accept responsibility for oneself, make independent decisions, and be financially independent to being in their perception an adult. Third, emerging adulthood is a period of identity explorations in love, work, and worldviews, which differs from Erikson's (1968) notion that identity exploration is really a function of adolescence. Explorations in these three areas can be intense and sometimes disappointing, as well as satisfying. To a large extent, emerging adults are optimistic about the future (Arnett, 2000), but there is a great deal of variability.

Emerging Adulthood and TBI. In 2013, an estimated 329,290 emerging adults and children $(\leq 19$-year-old) were treated in U.S. emergency rooms, for sports and recreation-related injuries that included a diagnosis of TBI (Coronado, Haileyesus, Cheng, Bell, Haarbauer-Krupa, Lionbarger, 2015; Taylor, Bell, Breiding, Xu, 2017). Although falls are the leading cause (47\%) of TBI related injuries (Taylor et al., 2017), among emerging adults, motor vehicle accidents are the leading cause of deaths (CDC, 2017).

The combination of TBI and being in the emerging adulthood period can present the perfect dilemma for the individual attending college. The quest of the emerging adult for (a) the ability to make independent decisions, (b) the ability to be self-responsible (independent), and (c) the ability to be financially independent (Arnett, 2014) of parents and careers is challenged when combined with TBI. Traumatic brain injury creates interference in the emerging adulthood phases. Mezirow (2000, 2009) noted that the presence of a new phenomenon (e.g., TBI) that does not seem to fit current worldviews 
can further disorient and prevent the natural process of self-exploration and selfidentification of the emerging adult with TBI.

The emerging adulthood phase, even without the presence of a TBI, is referred to at times, as being tumultuous and painful (Arnett, 2014). It is a time when many emerging adults experience feelings of low esteem and uncertainty. The ability to explore their serpentine paths in college while searching for that "Aha" moment of finally finding their long-sought after major (Arnett, 2014) can become a fleeting and sometimes elusive goal for the emerging adult, especially those with TBI.

The ability of emerging adults with TBI to reintegrate into their new acquired life, with existing conditions such as cognitive and social impairments, and dictated by their newly acquired TBI, is an accomplishment that should be applauded. Fostering selfefficacy, self-determination and self-regulation can assist the emerging adult with TBI with reentry into activities that can enable the accomplishment of postsecondary education goals. Development of study strategies among students (e.g., emerging adults) can result in outstanding academic performance because the study strategies assist students in how to plan, monitor and evaluate their learning and performance (Rosenfeld, Maas, Bragge, Morganti-Kossmann, Manley, \& Gruen, 2012).

The emerging adult with a newly acquired TBI and its concomitant negative effects is at risk for feelings of hopelessness and despair. The phase remains dormant until the emerging adult can embrace the new misfit between their old values and beliefs and the new ones demanded by becoming a fully functioning adult (Arnett, 2004). Convertino (2015) defines misfit as the inability to conform to a particular group or situation. Exploring with others the newly discovered "misfit" between one's principles 
and one's environment, in Arnett's view, is a desirable change. Feelings of loss of control is a common feature among emerging adults with TBI.

\section{Persistence}

Being able to succeed in postsecondary education requires persistence, which is the key factor needed in the endurance of challenges faced by the emerging adult with TBI attending college (Nunez \& Sansone, 2016). As Tinto (2016) indicated, the intense

desire that results in persistence is believed to be comprised of three components: (a) selfefficacy (Bandura, 2010)-belief of self's ability to succeed at a specific task or situation; (b) sense of belonging (Maslow, 1943)-feeling as a part of a community, such as a school body; and (c) perceived value of the student's curriculum (Wigfield \& Eccles, 2000)perception of studies possessing adequate value and significance to deserve their time and effort.

Self-efficacy is important because the belief of one's ability to succeed at a specific task or situation, is an important variable in predicting persistence (Friedman, 2003). Higher efficaciousness rather than lower efficaciousness, is associated with higher achievement instead of lower achievement, among emerging adults engaging in postsecondary education. Students with high levels of self-efficacy exert more effort and persist longer than students with low self-efficacy in the face of difficulties; success requires persistent effort. The belief in one's ability to be successful in academic challenges is therefore vital in postsecondary education.

Belongingness is important because it is an essential hierarchial need of Maslow (1943). Researchers suggest that after the physiological and safety needs are met, the need for self-belongingness, a fundamental component of humans, becomes a necessity 
(Amzat, Don, Fauzee, Hussin, \& Raman, 2017; Levett-Jones \& Lathlean, 2008).

Feelings of self-belongingness adds value and meaning to task and goals among emerging adults with TBI as they strive to surmount seemingly insurmountable hurdles encountered in postsecondary education (Stillman \& Lambert, 2013).

Emerging adults deprived of a sense of belongingness can experience reduced self-esteem, increased stress and anxiety, depression and a reduction in general wellbeing, which increases susceptibility of conformation to poor academic performance (Levett-Jones, Lathlean, Higgins, \& McMillan, 2009). Persistence increases when there is a feeling of belongingness and social interactions and integrations with peers (Kuh, Kinzie, Buckley, Bridges, \& Hayek, 2011; Tinto, 1973, 1993).

Expectancy-value is important as it is perceived as a principal indicator of motivational sources for students in their educational achievement (Eccles \& Wigfield's 1995; Jacobs, Lanza, Osgood, Eccles, \& Wigfield, 2002; Wigfield, 1994). Achievement motivation is dependent on competence-defined expectancy for success and perceived values in the content (Eccles \& Wigfield's 1995; Jacobs et al., 2002). The perceived cost and value of the academic studies and effort involved, by the emerging adult with TBI, will determine their academic performance (Barron \& Hulleman, 2015; Flake, Barron, Hulleman, McCoach \& Welsh, 2015; Perez, Cromley, \& Kaplan, 2014).

Higher levels of perceived value predict higher levels of academic performance (Axler, 2008; Tinto, 2016). Students' expectancy-values can affect academic performances (Wigfield, \& Eccles, 2000). Having the ability to identify available resources (Yosso, 2005), enables the mindset of emerging adults with TBI to view and 
utilize available resources that can enhance academic performance in postsecondary education. Yosso posits that the existence of success among emerging adults' college achievement, is determined by the availability and accessibility of the various resources such as, familial and social, that are necessary toolsets for persistence in postsecondary education among emerging adults with TBI. The awareness will improve the perceived value of postsecondary education among emerging adults with TBI and the skillset needed to enhance learning.

Studies propose that (academic) performance is directly related to ability and motivation of the student (Chan, Schmitt, 2004; Griffin, MacKewn, Moser, \& VanVuren, 2013; Nonis, \& Wright, 2003). Traumatic brain injury limits the ability of the emerging adults to academically perform. Consequently, the fostering of self-efficacy, belongingness, and perceived value can assist the emerging adult with TBI with adapting and modifying learning strategies, and motivating the necessary academic persistence necessary to resume activities that can enable the attainment of postsecondary education goals.

\section{Significance of the Study}

While traumatic brain injury is not new to researchers, there still remains a major gap in the number of available published studies addressing the emerging adult with TBI participating in postsecondary education. With the influx of military service men and women into postsecondary education (Ness, Rocke, Harrist, \& Vroman, 2014; Ness \& Vroman, 2014), the need for additional knowledge in traumatic brain injury has been magnified exponentially. The findings of the present study can provide major contributions to emerging adulthood theory where those with TBI have not been 
sufficiently investigated, and also the fields of adult education and human resource development. Being able to identify predicting variables that can be used to enhance the participation of emerging adults with TBI in postsecondary education may be an accomplishment that will resonate throughout academe. Academic personnel could obtain a clearer understanding of the essential needs and predicting factors of persistence that support postsecondary education among emerging adults with TBI. Researchers will be able to build on the findings of the current study, to further explore the role of other unknown variables, associated with postsecondary education and emerging adults with TBI.

The findings of the present study can assist emerging adults with TBI in ways to maximize their available resources (social, familial, resistance and navigational) as toolsets in their postsecondary education participation. The conceptual framework being utilized in this research may be instrumental in identifying the role of demographics and psychological factors in predicting persistence in postsecondary education among emerging adults with TBI. A viable framework can increase and maximize productivity among individuals with disability such as TBI, which can help enhance the quality of employees in the workforce.

The outcomes of the study may be instrumental in developing strategies to increase persistence and thereby the retention rate of emerging adults with TBI in the academic setting, and within the workforce. The knowledge obtained from this study can empower not only students with disabilities such as TBI, but also policy makers such as academic administrators, human resource directors, governmental leaders, decision 
makers, and other researchers interacting with emerging adults with TBI who are struggling to achieve their career goals.

\section{Definition of Terms}

Emerging adulthood. The term used to describe a new conception of development for the period ranging from the late teens through the mid- to upper twenties. It defines the emerging adulthood period, typically between the ages of 18-to29 , as the time from the end of adolescence to the young adulthood when, though not universally set, the responsibilities of a stable job, marriage and parenthood become in view (Arnett, 2014). The emerging adult spends significant time and energy thinking about themselves and exploring their identities during the period (Arnett, 2014; Douglas 2007).

Implicit theories of intelligence. Is a 14-item measure that refers to an individuals' core beliefs of intelligence. Implicit theories of intelligence (Sternberg, 1985) comprises of two theories, entity, where the intelligence is considered to be fixed and unchangeable and incremental whereby the belief is intelligence, malleable and can be increased with effort

Mindset. The belief that abilities can be learned through effort and persistence, and that the ability to learn is not fixed, but can be changed (Dweck, 2007).

Persistence. The ability to adjust to postsecondary education and the aptitude to succeed in academic performance by meeting a number of required minimal standards (Tinto, 1993). Persistence is considered to be motivation driven and is crafted by the student's major experiences and intense desire to stay in college and graduate (Tinto, 2016). For the purpose of this study, persistence is being defined as the continuation in 
postsecondary education [retention] during the period of study assigned to this research project.

Postsecondary education. Is the pursuit of higher education after the completion of high school (secondary) or general education diploma. In the present study, postsecondary education excludes vocational or trade schools.

Quality of life (QoL). This construct is the perception of the overall well-being of individuals and societies that include negative and positive features of life (Degeneffe \& Tucker, 2012). Chandra and Ozturk ( as cited by Degeneffe \& Tucker, 2012) further clarified QoL as the perception that incorporates physical health, psychological state, level of independence, social relationships, personal values and beliefs and interaction with the environment.

Traumatic brain injury. Traumatic brain injury, which ranges from mild to severe, is caused by a bump, blow, or jolt to the head or a penetrating head injury and interrupts the normal function of the brain (CDC, 2017).

\section{Assumptions}

Traumatic brain injury is perceived as an invisible silent disability (Mueller, Mueller, \& Schoemaker, 2009). Consequently, unless a disability is disclosed, the emerging adult with TBI may be perceived as being dumb, mentally slow, lazy, and/or absent-minded, in addition to many other descriptive assumptions that are unwarranted excuses. The goal of this research is to examine the relationship between persistence in postsecondary education among emerging adults with TBI and predicting factors such as:

(a) gender, (b) socioeconomic status (SES); (c) employment, (d) years of education, (e) age at onset of injury, (f) existence of familial capital, and (g) hours spent studying for a 
class. For the purpose of this study, lack of persistence is referred to dropping out from postsecondary education during the specified period of study assigned to this research.

It is assumed that the data obtained from a Secondary Data Base Center (Lythgow, Hudson, Andras, \& Chinnery, 2011) is accurate. It is also assumed that the personal information of subjects is protected and no information given is in violation of Health Insurance Portability and Accountability Act (HIPAA) during the obtaining and dissemination of the information process. The goal of HIPAA is to protect the privacy of patients.

The research assumes that information obtained from the subjects, information reported by subjects and information entered into the database are accurate. It also assumes that all diagnoses are accurate and there are no incidents of thoughtful misdiagnoses. Finally, it can be assumed that the data collection process was conducted in good faith and there was no attempt by the Secondary Database Center to falsify or exaggerate the information.

\section{Organization of the Study}

The study examined the role of demographic and psychological factors in persistence of postsecondary education among emerging adults with TBI. In the present chapter, the background of the problem, purpose of the study, statement of the problem, research questions, conceptual framework, significance of the study, assumptions, and definition of terms and organization of the study were introduced. Chapter 2 presents a review of literature on predicting factors related to persistence of postsecondary education among emerging adults with TBI. The research design is presented in Chapter 
3 , results in Chapter 4 and the implications of the results for theory, research and practice are presented in Chapter 5. 


\section{CHAPTER II}

\section{LITERATURE REVIEW}

Traumatic brain injury is a significant issue in the United States, as evidenced by its prevalence in the American population (Centers for Disease Control, 2016) and the resulting damage to individuals' cognitive and functional abilities, whether temporary or permanent (Faul et al., 2010; McMahon et al., 2014). Emerging adults are a noteworthy group of concern in relation to traumatic brain injury as the deficits that they experience in language, reasoning, memory, attention, and other cognitive faculties that result from traumatic brain injury can contribute to major difficulty and potential negative impacts on academic performance and learning (Amen et al., 2015; Centers of Disease Control and Prevention, 2016). While past studies have examined the ways in which young children with TBI have recovered and persisted through their education (Karver et al., 2012), there is still a lack of knowledge on the factors that are associated with persistence among emerging adults undergoing postsecondary education. The research problem that the current study aims to address, is the association with persistence among emerging adults with TBI undergoing postsecondary education.

The purpose of the present study, then, is to examine the association between demographic and socio-psychological factors such as (a) gender (sex), (b) socioeconomic status (SES), (c) employment; (d) years of education, (e) age at onset of injury, (f) existence of familial capital/parental involvement, and (g) hours spent studying for a class and persistence in postsecondary education among emerging adults with traumatic brain injury. Knowledge obtained from the study may aid in providing a clearer 
understanding among academic personnel and administrations regarding the needs and facilitators of academic success for emerging adults with traumatic brain surgery.

The literature review is organized into three main themes. The first theme discusses traumatic brain injury, particularly as it affects emerging adults undertaking postsecondary education. The second theme discusses the components of the study's conceptual framework — namely, emerging adult (Arnett, 2000, 2014) and persistence theories (Tinto, 1993) — and how it may apply to persistence among emerging adults with traumatic brain injury. The third theme discusses what is currently known about the relationship between persistence and the variables to be investigated in this study. The chapter will close with a chapter summary. To write the literature review, the following online databases were utilized: Google Scholar, Florida International University database (ProQuest Academic Search), EBSCOhost Online Research Databases, Emerald Insight, and Wiley Online Library. The key search terms that were used to find relevant references included the following: traumatic brain injury, emerging adulthood, academic persistence, gender and persistence, socioeconomic status and persistence, age of onset of brain injury and persistence, familial support and persistence, student employment and persistence, educational level and persistence, and study time and persistence.

\section{Traumatic Brain Injury in Emerging Adults}

Over the past five decades, there has been a significant shift in disability policy making within the USA. The federal government has made efforts to protect the rights of individuals with disabilities and equal opportunity for education for all (Department of Health and Human Services, n.d.). In 1964, the Civil Rights Act of 1964 became the first complete civil rights legislation passed to protect the rights of minorities and other 
marginalized individuals within the education setting. The Civil Rights Act of 1964 was further enforced with the enactment of the Rehabilitation Act of 2004, to ensure that inclusion and accessibility was a reality (Department of Health and Human Services, n.d.).

Accountability and inclusion continued to be of concern at the national level and was addressed with regulations such as the Elementary and Secondary Education Act (ESEA), $1994-2001$ and further reinforced by the 1997 and 2004 authorizations of the Individuals with Disabilities Education Act (IDEA). The overall goal of the government's involvement and the metamorphosis of its laws and regulations was to ensure that the performance of every student with disabilities (SWD) was goal-oriented and that their performances were consistent with their required adequate yearly progress (Thurlow, Quenemoen, Altman, \& Cuthbert, 2008).

Even with the installation of regulations such as No Child Left Behind (NCLB) and IDEA, SWD entering postsecondary arena are met with many challenges. An individual who is diagnosed with a disability while in high school can benefit from the transitional strategies presented by IDEA and is informed of available resources and expected challenges as they contemplate postsecondary education (Denney \& Daviso, 2012). On the contrary, students who develop a disability while participating in postsecondary education will likely not have the knowledge of possible strategies and available accommodation that regulations such as Section 504 of the Rehabilitation Act provides. In the customization of knowledge delivery developed by student's interest, strengths, weaknesses and what is best fitted, federal policies such as an individualized 
education program (IEP) accompanied with IDEA, are able to foster self-advocacy and self-determination [persistence] among students (Denney \& Daviso, 2012).

Traumatic brain injury, a major public health concern, presents significant medical and socioeconomic problems and is the leading cause of death in the emerging adult population (CDC, 2017; Haddad \& Arabi, 2012; Rosenfeld, Maas, Bragge, Morganti-Kossmann, Manley, \& Gruen, 2012). Primary neuropsychological impairment such as cognitive decline can have a significant negative impact on emerging adults with TBI pursuing postsecondary education (Degeneffe \& Tucker, 2012; Kennedy, Krause, \& O’Brien, 2014; Kennedy, Krause, \& Turkstra, 2008).

Individuals with TBI may still be capable of returning to education, as well as many of their regular activities. The brain's ability to regenerate, continues to be of great interest to researchers across a broad range of disciplines. Cognitive reserve, the brain's ability to maintain function despite damage, suggests that the brain is able to resist brain damage and has reserves that lend to the resilience of the recovery process (Schneider et al., 2014). Findings from studies conducted on zebrafish and rats, for example, claim there is evidence of neuron regenerations and proliferations in post-traumatic brain injury (Kernie, Erwin, \& Parada, 2001; Kishimoto, Shimizu, \& Sawamoto, 2012; Sun, 2014), which disputes previous beliefs that the brain is incapable of restoring itself. Moreover, animal study findings continue to support the theory that following an injury, the brain is able to structurally restore and functionally recover, either by only manipulating axon growth regulators, or combined with activity-dependent strategies (Chen \& Zheng, 2014).

Despite the brain's capacity to recover from damage, traumatic brain injury compounded with being an emerging adulthood, creates a volatile condition that can 
present overwhelming challenges to many. Aside from the medical effects of TBI, studies have found that emerging adults commonly experience feelings of in-between, uncertain of own identities, and feelings of wanting to belong combined with other social issues (Arnett, 2004; Lane, 2014). Additionally, identity crises such as feelings of not being an adult and "near-constant life changes propelling one toward adulthood," can be difficult to deal with while navigating postsecondary education (Lane, 2014, p. 30). This state of identity crisis compounds the challenges faced by emerging adults with TBI, who are trying to navigate postsecondary education. The identity crises and other psychological challenges, can oftentimes result in critical life changes among the emerging adults, with exponentially magnified challenges presented with TBI (Lane, 2013; Lee, \& Gramotnev, 2007; Weiss, Freund, \& Wiese, 2012). Repeated failures of coursework, frequent feelings of self-doubt, questioning stares from classmates, repeated missed graduation deadlines, aging out of the system, and recurring financial aid issues are only a few of the real-life challenges faced by emerging adults with TBI while in postsecondary education (Arnett, 2014; Degneffe \& Tucker, 2014; Soria, Weiner, \& Lu, 2014).

Taken together, the literature has suggested that postsecondary education is likely to be a challenging endeavor for emerging adults with TBI. Emerging adults with TBI need to cope not only with the medical after-effects of TBI (Degeneffe, \& Tucker, 2012; Kennedy, Krause, \&Turkstra, 2014), but also with the psychological difficulties of adjusting to a new stage in life that comes naturally with transitioning from adolescence to adulthood (Arnett, 2004; Lane, 2014). On the basis of these findings, there is a great 
need to study the role of persistence among the emerging adult population with TBI, as well as the factors that are associated with persistence.

\section{Conceptual Framework}

The conceptual framework utilized in the study is a combination of the emerging adult (Arnett, 2014, and persistence theories (Tinto, 1993). The framework identifies scientific standards and establishes parameters within which growth, development and goal achievement of the emerging adult with TBI can occur. The twofold framework functions as an identifier and a framework in guiding the investigation of the relationship of the predicting variables and persistence.

\section{Emerging Adulthood}

Arnett's (2014) theory of emerging adulthood identifies and explains the characteristics of what is considered as normal emerging adults. Characteristics that are considered as normal for the emerging adults are but not limited to, (a) risk-taking behaviors; (b) sensation-seeking behaviors, (d) feeling of wanting to belong (e) feeling of need to be financially independent (f) feeling of need to make independent decisions and

(g) feeling of need to be engaged in school activities away from the parental home (Arnett, 2014; Blinn-Pike, Worthy, Jonkman, \& Smith, 2008).

As a result of the injury of the frontal lobes that are responsible for decision making, in addition to other critical cognitive functions, the emerging adult with TBI experiences cognitive and physical impairments which can most often result in outcomes that are below standards (Kennedy, \& Coelho, 2005; Rosema, Muscara, Anderson, Godfrey, Eren, \& Catroppa, 2014). Social expectations for emerging adults with TBI and their actual abilities may be incompatible. Emerging adults with TBI are constantly 
challenged with lack of motivation and the ability to self-regulate because of their brain injury (Hattie \& Temperly, 2007). Consequently, the emerging adult with TBI is at risk for low self-esteem and even self-depreciation.

Although there are limited published Studies regarding the predicting variables and its effect on persistence among emerging adults with TBI, numerous studies have been done addressing the relationship of predicting variables on the emerging adults without TBI. With the researcher's intent of exploring new constructs that may disclose new meanings and understandings (Reio, 2011) of emerging adults with TBI attending college, a combination of emerging adulthood (Arnett, 2014) and persistence (Tinto, 1993) will be utilized as the overarching framework for guiding the study.

\section{Persistence}

Tinto (1993) succinctly defines persistence as the ability to adjust to postsecondary education and the aptitude to succeed in academic performance by meeting a number of required minimal standards. Persistence is considered to be motivation driven and is crafted by the student's major experiences and intense desire to stay in college and graduate (Tinto, 2016). Tinto theorizes that the intense desire to persist in postsecondary education is believed to be comprised of self-efficacy, sense of belonging, and the perceived value of the curriculum (Bandura, 2010; Maslow, 1949, Tinto, 2016). In summary, persistence is the outcome of a mindset of guiding behaviors, in spite of major challenges or obstacles, which could be identified by the student or/and others in the environment.

Being able to identify and deal effectively with the existing academic challenges related to persistence will assist in managing the educational experience for the emerging 
adult with TBI participating in postsecondary education. As noted by Yosso (2005) [cf. Cramer, Pellegrini-Lafont, \& Gonzalez, 2014], individuals often have access to a number of resources that they are unaware of, such as: (a) social, relating to social network, (b) familial, relating to family network, (c) aspiration, relating to personal goals and dreams, (d) navigation, relating to available avenues and resources within the academic institution and that can result in significant life-changing academic achievements for this population, and (e) resistance, relating to knowledge and ability of being a change agent and selfadvocate. Accessing such resources and being integrated into the school increase the likelihood of persistence (Lopez, 2018; Spady, 1970).

Several studies suggest that gender has no statistically significant effect on persistence (Baker \& Velez, 1996; Liu \& Liu, 2000; Wiggam, 2004). However, Tinto (1993), Feldman (1993) and DuBrock and Fenske (2000) argue that gender does have a significant effect on academic persistence. Still, there are gender differences in persistence in that females who are enrolled part-time tend to persist in postsecondary education more than males (Markle, 2015); interestingly, there was not a significant difference between males and females for full-time students. Moreover, a recent study concluded that gender appears to function as a controlling variable that possibly influences the relationship and strength of the dependent variable of academic performance and persistence (Agnew, 2014). Thus, the effects of gender are mixed and therefore merit further research, especially among those students with TBI.

Researchers have concurred that grade point average (GPA) and confidence in graduating are positively associated with persistence (Edwards \& McKelfresh, 2002; Hartley, 2011; Markle, 2015; Herbert, Hong, Byun, Welsh, Kurz, \& Atkinson, 2014; 
Stewart, Doo Hun, \& JoHyun, 2015). For example, in the Herbert et al. (2014) study of students who sought disabilitity services, GPA was by far the most powerful predictor of graduation. Similarly, Stewart et al. (2015) found that high school GPA and firstsemester college GPA were the best predictors of persistence in a longitudinal study of university students. Markle (2015) also discovered that GPA predicted persistence, but also noted that confidence in graduating was a strong predictor of persistence as well among a group of nontraditional undergraduate students.

Rosema et al. (2014) suggested that there are behavioral and emotional links across domains which demonstrate deficits in cognitive skills and are essential to social functions such as executive functions and communication skills. The primary neuropsychological impairment, a physiognomy, referring to a feature, is caused by mild to severe TBI, results in the reduction of information processing speed, which is directly related to deficits in attention, orientation and executive functioning and ultimately affects abilities such as memory (Batista, Zivadinov, Hoogs, Bergsland, Heininen-Brown, Dwyer, ... \& Benedict, 2012; Grossman, Ge, Jensen, Babb, Miles, Reaume, ... \& Inglese, 2012). Cognitive mental and social impairment, which can be manifested from paralysis, seizures, inappropriate social behavior, depression, not comprehending spoken words and inability to control motor skills, are also associated with TBI. Any or all of these characteristics can affect persistence among emerging adults with TBI participating in postsecondary education.

\section{Self-Motivation}

Bandura (1989) theorized self-efficacy as encompassing multiple dimensions that perceive individuals as being (a) agentic-being self-organizing, proactive, and self- 
reflective, (b) purposeful, (c) proactive, (d) self-evaluative, and (e) self-regulatory. Academic self-efficacy has been demonstrated to be a strong predictor of academic achievement (Bandura, 1989). For example, in an empirical study conducted by Komarraju and Nadler (2013), the relationship between self-efficacy and academic achievement was examined with emphasis on why implied beliefs, goals, and effort regulation were important. Komarraju and Nadler included undergraduate students $(N=$ 407) recruited from an Introduction to Psychology subject pool for course credit, and from undergraduate psychology courses for extra credit. Table 1 further describes the participants and setting.

\section{Table 1}

Description of Self-Motivated Participants

\begin{tabular}{|c|c|c|c|c|}
\hline Sample & Race/Ethnicity & Age & Majors & Design \\
\hline $\begin{array}{l}N=407 \\
\text { Men-48 \% } \\
\text { Women-52\% } \\
\text { Freshmen-52\% } \\
\text { Sophomores-12\% } \\
\text { Juniors-17\% } \\
\text { Seniors-18\% }\end{array}$ & $\begin{array}{l}\text { Euro } \\
\text { American- } 66 \% \\
\text { Afr. American- } \\
23 \% \\
\text { All others-11\% }\end{array}$ & $\begin{array}{l}\text { Mean } \\
20.5\end{array}$ & $\begin{array}{l}\text { Liberal arts-29\% } \\
\text { Science-12\% } \\
\text { Bus. admin.-9\% } \\
\text { Education-9\% } \\
\text { Appl.Sci. \& Arts- } \\
7 \% \\
\text { Mass comm. \& } \\
\text { media art-5\% }\end{array}$ & $\begin{array}{l}\text { Take home survey } \\
\text { questionnaire: } \\
\text { 1. } 81 \text { Item } \\
\text { Motivated } \\
\text { Strategies for } \\
\text { Learning } \\
\text { Questionnaire } \\
\text { 2. Assessed } \\
\text { motivational } \\
\text { orientations }\end{array}$ \\
\hline
\end{tabular}

Note. Komarraju, M., \& Nadler, D. (2013). Self-efficacy and academic achievement: Why do implicit beliefs, goals, and effort regulation matter? Learning and Individual Differences, 25, 67-72.

Komarraju and Nadler's (2013) study was guided by the following hypotheses: 
Hypothesis 1. Students who have high self-efficacy are more likely to subscribe to an incremental theory of intelligence compared to students with low self-efficacy (who are more likely to subscribe to an entity theory).

Hypothesis 2. Students who have high self-efficacy will prefer learning/mastery goals relative to students with low self-efficacy.

Hypothesis 3. Students who are highly motivated, confident that they can succeed (intrinsic, extrinsic, and task value, control of learning and self-efficacy, low test anxiety), have well developed cognitive and metacognitive strategies (rehearsal, elaboration, organization, critical thinking, and self-regulation), and make effective use of their resources (time and study environment, effort regulation, peer learning, and help seeking) will report a higher grade point average (GPA).

Hypotheses 1 and 2 showed significant differences between the high self-efficacy and low self-efficacy groups, after controlling for participants age and gender (Table 4), partial $\eta^{2}=.19, F(8,390)=11.383, p<.001$. Gender, partial $\eta^{2}=.06, F(8,390)=3.16, p$ $=.002$, and age, partial $\eta^{2}=.06, F(8,390)=3.21, p=.002$, were significant covariates of implicit theories of intelligence and academic goals. Implicit theories of intelligence and academic goals is a 14-item measure that refers to individuals' core beliefs of intelligence being either fixed (entity theory), or malleable (incremental theory). Univariate ANOVAs revealed significant differences between the two self-efficacy groups on entity theory of intelligence and various goals (achievement outcome, achievement ability, normative outcome, learning, and mastery). The findings also showed that the low selfefficacy group $(M=2.72, S D=1.05)$ scored significantly higher than the high selfefficacy group $(M=2.48, S D=1.11)$ on entity theory of intelligence, partial $\eta^{2}=.01$, 
$F(1,397)=4.95, p=.027$. In addition, the high self-efficacy group scored significantly higher than the low self-efficacy group on achievement outcome goals (partial $\eta^{2}=.07$, $F(1,397)=30.77, p<.001)$, achievement ability goals $\left(\right.$ partial $\eta^{2}=.02, F(1,397)=$ $9.55, p=.002$ ), normative outcome goals (partial $\eta^{2}=.03, F(1,397)=13.22, p<.001$ ), learning goals (partial $\left.\eta^{2}=.13, F(1,397)=57.26, p<.001\right)$, and mastery goals (partial $\eta^{2}$ $=.12, F(1,397)=52.06, p<.001)$.

Regarding Hypothesis 3, the findings showed several significant relationships between GPA and the subscales of the Motivated Strategies for Learning Questionnaire Table 2

Multivariate Analysis of Covariance (MANCOVA) for Differences between High and Low Self-Efficacy Groups in Theories of Intelligence and Academic Goals $(N=407)$

\begin{tabular}{lccccc}
\hline Variable & $\begin{array}{c}\text { Self-efficacy } \\
\text { group }\end{array}$ & $M$ & $S D$ & $F$ & $\begin{array}{l}\text { Partial } \\
\dot{\eta}^{2}\end{array}$ \\
\hline Entity & Low & 2.72 & 1.05 & $4.95^{*}$ & .01 \\
& High & 2.48 & 1.11 & & \\
Incremental & Low & 4.29 & 0.99 & $3.34^{* * *}$ & .01 \\
& High & 4.48 & 1.12 & & \\
Achievement & Low & 5.50 & 0.71 & $30.77^{* * *}$ & .07 \\
Outcome & High & 5.82 & 0.45 & & \\
Achievement Ability & Low & 4.47 & 1.23 & $9.55^{* * * *}$ & .02 \\
& High & 4.83 & 1.24 & & \\
Normative outcome & Low & 4.13 & 1.26 & $13.22^{* * * *}$ & .03 \\
& High & 4.58 & 1.37 & & .00 \\
Normative Ability & Low & 3.13 & 1.28 & .60 & .13 \\
Learning & High & 3.24 & 1.49 & & \\
& Low & 4.74 & .93 & $57.26^{* * * *}$ & .13 \\
Challenge Mastery & High & 5.37 & .74 & & \\
& Low & 3.62 & 1.19 & $52.06^{* * * *}$ & .12 \\
\hline Now & High & 4.47 & 1.17 & & \\
\hline
\end{tabular}

Note. ${ }^{*} p<.05 . * * p<.01 . * * * p<.001$. Adapted from Komarraju, M., \& Nadler, D. (2013). Self-efficacy and academic achievement: Why do implicit beliefs, goals, and effort regulation matter? Learning and Individual Differences, 25, 67-72. 
(MSLQ) as depicted in Table 2. Most noteworthy, college GPA was positively correlated with task value, control of learning beliefs, self-efficacy, self-regulation, time management, and effort regulation; and negatively with test anxiety.

Komarraju and Nadler (2013), for additional testing of hypothesis 3, conducted hierarchical regression analyses using the block of variable entering method for each block or set of variables as noted in Table 3. To predict college GPA, the variables were entered as follows: (a) the subgroup of motivation variables were entered in block one; (b) cognitive and metacognitive learning strategies were entered in block two; and

Table 3

Intercorrelations between GPA and Subscales of the MSLQ: Motivational Orientations, Cognitive-Metacognitive Strategies, and Resource Management $(N=257)$

\begin{tabular}{|c|c|c|c|c|c|c|c|c|c|c|c|c|c|c|c|c|}
\hline Variable & 1 & 2 & 3 & 4 & 5 & 6 & 7 & 8 & 9 & 10 & 11 & 12 & 13 & 14 & 15 & 16 \\
\hline 1.GPA & - & & & & & & & & & & & & & & & \\
\hline \multicolumn{17}{|c|}{ Motivarional orientations } \\
\hline 2. Intrinsic & .11 & - & & & & & & & & & & & & & & \\
\hline 3. Extrinsic & .05. & $27^{\mathrm{*}}$ & - & & & & & & & & & & & & & \\
\hline 4. Task value & $.13^{*}$ & $57^{* *}$ & $30 " *$ & - & & & & & & & & & & & & \\
\hline 5. Control learning & $.14^{*}$ & $A 1^{\mathrm{*}}$ & $.23^{* *}$ & $39^{9 *}$ & - & & & & & & & & & & & \\
\hline 6. Sell-efficacy & $30^{\circ "}$ & $53^{* *}$ & $36^{* *}$ & $53^{* \prime}$ & $.35^{*}$ & - & & & & & & & & & & \\
\hline 7. Test anxicty & $-.17^{* *}$ & $-\infty 2$ & $.21^{* *}$ & -0.01 & .01 & $-.28^{* *}$ & - & & & & & & & & & \\
\hline \multicolumn{17}{|c|}{ Cognitive-metocognititue } \\
\hline 8. Reherssal & $.19^{* *}$ & $.26^{* *}$ & $.38^{4 *}$ & $35^{* *}$ & $.17^{* *}$ & $29^{\prime \prime \prime}$ & $.13^{*}$ & - & & & & & & & & \\
\hline 9. Elaboration & 09 & $.41^{* *}$ & $22^{* *}$ & $49^{* *}$ & $.18^{* *}$ & $A 2^{* *}$ & -07 & $.46^{* *}$ & - & & & & & & & \\
\hline 10. Organization & .11 & $31^{* *}$ & $.27^{* *}$ & $29^{\prime \prime}$ & .07 & $27^{* *}$ & $.14^{4}$ & $.53^{* *}$ & $51^{* *}$ & - & & & & & & \\
\hline 11. Critical thinking & -.02 & $.46^{* \prime}$ & $.15^{* *}$ & $32^{\prime \prime *}$ & $23^{* *}$ & $32^{* \prime}$ & .01 & $25^{* \prime \prime}$ & $56^{* \prime}$ & $34^{* 4}$ & - & & & & & \\
\hline 12 Sell-regulation & $.14^{*}$ & $51^{*}$ & $.19^{* *}$ & $38^{8 *}$ & $20^{2 *}$ & $.48^{* \prime}$ & -.07 & $A 7^{* *}$ & $65^{* 1}$ & $.52^{24}$ & $.62^{\prime \prime}$ & - & & & & \\
\hline \multicolumn{17}{|l|}{ Ressource manngerment } \\
\hline 13. Time \& study & $311^{* *}$ & $33^{* *}$ & $25^{* *}$ & $37^{* *}$ & $20^{* *}$ & $.44^{* *}$ & $-.11^{*}$ & $50^{\circ *}$ & $38^{* *}$ & $.40^{\circ *}$ & $21^{* *}$ & $51^{* *}$ & - & & & \\
\hline 14. Efflort regulation & $39^{* *}$ & $39^{* *}$ & $22^{* *}$ & $44^{* *}$ & $.18^{* *}$ & $50^{\circ \prime *}$ & $-23^{* *}$ & $40^{* *}$ & $38^{* *}$ & $.30^{\circ *}$ & $.18^{\mathrm{*}}$ & $A 7^{* *}$ & $.66^{\prime \prime}$ & - & & \\
\hline 15. Peer learning & -.01 & $28^{* \prime}$ & $.20^{* *}$ & $.12^{* *}$ & .05 & $25^{* 4}$ & $.10^{\circ}$ & $29^{* *}$ & $31^{* *}$ & $.30^{\circ *}$ & $33^{* \prime}$ & $39^{\circ "}$ & $.14^{* *}$ & .08 & - & \\
\hline 16. Help seeking & -.06 & $.17^{* *}$ & $.15^{* *}$ & $22^{* *}$ & -.05 & $24^{* *}$ & .06 & $.26^{* *}$ & $30^{\circ *}$ & $.19^{* *}$ & $.18^{\prime \prime \prime}$ & $.36^{\circ \prime}$ & $.21^{* *}$ & $14^{\prime \prime}$ & $56^{\circ "}$ & - \\
\hline
\end{tabular}

Note. $* p<.05 . * * p<01$

Adapted from Komarraju, M., \& Nadler, D. (2013). Self-efficacy and academic achievement: Why do implicit beliefs, goals, and effort regulation matter? Learning and Individual Differences, 25, 67-72. 
(c) resource management strategies were entered in block 3. The researchers noted that from the first subgroup of motivation variables, self-efficacy was the only variable that significantly predicted college GPA: $\beta=.30, b=.20, t(254)=4.95, p<.001$. From the second subgroup of cognitive and metacognitive learning strategies, there were no incremental significant predictors.

Komarraju and Nadler (2013) concluded that: (a) high self-efficacy students give more importance to performance and mastery goals, than to other goals (b) low selfefficacy students believe that intelligence is fixed, (c) self-efficacy, effort regulation and (d) effort-regulation partially mediates the relationship between self-efficacy and achievement and (e) self-efficacious students are more likely to persist through difficult material and report a higher GPA than students with low self-efficacy.

Table 4

Summary of Hierarchical Regression Analysis for Motivational Orientations, CognitiveMetacognitive Strategies, and Resource Management Strategies Predicting GPA $(N=$ 257)

\begin{tabular}{lclccccc}
\hline Outcome & Step & \multicolumn{1}{c}{ Variable } & b & SE b & B & $\mathbf{R}^{\mathbf{2}}$ & Adjusted R $^{\mathbf{2}}$ \\
\hline College GPA & 1 & Self-efficacy & .20 & .04 & $.30^{* * * *}$ & .09 & .08 \\
& 2 & Self-efficacy & .09 & .05 & $.14^{*}$ & & \\
& & Effort regulation & .17 & .04 & $.32^{* * *}$ & .16 & .16 \\
& \multirow{2}{*}{3} & Self-efficacy & .12 & .05 & $.17^{* *}$ & & \\
& & Effort regulation & .17 & .03 & $.32^{* * *}$ & & \\
& & Help seeking & -.07 & .03 & $-.15^{* *}$ & .18 & .17 \\
\hline
\end{tabular}

Note. $* p<.05 . * * p<.01 . * * * p<.001$.

Adapted from Komarraju, M., \& Nadler, D. (2013). Self-efficacy and academic achievement: Why do implicit beliefs, goals, and effort regulation matter? Learning and Individual Differences, 25, 67-72.

In summary, persistence is a key factor needed in the endurance of challenges faced by students in postsecondary settings, especially the emerging adult with traumatic 
brain injury (Nunez \& Sansone, 2016). While research is available regarding the factors associated with persistence among regular emerging adults, little is known of the contributing factors influencing persistence in the academic performance of emerging adults with TBI participating in postsecondary education.

Additionally, while several studies have been conducted regarding young children with TBI and their recovery phases, few studies have been published on the emerging adults with TBI participating in postsecondary settings. With the increase in awareness of traumatic brain injury among emerging adult service men and women desiring college education there has been a rekindled interest. The chapter investigates the influence of persistence among emerging adults with TBI participating in postsecondary education, as it relates to the following variables: (a) gender, (b) socioeconomic status (SES), (c) employment, (d) years of education, (e) age at onset of injury, (f) existence of familial support, and (g) hours spent studying for a class.

\section{Predicting Factors Affecting Persistence}

Researchers have corroborated and suggested that various factors such as gender and socioeconomic status can influence the academic performance of postsecondary education students (Cubeta, Travers, \& Sheckley, 2001; Strauss, \& Volkwein, 2002; Trainor, 2008). However, as there is a major gap in the literature regarding the factors that influence persistence among individuals with TBI, it may be helpful to look at the recent findings among the majority population.

\section{Familial and Social Support}

Researchers have conceptualized that social support has protective qualities to enhance the transitioning process of the emerging adult in their postsecondary and 
professional life. Kenny (1987) noted that first year postsecondary students appeared to effectively adjust to college life if familial support was converted to actions consistent with social support. Kenny, Blustein, Chaves, Grossman, \& Gallagher (2003), in a study with a multiethnic sample of urban high school students, perceived social support was recognized as predictors for the career goals and career success aspirations of students. Masten, Burt, Roisman, Obradović, Long, and Tellegen (2004), in their longitudinal study of nearly 30 years, discovered that social quality was a characteristic of resilience and a predictor of the emerging adult success in their various developmental tasks, such as academic performance. Variable focus and patient focus analyses were the methods of data extraction utilized in the study conducted by Komarraju and Nader (2013). One hundred and seventy-three participants were observed from childhood to young adult stage over a period of almost 30 years. The participants were obtained from the Project Competence longitudinal study of a school cohort. Variables observed were (a) adversity, (b) competence and (c) key resources. Regressions and extreme-group analyses indicated significant continuity in competence and resilience, in addition to predictable change. The researcher claimed that success in developmental tasks among the participants were secondary to related core resources originating in childhood (e.g., IQ, parenting quality, and socioeconomic status) and also to a set of adaptive resources (e.g., planfulness/future motivation, autonomy, adult support and coping skills). The emerging adults that transitioned from childhood to adulthood with the usage of adaptive resources attained a $90 \%$ retention rate (persistence) in postsecondary achievement.

Galambos, Barker, and Krahn (2006) support Masten's (2004) study in his findings of a longitudinal investigation that tracked 1000 Canadians throughout their 
emerging adult years. The findings depicted the existence of significant correlation between increased social support and well-being. More recently, Lent et al. (2015) found that social support significantly predicted students' self-efficacy and academic outcomes. Thus, when students receive support from their peers, faculty members, and family members, they are more likely to feel more able to accomplish their academic tasks, and this makes it more likely for them to fulfill their academic goals.

Traumatic brain injury has significant impact on familial infrastructure as a result of the economical and emotional strain resulting from TBI. Low priority on educational pursuits for career development, coupled with time constraints, low funding, low intellectual functioning, operating with the mindset of basic survival needs, are some of the potential variables that emerging adults within a low socioeconomic family framework may face (Finnanger, 2015). The emerging adults with TBI living under similar conditions are also exposed to professional diagnosis with low expectations, not only from the family, but also from society. Family and society low expectations of emerging adults with TBI was evident in Brown et al. (2013) qualitative study, which posited that parents of individuals with TBI reportedly distanced themselves from their children, to cope with their situation that they perceived as unfavorable long-term outcomes among their offspring.

Sandhaug, Andelic, Langhammer and Mygland (2015), in their effort to examine community integration of individuals with TBI, and to identify social demographic, injury -related and rehabilitation that was associated as predictors of Community Integration Questionnaire (CIQ). The Community Integration Questionnaire is a rehabilitative measure used to assess individuals with brain injury social role limitations 
and community integrations. The scoring system ranges from $0-29$ and is broken into: (a) home integration $=10$ points; (b) social interaction $=12$ points; and (c) productive activity $=7$ points. The characteristics of the 57 outpatient participants were: (a) 21 moderate diagnosis of TBI and 36 with severe diagnosis of TBI; (b) ages 17 - 74 years old; (c) 43 males and 14 females. A regression model using CIQ total score at two years as an outcome measure was used to analyze possible predictors. The outcome showed a significant difference between the moderately and severely injured patients in productivity scores $(p<.003)$. Difference in the total CIQ demonstrated marginal significance $(p<0.074)$. Use of rehabilitation service $(\beta=7.766 ; p<.001)$ and living with a spouse [familial support] in the study were two significant $(\beta=4.251 ; p<0.002)$ positive predictors of community integration.

Previous studies (e.g., Andelic, Stevens, Sigurdardottir, Arango-Lasprilla, \& Roe, 2012; Sander, Kreutzer, Rosenthal, Rosenthal, Delmonico and Young, 1996; Willer, Rosenthal, Kreutzer, Gordon \& Rempel, 1993) noted less integration into the home, education and the community with those who were 1-year post-TBI, as compared to their involvement, prior to their injury. Notwithstanding, Sandhaug et al. (2015) reported significant integration into the home, education and community 2-years post-TBI.

There are limited studies conducted on the link between the effects of the impaired neuropsychological, social and psychological function among emerging adults with TBI and their cognitive functioning. Chevignard et al. (2016), for example, conducted a study to assess academic outcome, health-related quality of life (HRQoL), amount of ongoing care and participation, after childhood TBI over 7-8 years post injury, as compared to a matched uninjured control group. Sixty-five subjects' ages ranging 
from $0-15$ years of age with TBI, were compared to a similarly matched control group of uninjured subjects. Both injured and uninjured groups were compared over a period of 7 -8 years regarding (a) schooling modalities (b) amount of needed ongoing care, (c)

participation and (d) family socio-economic status (SES; assessed by parental education level). The instruments used were standardized questionnaires of HRQoL, such as PedsQoL which included fatigue module and the Child and Adolescent Scale of Participation (CASP).

Table 5 summarizes the outcome of the study conducted by Chevignard et al.

Table 5

Outcome of Longitudinal Study on Individuals with TBI and Individuals with non-TBI

\begin{tabular}{|c|c|c|c|}
\hline & $\begin{array}{c}\text { Control } \\
\text { (non-TBI) }\end{array}$ & $\begin{array}{l}\text { TBI } \\
\text { group }\end{array}$ & Significance \\
\hline Initial & No & No & \\
\hline Intellectual Ability & difference & difference & \\
\hline Severity & No & No & \\
\hline factors & difference & difference & \\
\hline Mainstream & No & No & \\
\hline education & difference, $100 \%$ & difference, $62 \%$ & \\
\hline Ongoing & Low & High & \\
\hline \multicolumn{4}{|l|}{ rehabilitation } \\
\hline Self-related & $83.9 ; 95 \%$ & $71.1 ; 95 \%$ & $p=$ \\
\hline HRQoL & IC 79.3-88.4 & IC 64.8-77.5 & 0.0026 \\
\hline Fatigue & $61.1 ; 95 \%$ & $77.4 ; 95 \%$ & $p=$ \\
\hline module & IC 54.6-67.5 & IC 71.9-82.8 & 0.0005 \\
\hline \multicolumn{4}{|c|}{$\begin{array}{l}\text { Note. Adapted from Chevignard, M., Francillette, L., Toure, H., Brugel, D., Meyer, P., } \\
\text { Vannier, A. L. ... \& Watier, L. (2016). Academic outcome, participation and health- } \\
\text { related quality of life following childhood severe traumatic brain injury: results of a } \\
\text { prospective longitudinal study: The seven-year follow-up of the TGE cohort. Annals of } \\
\text { Physical and Rehabilitation Medicine, 59, e133. }\end{array}$} \\
\hline
\end{tabular}

(2016). Of the initial 65 participants, 39 remained after a mean delay of almost 8 years.

The mean coma duration was 6.6 days $(S D=4.46)$. When demographics, severity factors 
and initial intellectual ability elements were introduced, there was no significant difference between the TBI group and the control group.

Compared to $100 \%$ of the control group participating in mainstream education, there was only $62 \%$ of the TBI group participating in mainstream education. The TBI group was also a recipient of high ongoing rehabilitation. There were a significant difference in the self -reported HRQoL $(p=0.0026)$ and the fatigued module $(p=$ 0.0005) among the TBI group as compared to the control group.

\section{Gender}

Holland and Schmidt (2015) suggest that there are there are two main factors that can affect the postsecondary education among the emerging adult with TBI. Static or unmodifiable factors, such as: (a) age, (b) gender, (c) sex, (d) intellectual abilities/education, and (e) pre-injury psychiatric history are considered as factors that are uncontrollable. The second factor also known as a dynamic or modifiable factor consists of (a) socioeconomic status, (b) family functioning/social support, (c) nutrition, and (d) exercise. King's (2004) model refers to protective factors, such as social and family support and vulnerability factors such as depression, as factors that can impact postsecondary education among [emerging] adults with TBI. Studies have revealed that both static and dynamic factors can positively impact the multiple domains, such as (a) cognition, (b) emotion regulation, (c) health and wellness and (d) behavior. Unfortunately, there appears to be limited published studies that systematically examine the outcomes of the studies that were previously mentioned (Holland \& Schmidt, 2015).

Recent literature has presented mixed results regarding gender and persistence. Some researchers found that female students tend to have higher levels of persistence 
than males, as evidenced through higher rates of degree completion (Figlio et al., 2016) and higher GPAs (Keiser et al., 2016; D'Lima, Winsler, Kitsantas, 2014) among female students. Moreover, female students with cognitive disabilities had lower risk of attrition than their male counterparts, and were found to need less time to graduate than male students with cognitive disabilities (Wessel et al., 2009).

Various factors have been suggested to contribute to the outcome. First, Sanchez, Lowman, and Hill (2016) found that postsecondary students who come from low-income, first-generation, and/or underrepresented racial/ethnic backgrounds, majority of which are females, are more likely to have a more rigorous and challenging academic history. The rigorous and academic challenges faced by marginalized postsecondary students, could have enhanced their ability and inclination to persist in their future studies (Sanchez et al., 2016). Second, significant gender differences are evident regarding the use of self-regulated learning strategies, with a number of researchers suggesting that female students use self-regulation strategies more often than males, thus improving their academic outcomes (Ongowo \& Hungi, 2014; OzsoyGunes, Gunes, \& Kirbaslar, 2014; Senler \& Sungur-Vural, 2014).

On the other hand, there has also been evidence for the opposite result, particularly among young adults with TBI. Compared to men, women were found to encounter more difficulties in adjusting back into their daily lives after TBI, and reported a worse overall quality of life than men (Hoge et al., 2008; Seibert et al., 2002). Males and females were also found to differ in terms of susceptibility to different clinical syndromes following TBI. While male adolescents and emerging adults are more at risk of developing externalizing disorders such as substance abuse, antisocial, and conduct 
disorders following TBI, female adolescents and emerging adults are more at risk of developing internalizing disorders such as depression and anxiety (Scott et al., 2015). The dissimilarity of at-risk disorders among male and female adolescents, is primarily the result of structural and hormonal differences that exist between the male and female brains (Albert, 2015; Scott et al., 2015). Internalizing disorders may put female emerging adults at a disadvantage in terms of academic outcomes, as studies have shown that the presence of depression and anxiety is significantly associated with decreased academic performance and an increased risk of dropping out of education (Abdelhamid et al., 2016).

Some studies showed no significant difference in persistence between males and females. Sanchez and Smith (2017), for example, found that males and females are likely to graduate at similar rates and attain similar grades. Moreover, while there are gender differences in terms of TBI and behavioral sequelae and resulting complications following the incident (i.e., externalizing disorders for men, internalizing disorders for women), there is evidence that these symptoms are simply different expressions of the same brain dysfunction (Alexandrino-Silva et al., 2013). Resch et al.'s (2009) longitudinal study on individuals' experiences of the first five years of adjustment following TBI, found gender to be an insignificant factor in the equation, with no significant gender differences in life satisfaction trajectories over the course of five years. Resch et al. (2009) finding was supported by another longitudinal study by Williamson et al. (2016), this time over the course of ten years. While the participants reported increased adjustment and life satisfaction as time passed, men and women had more or less similar results. 
Altogether, recent literature has exhibited different findings regarding the association between gender and persistence. Among the general population, it is evident that women may be more likely to exhibit better academic performance and graduate at a faster rate than are men (Mau, 2016; Sanchez, Lowman, \& Hill, 2016; Wessel et al., 2009). However, other studies, particularly among students with TBI, have presented different results, suggesting that females might have a more difficult time persisting through postsecondary education than men, because they are less likely to adjust as well as their male counterparts (Abdelhamid et al., 2016). Ultimately, however, researchers recognize the need to continue studying the reliability of gender in predicting academic persistence, particularly among emerging adults with TBI (Scott et al., 2015; Williamson et al., 2016).

\section{Socioeconomic Status}

A growing body of research has investigated the importance of socioeconomic status on college students' academic lives. Researchers are generally in agreement that students of low socioeconomic status face more challenges than do those of high socioeconomic status. First, low-SES students tend to encounter more negative emotional experiences. According to Stebleton, Soria, and Huesman (2014), low-SES students are more likely than high-SES students to experience and express higher levels of emotional distress, and exhibit higher levels of self-reported depression. These negative emotional states are especially evident in students' physiological functioning. John-Henderson et al. (2014) found that higher levels of physiological stress symptoms are present in low-SES students compared to high-SES students. 
Second, identity management is a more challenging endeavor for low-SES college students than high-SES students. A study by Moschetti and Hudley (2015) found that low-SES students find higher education a new and unfamiliar environment than do highSES students, and they find it more difficult to accept their new identity as college students. Low-SES students maladaptive challenges to unfamiliasr environment, can be largely attributed to the finding that they are a minority group in higher education, which is likely to constantly remind them of their dissimilarity to the other students (Hearn \& Rosinger, 2014). Low-SES students experiencing difficulty in accepting new identities as college students, lead them to common feelings of not beloning in their new college environments, as revealed by Harackiewicz et al. (2014). Additionally, the study participants reported that they tend to experience imposter syndrome, which is the feeling that they are frauds and deceptively misled others to believe that they belong in college, when in fact they do not deserve tto be college students. (Clance, \& Imes, 1978; Harackiewicz et al., 2014).

Third, low-SES students are especially prone to discrimination and negative views from others. A study by Durante, Tablante, and Fiske (2017) found that low-SES students are subject to various negative stereotypes in others' views. They are often thought lowly of regarding their competence and skills, being considered less able and less competent than high-SES students. Imposter syndrome and the low-expectation from peers and society, intensifies classism within the higher education environment (classism being the "negative attitudes, beliefs, and behaviors directed toward those with less power, who are socially devalued;" Lott, 2012, p. 654), and was found to significantly affect low-SES and first-generation students. In the context of 
postsecondary education, classism was found to strongly reduce low-SES and firstgeneration students' academic satisfaction and outcomes (Allan, Garriott, \& Keene, 2016).

Lastly, along with low-SES tends to come a heightened sense of uncertainty and insecurity of the future. Low-SES students not only have fewer resources to work with, but are also likely to develop a mindset that their efforts are not likely to result in the outcomes that they would ideally merit (Oyserman, 2013). Low-SES students selfperception of imposter syndrome, is even more likely when students do not believe that they are equipped with adequate skills and abilities to attain their goals. As a result, they are more likely to view difficulties and challenges as hopeless circumstances and are more likely to be less motivated to develop strategies to overcome their problems (Jury, 2017; Oyserman, 2013).

Despite evidence that SES is associated with their respective circumstances that may influence levels of persistence (Oyserman, 2013; Stephens, Brannon, Markus, \& Nelson, 2015), other researchers emphasize the possible role of students' perceptions on socioeconomic mobility. Browman and Destin (2016) suggest that students have the ability to move from one SES to another with the usage of low-SES students' academic motivation and persistence. The idea of socioeconomic mobility-particularly that people can move up the socioeconomic ladder - is a core aspect of the ethos of the American dream, and has been heavily promoted in politics and in mass media (Ghosh, 2012).

Eagan et al. (2014) conducted a survey research study on over 141,000 college freshmen and the results revealed that students from low-SES backgrounds who 
expressed that they look forward to improving their earning power after attaining their degree use this goal as motivation to persist through postsecondary education. In other words, their perception that completing their studies can result in a more financially secure future, with a stable employment and a comfortable income, is a key factor that contributes to low-SES students' academic persistence and resilience (Eagan et al., 2014).

Similarly, Oyserman, Destin, and Novin (2015) found that students who have salient goals of a successful future were more likely to treat situations of academic difficulty as opportunities to practice persistence. With students ability to perceive a successful future, it can be argued that although low-SES students have a higher propensity for challenges throughout their postsecondary education, their perception on whether or not they believe in the possibility to live a better life in the future, through education, can influence their ability and inclination to persist in the face of challenges (Browman, Carswell, \& Svoboda, 2017; Oyserman Smith \& Elmore, 2014).

A noteworthy observation by some researchers is that the influence of perceptions on socioeconomic mobility is significantly stronger for students who stand at the lower end of the socioeconomic spectrum than for those at the higher end (Davidai \& Gilovich, 2015). The socioeconomic mobility is significantly stronger for the students who are at the lower socioeconomic spectrum than those at the higher end, because people's common thoughts regarding socioeconomic mobility leans towards the prospect of moving up, but not down, the socioeconomic ladder. Kraus and Tan (2015) supported these findings, but suggested that mobility can also impact high-SES students' persistence. Either looking forward to moving further up the socioeconomic ladder or being concerned about moving down the ladder can also enhance their perception on the 
importance of educational attainment, thus increasing their persistence (Kraus \& Tan, 2015).

On the basis of these findings, it may be safe to say that the influence of SES on persistence may not be as straightforward as it initially appears. At face value, research regarding SES and persistence seem to lean toward the likelihood that persistence may be higher among high-SES students compared to low-SES students because of the large number and severity of challenges that low-SES students encounter in postsecondary education (Harackiewicz et al., 2014; Oyserman, 2013; Stebleton, Soria, \& Huesman, 2014). However, studies show that other factors may come into play to determine academic success. One's socioeconomic background may not be as important at developing persistence if one has an optimistic mindset on their ability to climb the socioeconomic ladder through one's education (Davidai \& Gilovich, 2015; Kraus \& Tan, 2015; Oyserman et al., 2015). Nevertheless, there is still a major lack in research regarding the relationship between SES and persistence among emerging adults with TBI undergoing postsecondary education.

In a study conducted by Soria, Weiner, and $\mathrm{Lu}$ (2014), six large public research universities were investigated to examine financial decisions of low-income/working class undergraduate students. The study was conducted via the usage of survey as data gathering instruments. It was administered to 213,160 undergraduate students across nine large public universities that were classified by the Carnegie Foundation as having high research activities. The response rate of the completed survey was $38.1 \%(n=$ 81.199). As a consequence of incomplete surveys, the final response rate was $24.7 \%$ ( $n=$ 52740). The majority of the responders were female (59.1\%) and white (59.4\%). The 
measure of the social class included, (a) social class background, (b) mother's education, (c) father's education and (d) family income. The participants were permitted to selfcategorize their social group. The study revealed, low-income and working students are more likely to make decisions that could negatively impact their academic performance and consequently delay graduation, or result in an increased debt at graduation (Soria et al., 2014).

\section{Employment}

As indicated in a previous study (Pareja, 2005), parental employment with special emphasis on maternal employment, had a direct relationship with their students' academic achievement. The study proposed that increased parental participation in the workforce resulted in a high-grade point average (GPA) as reflected in increased A's and B's on the students' report cards. However, parental participation in the workforce also resulted in increased negative math test score growth over the period of the students' four years of study in a postsecondary setting. Further investigation is needed to explore the possible rationale for the effect of parental participation in the workforce on the students' grades. Persistence is highly impacted with increase grade point average (GPA) and confidence (Edwards \& McKelfresh, 2002; Hartley, 2011; Markle, 2015; Herbert, Hong, Byun, Welsh, Kurz, \& Atkinson, 2014; Stewart, Doo Hun, \& JoHyun, 2015).

Employment and work experience during the school year at the secondary and postsecondary levels are evident among students with and without disabilities alike (Wehman, 2013). For people with disabilities particularly, researchers have suggested that hands-on practical experience in students' respective fields of study or prospective career fields through part-time jobs, summer employment, and field-based internships are 
helpful ways for students to gain real-world knowledge and experience while they have not yet completed their studies (Hendricks et al., 2015). Prior research has examined the pros and cons of working while still in school. For example, Therriault and Krivoshey (2014) suggested that being a working student can be beneficial in the long run through the early acquisition of work experience, professional connections, and soft skills (including problem solving, time management, and communication skills) that prove useful not only in the academic world but also in the professional world. However, the time that students spend on the job can compete with the time that they can spend studying and being involved in other academically related activities (Therriault \& Krivoshey, 2014).

Research is mixed regarding how student employment is associated to persistence in postsecondary education. On one hand, some researchers argue that student employment results in reduced postsecondary persistence among students. For example, Therriault and Krivoshey (2014) found that students with a part-time status at school have a $30 \%$ less predictive probability of attaining their college degree in comparison to students who study full-time. Moreover, working for more than 20 hours per week further increases the likelihood that a student will not persist in college (Therriault \& Krivoshey, 2014). The negative relationship can be largely attributed to the amount of time students can allocate to their academic activities when they also have a job to manage. A study by Stewart et al. (2015) examined the effects of financial aid on student persistence among postsecondary students and found that financial aid helps increase student persistence. While students receiving financial aid appear to have a high college persistence, it is in part because aid or grant funds commonly require students to maintain 
a certain GPA to continue availing of financial aid (Stewart et al., 2015). The

relationship between financial aid and college persistence is mainly because financial aidreceiving students, would be able to work less or let go of their jobs, thus having more time to focus on their studies (Stewart et al., 2015).

In contrast, research has provided evidence that having a job while pursuing one's degree has little significant impact on one's postsecondary persistence (Darolia, 2014). A relevant factor that contributes to this is the way that college students choose to manage their time. Whereas high students tend to spend less time on academic activities if they work (Kalenkoski \& Pabilonia, 2012), the same effect is not as evident among college students. According to Babcock and Marks (2011), college students tend to allocate much less time for class and academically-related activities outside the classroom as compared to high school students, and as compared to college students in the past. Given this, it is likely that the time that college students spend at work does not significantly reduce study time, but rather reduces their time for leisure or other activities that are not related to their studies (Babcock \& Marks, 2011). According to Foshnacht, McCormick and Lerma (2018), postsecondary students spend approximately 3 hours per day attending classes and studying. Foshnacht et al. (2018) and Goldrick-Rab (2016) posited that low socioeconomic students, especially those receiving Pell grants, spent more time studying, than their more socially advantaged counterparts (Pell Institute, 2015).

Additionally, the time and amount of work was found to have little significance on the rate at which college students accrue credit each term. Rather, the intensity of the work is more influential on credit accrual per term (Body, Bonnal, \& Giret, 2014; Darolia, 2014; Triventi, 2014). Body et al. (2014), Darolia (2014) and Triventi (2014) 
finding has encouraged researchers to suggest that working may not be detrimental to college students' academic standing and progress, especially if students take on jobs that complement their academic lessons by providing a real-life context through which they can practice what they have learned (Calderwood \& Gabriel, 2017; Darolia, 2014).

Similar to the findings regarding the relationship between SES and persistence, findings regarding the relationship between employment and postsecondary persistence are not as straightforward as they seem. While initially the literature seems to indicate that being a working student is more likely to result in attrition and lower academic outcomes because of the amount of time that a job may potentially take from academic activities (Stewart et al., 2015; Therriault \& Krivoshey, 2014), other researchers suggest that this may not always apply for a few reasons. First, recent postsecondary students are more likely to spend less time on studying (Babcock \& Marks, 2011; Kalenkoski \& Pabilonia, 2012), giving them greater flexibility to spend the rest of their time with a job if they wish to do so. Second, it is not necessarily the amount of time spent on work as compared to studies, but rather the intensity of the work that may predict students' postsecondary persistence. Mentally exhausting and draining work may deplete students' energy and motivation to handle their academic obligations, resulting in overall lower persistence (Choi, 2018; Darolia, 2014).

Choi (2018) suggests that employment has less negative impacts on postsecondary persistence among the students with a socially disadvantaged background. Choi (2018) examined the National Longitudinal Survey of Youth 1997 (NLSY97) dataset which tracked a nationally representative sample of approximately 9000 youth, who were interviewed annually. Choi's focus was on actively engaged postsecondary 
students. The information gathered during the interview included, social and family background, schooling demographic changes and employment and outcomes. In regards to employment, the students were categorized into three groups: a) intense work ( $\geq 20$ hours per week), b) moderate work ( $<20$ hours per week), and c) no work ( 0 hours per week). Choi's descriptive analysis revealed that the students from a socially disadvantaged background were more involved in intense work as compared to teens from socially advantaged backgrounds. Choi's findings suggested that although engagement in intense work negatively impacted students from socially disadvantaged backgrounds, negative impact appeared to be insignificant, compared to the negative impact experienced by the students from socially advantaged backgrounds. The study also proposed that postsecondary persistence was lower in students' first year of postsecondary education, especially among those who participated in intense work. Once again, however, there is a lack of research on employment and academic [postsecondary] persistence in the context of emerging adults with TBI.

\section{Age at Onset of Injury}

In previous retrospective assessment studies, researchers (Baguley, Cooper \& Felmingham, 2006; Velikonja, Warriner and Brum, 2010) suggested that injury at a younger age predicted more self-reported external (aggressive) problems post TBI. Baguley et al. (2006) and Finnanger et al. (2015), in a study designed to assess prevalence and predicting factors of aggressive behaviors among individuals with moderate to severe post-TBI injury, noted that younger age at injury predicted increased aggressive behavior and rule breaking among those with moderate to severe post-TBI 
injury. Both Baguley et al. $(n=228)$ and Finnanger et al. $(n=67)$ corroborated the negative effect of demographic factors on undesirable outcomes of post-TBI injury.

Apart from emotional behavior, however, results on the relationship between age of onset of TBI and academic outcomes are somewhat mixed. On one hand, some studies found a positive relationship between age of onset and academic outcomes. Ewing-Cobb (2012) found a significant positive association between younger age at injury and placement in special education classes. According to the findings, younger age at injury was connected to lower functional academic skills in reading, writing, and mathematics. Furthermore, a longitudinal study by Todis et al. (2011) on the post-high school experiences of adolescents with TBI revealed that the participants who experienced TBI later in life were more likely to enroll and engage in postsecondary education as compared to those who experienced TBI at a younger age.

Conversely, research also suggests that a negative relationship between age of onset of TBI and academic persistence is possible. For example, Sariaslan, Sharp, D’Onofrio, Larsson, and Fazel (2016) studied the long-term medical and social outcomes associated with TBI among children and adolescents in Sweden. The results revealed that individuals who were older at first head injury, specifically after 15 years of age, exhibited higher rates of psychiatric hospitalization, premature mortality, and low educational levels. The finding was supported by Ransom et al. (2015) that compared the academic outcomes of children and adolescents with more recent symptoms of TBI and those of children and adolescents who have already recovered. According to the findings, symptomatic students had significantly more setbacks in learning, identified a greater number of classes they had difficulty in, and had lower school performance 
compared to recovered students. Moreover, these adverse effects following TBI were further aggravated among high school students compared to elementary and middle school students (Prasad, Swank, \& Ewing-Cobbs, 2017; Ransom et al., 2015). The researchers suggested that supports are particularly necessary for older students, as they are likely to encounter higher stress levels and greater academic demands as compared to younger students. Without such supports, the negative outcomes resulting from TBI may contribute to the development of depression and anxiety (Ransom et al., 2015).

Findings that an older age of injury onset results in more adverse long-term effects may be explained by the concept of neural plasticity. Kolb, Forgie, Gibb, Gorny, \& Rowntree, (1998) suggested that the brain uses the same recovery and plasticity mechanisms as a response to both aging and injury. Given the finite capacity of the brain to adapt to injury and the decreasing number of neurons as one ages, means that brain recovery is slowed and functional decline may occur at greater rates and with less chance of recovery among older individuals than younger individuals. This cognitive changes is consistent among various studies. For example, the Himanen et al. (2006) longitudinal study on the cognitive changes following TBI, showed that individuals who experienced TBI at an older age had higher risk for cognitive decline than individuals who experienced TBI at a younger age Moreover, Nudo (2013) found that the risk for psychiatric hospitalization among individuals who sustained TBI between 0-4 years old was lower, than individuals who sustained TBI between 20-24 years old.

Although the literature has presented findings on the possible effects of age at onset of injury on negative emotional behavior and academic outcomes among children and adolescents, no published studies relating to the association between age at onset of 
injury and cognitive, or academic performance among emergent adults was noted in the literature review.

\section{Education Level at Time of Injury}

Students face a variety of situations and discover more about themselves throughout the course of postsecondary education, and researchers have long investigated how their experiences during different levels of postsecondary education influence persistence. It is generally agreed upon in the literature that students face different types of challenges and need various types of support during different stages of their college life (Bessette, Morkos, \& Sangelkar, 2016). While these experiences certainly do not comprise the special circumstances that students with TBI encounter, students with TBI are still very much likely to identify with them (Ransom et al., 2015); thus, knowledge on persistence across the year levels would be instrumental in understanding the relationship between educational level and persistence.

From the literature, a trend can be observed across year levels. For both freshman and sophomore years, academic failure and attrition is largely driven by anxiety, lack of self-confidence, and a lack of social integration into their institutions. During freshman year, it is common for students to have low levels of academic self-confidence and high levels of unfamiliarity as they are still trying to adjust to the new academic environment and their new identities as college students (Tovar, 2015; Walsh \& Robinson, 2016). It is for this reason that social and academic support from professors, peers, and family members is crucial. Researchers have found that social relationships not only with peers, but also with professors, significantly facilitates retention and eventual degree obtainment (Walsh \& Robinson, 2016). 
Similarly, although sophomores are more familiar with the routines of postsecondary education, it is common to experience what is known as the "sophomore slump," a period of self-doubt and anxiety regarding their abilities and skills (Harris, 2017). Hall (2017) found that the experience of self-doubt and anxiety, can result in students' decreased interest in school, declining academic performance, higher rates of absences, and even dropping out of school. These findings were echoed by Webb and Cotton (2018) who added that during the second year of college many students experience feelings of low self-confidence in academic activities, a decline in course enjoyment, and increased thoughts of dropping out as compared to freshman year.

In comparison to the previous two years, persistence during junior and senior years appears to be largely influenced by students' perception on the quality of their college experiences. While freshmen and sophomores face the issue of adjusting to the environment and demands of postsecondary education, juniors and seniors have often already successfully coped with the challenges of academic and social integration (Neumann \& Finaly-Neumann, 1989). Bessette, Morkos, and Sangelkar (2016) also note that anxiety levels have decreased and self-recognition and self-confidence has increased by the higher levels of education, having already successfully undergone the many academic challenges in the previous years.

It is during this time, however, that persistence is heavily dependent on, if students find their college experiences meaningful and satisfactory. This feeling of value and satisfaction of college experiences, includes the quality of their relationship with peers and faculty members (Lorenzetti, 2009; Neumann \& Finaly-Neumann, 1989) and their perception on if the institution has provided them with opportunities that are 
relevant to their educational and future professional goals (Gbollie \& Keamu, 2017). A study by Hall et al. (2017) found that college seniors are less likely to feel motivated to continue with their studies and are more likely to drop out if they feel like they lack meaningful social connections and educational experiences. Similarly, a study by Allen, Robbins, Casillas, Oh, (2008) found that college juniors' perceptions of their social connectedness and commitment to their institution are significant predictors of enrollment in the following term.

From these findings, it is evident that the association between educational level and persistence are not as clearly defined. Researchers agree that the challenges students face at all educational levels are likely to result in a lack of persistence and retention if not adequately addressed, which may indicate that persistence may not depend as much on certain educational levels as compared to other protective factors such as social and academic support (Hall, 2017; Neumann \& Finaly-Neumann, 1989; Tovar, 2015; Walsh \& Robinson, 2016). Alternatively, perhaps future studies need to further investigate students' persistence and their trends across educational levels.

A few studies have been done particularly among students with TBI. So far, research has suggested an increased risk of complications from TBI when it has occurred during lower educational levels. Velikonja, Warriner and Brum (2010) noted increased self-reported behavior associated with lower education level prior to the injury, validating previous researchers' findings of fewer behavioral problems associated with higher education levels and higher socioeconomic status. Moreover, lower levels of education at the time of injury were significantly associated with poor cognitive outcomes (Finnanger et al., 2015). 
Greater executive dysfunction was also associated with lower education level at onset of injury (Finnanger et al., 2015). Despite these findings, however, research is still generally inconclusive regarding the relationship between educational level at injury and persistence. Studies regarding the effect of education level at time of injury on persistence among emerging adults with TBI in postsecondary education are currently needed.

\section{Hours Spent Studying}

Prior research on time spent studying appear to agree that quantity of time used to study may not be significantly associated with academic performance and persistence. For example, Darolia's (2014) study found no significant relationship between the amount of study time and postsecondary students' GPAs. Studies by Todis and Glang (2008) and by Helms and Libertz (2014) found consistent results, additionally suggesting that other factors may be more instrumental in determining students' academic persistence and outcomes.

Although some studies have suggested that study time does significantly affect academic performance, Nonis and Hudson (2006) argue that amount of time spent on studying has no direct influence on academic performance. In contrast, Rosenfeld, Maas, Bragge, Morganti-Kossmann, Manley, and Gruen (2013) and Nonis and Hudson (2006) claim that students who self-develop study strategies excel in academic performance. Thus, it may not necessarily be study time; rather, it may be the study strategies matter most when considering academic performance. By extension, then, those emerging adults with TBI tend to exhibit difficulty with self-regulation study strategies and hence the lack of academic performance. 
Several studies have been conducted on the role of self-determination among individuals with disabilities and the unanimous conclusion was self-determination is the core for the success of students with disabilities in postsecondary education settings (Field, Sarver, \& Shaw, 2003). Field and Hoffman (1994) and Ryan and Deci (2000), along with other researchers, as early as in the mid-1990s became forerunners of the importance of self-determination as a precursor for individuals (emerging adults) with disability academic achievement. Unfortunately, as chronicled throughout the research, there are limited published studies on self-determination and civilian emerging adults with TBI in a postsecondary education.

Although creating a conducive environment for learning is vital for all learners, it is especially a salient issue with emerging adults with TBI participating in postsecondary education. Non and Tempelaar (2016) concluded that the aftermath of students in a poor learning environment is that they will study significantly less than students in a conducive environment for learning, resulting in lowered academic performance.

Research has found evidence that internal factors such as intrinsic motivation, ambition, and determination, are more effective than external factors, such as praise and competition, at determining students' persistence. Prat-Sala and Redford (2010) investigated the interrelationships of social-cognitive factors and its impact on academic performance. The studied social-cognitive factors included motivation orientation, intrinsically and extrinsically, self-efficacy and approaches to studying and the changes in study overtime. A sample of 163 first year psychology undergraduate students attending a university in the United Kingdom participated in the study. With the usage of the Work Preference Inventory motivation questionnaire, the study revealed that both intrinsic and 
extrinsic motivation orientations were correlated with approaches to studying. The study suggested that students with a high self-efficacy approach took a more strategic or deeper approach to studying than the students with low self-efficacy who demonstated a shallower studying approach. The study demonstrated the importance of self-efficacy in understanding the approaches in motivation and learning of postsecondary education students. These findings are consistent with those of Todis and Glang (2008), which emphasized that even though students with TBI may need to reduce their course loads in the process of recovery, more important than study hours are students' levels of ambition, motivation, and diligence to succeed in their studies.

There are limited studies addressing emerging adults with TBI who are participating in postsecondary education, however a qualitative study conducted by Shaw, Brinckerhoff, Kistler and McGuire (as cited by Field, Sarver \& Shaw, 2003) found similar results to the previous ones. The researchers noted that the four students interviewed in the qualitative study reported taking classes 12 hours per week and spending 3- 4 hours per day preparing for their classes. Self-advocacy, selfdetermination, goal setting and flexibility in adjusting self-directed interventions were all noted in this study. The findings of this study revealed that GPA outcomes of the students in the study were directly related to their self-determination and persistence, self-advocacy, self-directed goals and interventions and ability to be flexible based on obstacles encountered (Field, Sarver, \& Shaw, 2003).

Additionally, researchers have also suggested that self-regulated learning strategies are more useful in optimizing the quality of study time rather than the quantity of study time. Optimizing the quality of study time can be done through self-regulated 
learning strategies (Bush et al., 2011; Helms \& Libertz, 2014). Instead of spending longer hours on their academic requirements, it may be more helpful to regulate one's study environment and choose to study during the time of day they find they are most productive to ensure that they are able to place the most amount of focus in their work (Helms \& Libertz, 2014).

\section{Self-Regulated Learning}

As described in a study conducted by Kennedy and Krause (2011), a comparison case study design was utilized to describe a program that integrated self-regulated learning theory. The purpose of the study was to demonstrate the feasibility of developing and implementing a coaching model and to identify individualized outcomes which included college achievement. Kennedy and Krause (2011) study included emerging adults with TBI who were participating in postsecondary education and were presented with cognitive impairments. The method used involved supported education that used a dynamic coaching model which encouraged the subjects to self-regulate their learning. The subjects were encouraged to reflect on their thoughts relating to their current condition and strategically plan, evaluate and monitor their improvement.

The outcome of Kennedy and Krause (2011) study identified the following areas: (a) decontextualized standardized test scores, (b) self-reported academic challenges, (c) number and specificity of reported strategies, (d) grades on assignments, (e) number of credits completed versus attempted, and (f) changes in academic status and campus life. The study by Kennedy and Krause (2011) also revealed that the usage of metacognitive self-regulated strategy, which includes strategy specificity for improving emerging adults with TBI postsecondary education academic performance. Strategy specificity reflects 
the emerging adults' ability to understand, use and describe in detail, the strategy designed for their academic improvement. The results of strategy specificity were: (a) college students improved on grade assignments after strategy instruction and increased usage of strategies, (b) completion of most attempted credit, (c) students in good academic standing, (d) positive academic decisions made by students, and (e) inconsistent performance on decontextualized tests pre- and post-intervention. The findings suggested that hybrid-supported education programs that are self-motivated and adjusts to the specific needs of emerging adults with TBI can be useful in improving academic performance.

Emerging adults are more likely to succeed academically if they are able to selfregulate their goals and learning (Peng 2012; Zimmerman, 2013). In a study that focused on the relationship between self-regulated learning and its effect on 135 emerging adults' academic achievement (Peng, 2012), five predicting variables (self-regulation, selfefficacy, intrinsic values, cognitive strategies and test anxiety) were examined to investigate if there was a relationship between the identified variables and academic achievement. No mention was made of TBI as an existing factor. Of the five predicting variables investigated, self-efficacy, intrinsic values and cognitive strategies were closely linked to the students' academic performance, while test anxiety was correlated with negative academic performance. Regression analysis clearly indicated that self-efficacy had the most powerful impact on performance (see Table $6 ; \beta=.484$ ). 
Table 6

Stepwise Regression Analysis

\begin{tabular}{|c|c|c|c|c|c|}
\hline \multirow[t]{2}{*}{ Model } & \multicolumn{2}{|c|}{$\begin{array}{l}\text { Unstandardized } \\
\text { Coefficient }\end{array}$} & $\begin{array}{l}\text { Standardized } \\
\text { Coefficients }\end{array}$ & \multirow[t]{2}{*}{$t$} & \multirow[t]{2}{*}{ Sig } \\
\hline & $B$ & $\begin{array}{r}\text { Std. } \\
\text { Error }\end{array}$ & Beta & & \\
\hline Constant & 64.537 & 6.239 & & 10.344 & .000 \\
\hline Self-efficacy & 4.084 & 1.048 & .484 & 3.896 & .000 \\
\hline Test anxiety & -1.503 & .636 & -.294 & -2.364 & .023 \\
\hline
\end{tabular}

Note. Adapted from Peng (2012). Self-regulated learning behavior of college students of science and their academic achievement. Physics Procedia, 33, 1446-1450.

\section{Summary}

Chapter 2 studied the literature concentrating on the role of persistence as it relates to the emerging adults with TBI in postsecondary education. In addition, Chapter 2 examined the available literature addressing predicting factors associated with persistence. On the basis of past research findings, it is evident that the relationship between persistence and various demographic and socio-psychological factors are still not clearly defined. More specifically, researchers have found that these relationships, such as those between SES and persistence (Eagan et al., 2014; Oyserman et al., 2015) and between educational level at time of injury and persistence (Hall, 2017; Harris, 2017; Neumann, \& Finaly-Neumann, 1989) are often more complex than they appear, with other factors coming into play and influencing these relationships.

The literature review has unveiled areas of concern, such as the need for relevant scholarly studies on the role of persistence among emerging adults with TBI in postsecondary education. In line with this, Chapter 3 discuss the methods used in the study to examine the role of persistence among emerging adults with TBI in 
postsecondary education, as well as the associations between demographic and sociopsychological factors and persistence among emerging adults with TBI in postsecondary education, as presented in the secondary dataset to be used in the study. 


\section{CHAPTER III}

\section{METHODOLOGY}

Out of ethical concerns, the study employs a nonexperimental research design; thus, causality cannot be assumed because there was not random assignment nor a control group in this preexisting research (Reio, 2011). A secondary dataset was utilized to investigate the role of persistence in emerging adults with TBI in postsecondary education. The secondary dataset was used to collect demographic and sociopsychological factors as well as the measure of persistence.

As opposed to a qualitative approach, which focuses on understanding a phenomenon from narration of experiences, a quantitative approach was used in this research because the focus of the study is to investigate the hypothesized relationships between the research variables. The results of the analysis of the secondary base dataset played a vital role in corroborating and identifying new predicting factors of persistence among emerging adults with TBI in postsecondary education. Chapter 3 will describe the research design, population and sampling, variables and instrumentation, data management and data analysis. Chapter 3 will conclude with a summary of relevant points.

\section{Purpose of Study}

The purpose of this study is to investigate the role of demographic and sociopsychological factors associated with predicting persistence in postsecondary education among emerging adults with traumatic brain injury. Based on the aforementioned research, (determining the relationship of demographic and socio-psychological factors with persistence in postsecondary education among emerging adults with TBI), the 
predicting variables to be employed in this study are: (a) gender, (b) socioeconomic status (SES), (c) employment, (d) years of education, (e) age at onset of injury, (f) existence of familial capital/parental involvement, and (g) hours spent studying for a class. Although there is limited published corroboration on the direct effect of the above stated predicted variables on persistence in postsecondary education, especially among emerging adults with TBI, the researcher explored the possible connection between the stated independent variables and persistence in postsecondary education among emerging adults with TBI. In this study, persistence was defined as the continuation of postsecondary education activities for a period of at least 5 years. Drop-out of postsecondary education activities was considered as absence of persistence in this study.

\section{Research Questions and Hypotheses}

The research questions and hypotheses listed below was used to guide this study:

RQ1: Is there a relationship between gender, socioeconomic status, time spent studying, age at onset of injury, employment, years of education and persistence in postsecondary education among emerging adults with traumatic brain injury?

$\mathrm{H}_{1}$ : There is a significant relationship between gender, socioeconomic status, time spent studying, age at onset of injury, employment, and years of education (independent variables) and persistence among emerging adults with TBI in postsecondary education.

$\mathrm{H}_{01}$ : There is no significant relationship among gender, socioeconomic status, time spent studying, age at onset of injury, employment, and years of 
education (independent variables) and persistence among emerging adults with TBI in postsecondary education.

RQ2: Is there a relationship between familial support and persistence in postsecondary education among emerging adults with traumatic brain injury?

$\mathrm{H}_{2}$ : There is a significant relationship between familial support and persistence among emerging adults with TBI in postsecondary education.

$\mathrm{H}_{02}$ : There is no significant relationship between familial support and persistence among emerging adults with TBI in postsecondary education.

\section{Research Design}

A quantitative, nonexperimental, cross-sectional, predictive correlational research design was used to investigate the role of demographic and socio-psychological factors associated with predicting persistence in postsecondary education among emerging adults with TBI. A nonexperimental design as opposed to an experimental design was employed because data manipulation was involved. A secondary dataset that is the result of a national study of emerging adults with TBI will be used in the study. Therefore, the data will be taken, after careful examination, "as is."

The predictive, correlational research design (Howell, 2012) is deemed as appropriate for the study because the focus is on investigating predictive relationships between variables. The focus of the study is to measure the relationship between the dependent variable of persistence and predictor variables such as (a) gender, (b) socioeconomic status (SES), (c) employment, (d) years of education, (e) age at onset of 
injury, (f) existence of familial capital/parental involvement, and (g) hours spent studying. Table 7 describes the predicting variable included in the present study.

Statistical tests such as descriptive analysis and logistic regression were used to address the research questions and test the hypotheses posed in the study.

Table 7

\section{Predicting Variables Description}

\begin{tabular}{|c|c|c|c|}
\hline Description & Name & Type of Data & Comments \\
\hline Gender & $\begin{array}{c}\text { Sex } \\
1=\text { Male } \\
2=\text { Female }\end{array}$ & Categorical & \\
\hline $\begin{array}{l}\text { Age at Onset of } \\
\text { Injury }\end{array}$ & Age & Continuous & ---------- \\
\hline $\begin{array}{l}\text { Hours spent } \\
\text { Studying }\end{array}$ & PRTSchool & Continuous & $\begin{array}{l}\text { PRTSchool = Participation in } \\
\text { School }\end{array}$ \\
\hline Employment & $\begin{array}{c}\text { PRTWork } \\
\text { EmploymentF }\end{array}$ & $\begin{array}{l}\text { Continuous } \\
\text { Continuous }\end{array}$ & $\begin{array}{l}\text { Participation in Employment } \\
\text { Employment at Follow-Up }\end{array}$ \\
\hline Education & $\begin{array}{c}\text { Education } \\
\text { Years of Education }\end{array}$ & Continuous & Education level \\
\hline EducationF & $\begin{array}{l}\text { Years of } \\
\text { Education }\end{array}$ & Continuous & Education level at Follow-Up \\
\hline \multirow{5}{*}{$\begin{array}{l}\text { Annual Earnings } \\
\text { Familial Support } \\
\text { index } \\
\text { (Index Scores = } \\
1-5 \text { ) }\end{array}$} & Earn & Continuous & SES \\
\hline & $\begin{array}{c}\text { PRTSocFrnd } \\
0=\text { No } \\
1=\text { Yes } \\
\text { PRTSocFam } \\
0=\text { No } \\
1=\text { Yes }\end{array}$ & Categorical & Socializing with family and relatives \\
\hline & $\begin{array}{c}\text { PRTSpouse } \\
0=\text { No } \\
1=\text { Yes }\end{array}$ & Categorical & Live with spouse or significant other \\
\hline & $\begin{array}{c}\text { PRTRelation } \\
0=\text { No } \\
1=\text { Yes }\end{array}$ & Categorical & Ongoing intimate relationship \\
\hline & $\begin{array}{c}\text { PRTFriend } \\
0=\text { No } \\
1=\text { Yes }\end{array}$ & Categorical & Close friend to confide in. \\
\hline
\end{tabular}




\section{Population and Sample Size}

A secondary database was the selected dataset of choice utilized in this study. The decision to use a secondary dataset is directly associated with the convenience, accessibility, and availability of the necessary data (Ghauri \& Gronhaug, 2005). The secondary data set is also inexpensive to the researcher with regards to data collection and it provides the ability to obtain a large sample size (to ensure and maintain statistical power). The Traumatic Brain Injury Model Systems and National Data and Statistical Center Research Center that provided the secondary data provided access to an 2436 unduplicated subjects, aged 18-to-29 years of age, who have been assessed and reassessed every five years, over a period of at least 15 years. Locating and acquiring primary data can be very time consuming and difficult when trying to guarantee the large sample sizes necessary for preventing statistical power loss (Lazzeroni \& Ray, 2012). Large sample sizes can assist in stabilizing the statistical parameters in a study (Motrenko, Strijov, \& Weber, 2014),

Although the usage of secondary database set in a study offers many appealing benefits, there are limitations. Limitations such as: (a) lack of researcher control over data quality, observations and types of measures used in data collection; (b) complexity of the dataset; and (c) an outdated dataset can present gaps in the form of unanswered questions in the study outcomes (Nimon \& Reio, 2011). In the present research, the dataset will be examined for evidence of quality observations and the use of rigorous, validated measures. 


\section{Variables}

As guided by the university's IRB supporting this study, all identifying factors used in this study were removed by the national database personnel prior to the electronic transfer of the dataset to the researcher. The data collected for this secondary dataset were obtained through the format of structured interviews and questionnaires obtained by

Table 8

Inclusion Guide for Selection of TBI Participants

Each Potential TBIMS Subject Should Be Screened With The Following Inclusion/Exclusion Criteria

The Inclusion Criteria for the TBIMS NDB are:

All persons:

1. Filling the above definition;

2. Meeting at least one of the following criteria for moderate to severe TBI;

- $\quad$ PTA > 24 hours

- Trauma related intracranial neuroimaging abnormalities

- Loss of consciousness exceeding 30 minutes (unless due to intubation, sedation, or intoxication)

- GCS in the emergency department of less than 13 (unless due to intubation, sedation, or intoxication);

3. Who are age 16 or older at the time of injury;

4. Presenting to the TBIMS's acute care hospital within 72 hours of injury;

5. Must receive both acute hospital care and comprehensive rehabilitation in a designated brain injury inpatient rehabilitation program within the TBIMS, Comprehensive rehabilitation must occur in a hospital, rehabilitation unit, rehabilitation hospital, hospital-based skilled nursing facility, skilled nursing facility, or long-term acute care hospital that meets the following criteria:

- Medical and rehabilitation care are supervised on a regular basis by a physician affiliated with the TBIMS

- 24-hour nursing care is provided to the patient

- PT, OT, Speech, Rehabilitation Psychology/Neuropsychology, and/or family support/education are provided in an integrated, team approach with the expectation of further gain.

- Regardless the setting in which it is constituted, a comprehensive rehabilitation program operates in a manner consistent with (a) CARF standards for brain injury inpatient rehabilitation and/or (b) Medicare requirements for inpatient rehabilitation.

If a TBIMS's comprehensive rehabilitation program co-exists with the programming that does not meet the above criteria, the TBIMS must explicitly define tits methodology for establishing the dates of admission and discharge from comprehensive rehabilitation that will be reported to the TBIMS Data 
trained personnel, who received uniform training (IRB\#: 105337). Subjects were identified for the Traumatic Brain Injury Model Systems and National Data and Statistical Center with theusage of an established criteria used for eligibility and enrollment of potential subjects as noted in Table 8 .

The data obtained from the structured interviews and questionnaires were inputted into the National Database. The dependent variable in this study is persistence and the predicting variables are: (a) gender, (b) socioeconomic status (SES), (c) employment, (d) years of education, (e) age at onset of injury, (f) existence of familial capital/parental involvement, and (g) hours spent studying for a class.

\section{Instrumentation}

To establish validity in the recruitment and identification process of potential Table 9

Measurement of Participants with Disability Attributes and Challenges

\begin{tabular}{|c|c|c|c|c|}
\hline \multicolumn{3}{|c|}{ Part 1: Functioning and Disability } & \multicolumn{2}{|c|}{ Part 2: Contextual Factors } \\
\hline \multirow[t]{2}{*}{ Domains } & Body functions & $\begin{array}{l}\text { Life areas } \\
\text { (tasks, actions) }\end{array}$ & $\begin{array}{l}\text { Environmental } \\
\text { factors }\end{array}$ & $\begin{array}{l}\text { Personal } \\
\text { factors }\end{array}$ \\
\hline & Body structures & & & \\
\hline \multirow[t]{2}{*}{ Constructs } & $\begin{array}{l}\text { Change in body } \\
\text { functions } \\
\text { (physiological) }\end{array}$ & $\begin{array}{l}\text { Capacity (executing } \\
\text { tasks in a standard } \\
\text { environment) }\end{array}$ & $\begin{array}{l}\text { External } \\
\text { influences on } \\
\text { functioning and } \\
\text { disability }\end{array}$ & $\begin{array}{l}\text { Internal } \\
\text { influences on } \\
\text { functioning } \\
\text { and disability }\end{array}$ \\
\hline & $\begin{array}{l}\text { Change in body } \\
\text { functions } \\
\text { (physiological) }\end{array}$ & $\begin{array}{l}\text { Performance } \\
\text { (tasks in current } \\
\text { environment) }\end{array}$ & & \\
\hline \multirow[t]{2}{*}{$\begin{array}{l}\text { Positive } \\
\text { Aspect }\end{array}$} & $\begin{array}{l}\text { Functional and } \\
\text { structural integrity }\end{array}$ & $\begin{array}{l}\text { Activities } \\
\text { participation }\end{array}$ & \multirow{4}{*}{$\begin{array}{l}\text { Facilitating or } \\
\text { hindering impact } \\
\text { of the physical, } \\
\text { social and } \\
\text { attitudinal world. } \\
\text { Barriers/ } \\
\text { hindrances }\end{array}$} & $\begin{array}{l}\text { Not } \\
\text { applicable }\end{array}$ \\
\hline & \multicolumn{2}{|c|}{ Functioning } & & \\
\hline \multirow[t]{2}{*}{$\begin{array}{l}\text { Negative } \\
\text { Aspect }\end{array}$} & Impairment & $\begin{array}{l}\text { Activity limitation } \\
\text { participation }\end{array}$ & & $\begin{array}{l}\text { Not } \\
\text { applicable }\end{array}$ \\
\hline & Disability & restriction & & \\
\hline
\end{tabular}


subjects enrolled in the National Database (Craig Hospital, 2017), all personnel for the research center (such as physicians, counselors, interviewers) received standardized training to ensure uniformity in data collection and reduction in personal biases. Personel knowledge of the inclusion and exclusion selection criteria as noted in Table 9 is a requirement for all intake/counseling staff at the research center.

Following the determination of eligibility into the program, each participant received a structured interview once every five years where they were asked the same questions per session (times tended to range from 30-60 minutes). A combination of five instruments were used by the National Database Research Center personnel: (a) Cognitive Functional Independence Measure (FIM; Forer, \& Granger, 1987), (b) Generalized Anxiety Disorder scale (GAD; Mallya, Sutherland, Pongracic, Mainland, \& Ornstein, 2015; Spitzer, Kroenke, Williams, \& Löwe, 2006), (c) TBI Quality of Life survey (TBIQoL; Frank-Stromberg, 1988; Norstrom \& Lubkin, 1990), (d) Glasgow Coma Scale (GCS; Teasdale, Maas, Lecky, Manley, Stocchetti, \& Murray, 2014); and (e) the Neurology Quality of Life Scale (Neuro-QoL; National Institute of Health, n.d.; Tulsky, Carlozzi, \& Cella, 2011). The FIM, which is a measurement for disability of the International Classification of Impairment Disabilities and Handicaps (Forer \& Granger, 1987; Uniform Data Set for Medical Rehabilitation, 1997), that measures the level of the participant's disability and the degree of assistance needed by the participant to carry out daily activities of daily living. As noted in Table 10, the subjects were not rated as a person or according to their attributes, but rather, by the challenges that they faced. The GAD was used to determine the level of existing anxiety; the TBIQoL was used to measure quality of life; the GCS (Teasdale et al., 2014) was used to measure the severity 
of traumatic brain injury, and the Neuro-QoL was used to measure the physical, mental, and social effects encountered by individuals living with neurological conditions.

\section{Cognitive FIM}

The Cognitive Functional Independence Measure (FIM; Forer \& Granger, 1987; Uniform Data Set for Medical Rehabilitation, 1997) was the instrument used to identify functions and attributes of individuals prior to and after rehabilitation care. The FIM is used as a basic indicator of disability that also tracks the changes of individuals during rehabilitative care. The Cognitive Functional Independence Measure instrument is used within 72 hours of admission and 72 hours prior to the discharge from rehabilitative care. Table 10 depicts the 18 items comprising the FIM. These 18 items are grouped into

Table 10

\section{Collection and Usage Attributes}

\begin{tabular}{|c|c|c|}
\hline Motor Subscale & Cognition Subscale & Ordinal scale (7-Point Likert) \\
\hline \multirow{14}{*}{$\begin{array}{l}\text { Eating } \\
\text { Grooming } \\
\text { Bathing } \\
\text { Dressing, upper body } \\
\text { Dressing, lower body } \\
\text { Toileting } \\
\text { Bladder management } \\
\text { Bowel management } \\
\text { Transfers - } \\
\text { bed/chair/wheelchair } \\
\text { Transfers - toilet } \\
\text { Transfers - bath/shower } \\
\text { Walk/wheelchair } \\
\text { Stairs }\end{array}$} & Comprehension & 1 - Total assistance with helper \\
\hline & Expression & 2 - Maximal assistance with helper \\
\hline & Social interaction & 3 - Moderate assistance with helper \\
\hline & Problem solving & 4 - Minimal assistance with helper \\
\hline & Memory & 5 - Supervision or setup with helper \\
\hline & & 6 - Modified independence with no \\
\hline & & helper \\
\hline & & 7 - Complete independence with no \\
\hline & & \\
\hline & & \\
\hline & & Total score for the FIM motor \\
\hline & & $\begin{array}{l}\text { subscale (the sum of individual } \\
\text { MSI) }=\text { value of } 13-91\end{array}$ \\
\hline & & $\begin{array}{l}\text { Total score for the FIM cognition } \\
\text { subscale (the sum of the } \\
\text { individual CSI) = value of } 5-35 \text {. }\end{array}$ \\
\hline & & $\begin{array}{l}\text { Total score for the FIM instrument } \\
\text { (the sum of MSI and CSI scores) = } \\
\text { value } 18-126 .\end{array}$ \\
\hline
\end{tabular}


two subscales; motor (13 items) and cognition (5 items). The higher score, is the more independent the individual is in completing the task associated to the item.

\section{Generalized Anxiety Disorder Scale}

The generalized anxiety disorder scale (GAD), (See Appendix), is a 7-item measurement, is considered to be a gold standard measurement to identify probable cases of GAD and assess its reliability and validity (Mallya, Sutherland, Pongracic, Mainland, \& Ornstein, 2015; Spitzer, Kroenke, Williams, \& Löwe, 2006). Generalized anxiety disorder is branded as excessive worry and/or distress about numerous daily activities (e.g., work, school and relationships) that cannot be attributed to another anxiety disorder (e.g., social anxiety; Mallya et al., 2015) The need for GAD scale is of great importance with TBI being a high-risk factor for anxiety and depressive disorders (Scholten, Haagsma, Cnossen, Olff, van Beeck, \& Polinder, 2016). Each item has the possible score of $0-3$. The GAD-7 score is calculated by marking the item with the appropriate scores of $0,1,2$, and 3 and totaling the scores for the seven questions. Upon completing the GAD questionnaire, the totaled scores are interpreted, using an interpreting table. Scores of 5, 10, and 15 have been identified as the indicating scores for mild, moderate and severe anxiety, respectively. Further recommendations are rendered if the indicating score is $\geq 10$.

\section{Traumatic Brain Injury Quality of Life}

The TBIQOL as seen in Table 11, is a 20-item, 5-point Likert type of scale that measures physical, emotional, cognitive, and social aspects of health-related quality of life (Toyinbo et al., 2016; Tulsky et al., 2016). Each subscale consists of 5 points and uses a patient-centered approach. This patient-centered approach expands the patient- 
reported outcomes and the information system, and the Neurology Quality of life measurement initiative. A few of the 20 items included in the TBIQOL scale, are depicted in Table 11.

Table 11

\section{Quality of Life Scale}

\section{Quality of Life Scale}

(A Measure of Function for People with Pain)

\begin{tabular}{|c|c|}
\hline 0 & Stay in bed all day. Feel helpless and hopeless about life \\
\hline 1 & Stay in bed at least half day. Have no contact with outside world. \\
\hline 2 & Get out of bed, but don't get dressed. Stay at home all day \\
\hline 3 & $\begin{array}{l}\text { Get dressed in the morning. Minimal activities at home. Contact with friends via } \\
\text { phone and email. }\end{array}$ \\
\hline 4 & $\begin{array}{l}\text { Do simple chores around the house. Minimal activities outside of home, } 2 \text { days } \\
\text { a week. }\end{array}$ \\
\hline 5 & $\begin{array}{l}\text { Struggle but complete daily home responsibilities. No outside activity. Not able } \\
\text { to work/volunteer }\end{array}$ \\
\hline 6 & $\begin{array}{l}\text { Work/volunteer limited hours. Take part in limited social activities on } \\
\text { weekends. }\end{array}$ \\
\hline 7 & $\begin{array}{l}\text { Work volunteer for a few hours daily. Can be active at least } 5 \text { hours a day. Can } \\
\text { make plans to do simple activities on weekends. }\end{array}$ \\
\hline 8 & $\begin{array}{l}\text { Work/Volunteer for at least } 6 \text { hours daily. Have energy to make plans for one } \\
\text { evening social activity during the week. Active on weekends. }\end{array}$ \\
\hline 9 & Work/Volunteer be active 8 hours daily. Take part in family life. \\
\hline
\end{tabular}

The time the participants use to complete the survey and to respond to the questions during the interview ranges between 30 to 90 minutes. The interviews with the subjects and data collection from the interviews were conducted and collected every five years upon the subjects return to the research centers and or clinics.

\section{Glasgow Coma Scale}

The Glasgow Coma Scale (GSC) is the most commonly used TBI scoring instrument. It has been shown that although GSC simple to use, it is reliable (Gabbe, Cameron, \& Finch, 2003), as depicted in Figure 3. Scores from the measure are used as a predictor of mortality and survival outcomes of brain injuries by measuring the level 
of consciousness and the severity of an acute brain injury (Michaud, Rivara, Grady, \& Reay, 1992). Figure 3 illustrates the scoring system using the GCS that helps determine the severity of the brain injury and the qualifying of participants into this study.
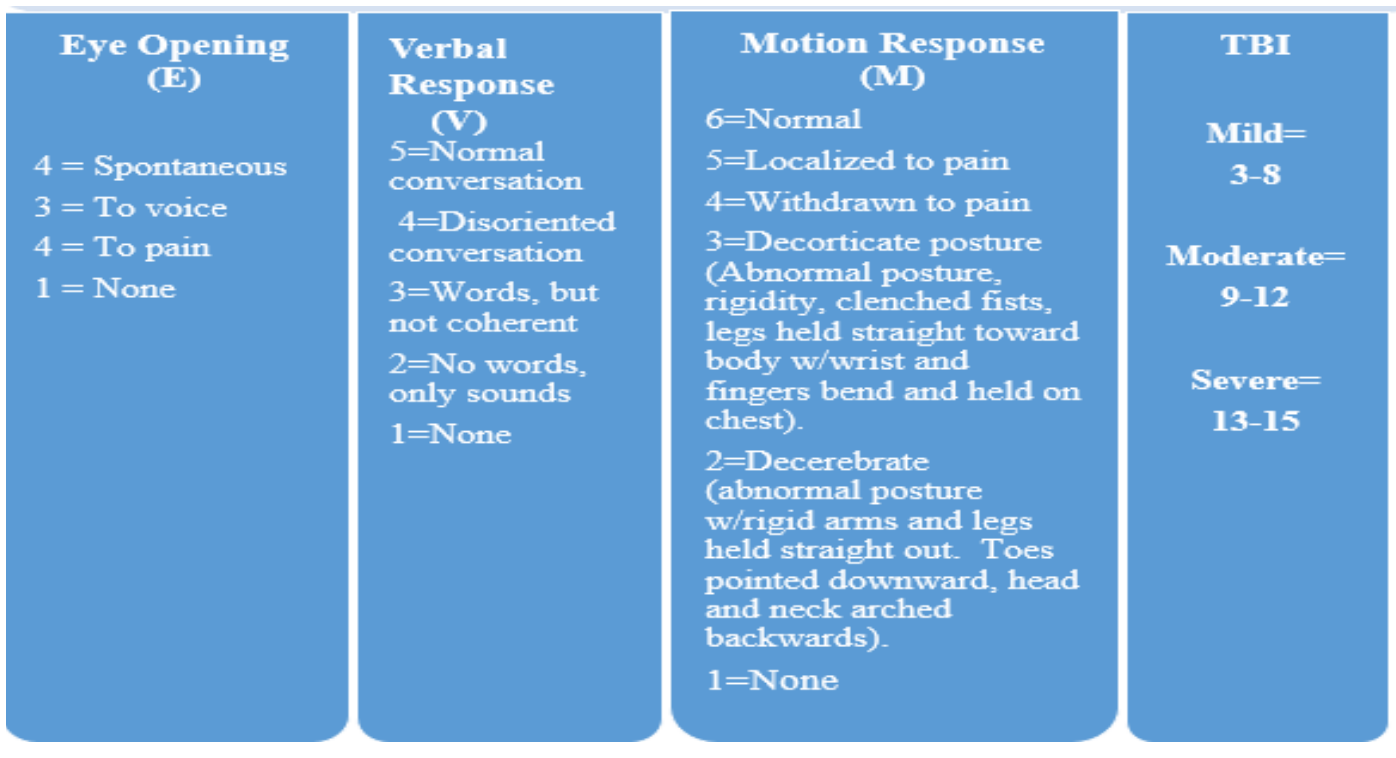

Figure 3. Illustration of GCS Scoring System

\section{Neurological Quality of Life Scale}

Neuro-QoL (Quality of Life in Neurological Disorders) is a measurement system that was designed to construct a psychometrically sound and clinically relevant health related quality of life measuring instruments for neurological conditions (National Institute of Health, n.d.). Its purpose is to evaluate and monitor the physical, mental, and social effects encountered by individuals living with neurological conditions (Cella, 2012; National Institute of Health, n.d.; Bertisch et al., 2017; Salsman et al., 2014). A distinctive characteristic of Neuro-QoL measuring tool is specifically designed to assess specific conditions, based on the TBIQoL measurement outcome (Perez et al., 2014; Bertisch et al., 2017). This simple and quick instrument is patient-centered and designed to develop health-related quality of life measurement systems, to address major 
neurological disorders (Gershon et al, 2012; Salsman et al., 2014). Neuro-QoL is individually designed for patient, based on client's identified needs.

\section{Data Collection Procedures}

The secondary dataset being used in this research was collected by the Traumatic Brain Injury Model Systems National Data and Statistical Center longitudinal database (Craig Hospital, 2017). In 1998, the U.S. Department of Education, National Institute on Disability and Rehabilitation Research (NIDRR) funded the Craig Hospital brain injury program and designated it as a TBI Model System.

All identifiers were removed from the dataset prior to delivery to the researcher, thus preventing any possibility of tracing identity of subjects involved in the study. The files are linked by the Field UID in each file. The methods used by the Traumatic Brain Injury Model Systems National Data and Statistical Center personnel to acquire data were structured interviews and questionnaires. The subjects interviewed and questioned were emerging adults with TBI and their parents and carers. The staff of 22 were all trained uniformly, to ensure that the information obtained is reliable.

\section{Data Analysis}

The main purpose of data analysis is to study the relationship between the predicting variables such as (a) gender, (b) socioeconomic status (SES), (c) employment, (d) years of education, (e) age at onset of injury, (f) existence of familial capital/parental involvement, and (g) hours spent studying for a class and persistence among emerging adults with TBI in postsecondary education. Descriptive statistics and logistic regression were methods of choice selected to be used in describing the available data and investigating the relationship between persistence and the emerging adults with TBI in 
postsecondary education. The outcome dependent variable is discrete [persistence $=1$, or dropout $=0$ ]. Therefore, specifically, a binary logistic regression was conducted in the present study (Howell, 2012). Some correlational analysis was conducted preliminarily to determine the strength and direction of relationships between the dependent and independent variables. All quantitative data were inputted into the IBM Statistical Package for Social Sciences (SPSS 23.0) for Windows to test the hypotheses. An alpha level of .05 (one-tailed) was used in both hypothesis tests. Using one-tailed statistical analysis is appropriate when theory and research supports the direction of relationship between two or more variables as was the case in this research (Howell, 2012). The research variables were discrete and continuous.

$H_{01}$ : There is not a significant relation between gender, socioeconomic status, time spent studying, age at onset of injury, employment, years of education and persistence among emerging adults with TBI in postsecondary education.

To test $H_{0 I}$, logistic regression analysis was conducted by investigating the impact of gender, socioeconomic status, time spent studying, age at onset of injury, employment, years of education on the role of persistence among emerging adults with TBI in postsecondary education. Logistic regression is a statistical technique used for analyzing where there are one or more independent variables that determine a dichotomous outcome (Howell, 2012).

$H_{02}$ : There is not a relationship between familial support and persistence among emerging adults with TBI in postsecondary education.

To test $H_{02}$, logistic analysis was used to test the relationship between familial support and persistence among emerging adults with TBI in postsecondary education. 


\section{Human Participation and Ethics Precautions}

The researcher received permission to use a secondary dataset from the Traumatic Brain Injury Model Systems National Data and Statistical Center. Because all identifiers were removed by the Center's personnel prior to delivery, there was no possible way to identity the subjects of this dataset; thus, this research should pose no risk or harm to human subjects and the confidentiality of the participants was secure.

\section{Summary}

The method used to conduct this study is outlined in this chapter and is divided into the following sections: (a) introduction; (b) research questions, (c) population and sample, (d) instrumentation; (e) data collection/procedures; (f) data analysis; (g) human participation and ethics precautions; and (h) summary. Although human subjects are involved in this research, with the usage of a secondary dataset, precautionary measures are applied to ensure complete confidentiality of human subjects and their personal information, involved in this study. All participant identifiers were removed from the dataset before electronic transmission to this researcher. 


\section{CHAPTER IV}

\section{RESULTS}

\section{Introduction}

The purpose of this study was to investigate the role of demographic and sociopsychological factors associated with predicting persistence in postsecondary education among emerging adults with traumatic brain injury (TBI). This Chapter is organized by a discussion of the sample demographics, research question/hypothesis testing, and a summary of the results. Data were analyzed with SPSS 23 for Windows. The following provides a discussion of the sample demographic.

\section{Sample Demographics}

Data were obtained on 2,436 participants with TBI ranging from ages 16-29 years of age at injury $(M=22.46, S D=3.61)$, with a median age of 22 . Males $(75 \%, n=$

Table 12

Gender and Race

\begin{tabular}{llcc}
\hline Variable & Description & $N$ & $\%$ \\
\hline Sex & Female & 608 & 25.0 \\
& Male & 1,825 & 75.0 \\
& Total & 2,433 & 100.0 \\
& & & \\
Race & White & 1,414 & 58.0 \\
& Black & 449 & 18.4 \\
& Asian/Pacific Islander & 86 & 3.5 \\
& Native American & 20 & 0.8 \\
& Hispanic Origin & 420 & 17.2 \\
& Other & 47 & 1.9 \\
& Total & 2,436 & 100.0
\end{tabular}

*Note. Percentages represent valid percentages. 
$1,825)$ outnumbered females $(25.0 \%, n=608)$. in the sample by a factor of three to one. Gender was missing on three participants. Regarding race, $58.0 \%(n=1,414)$ of the sample was White, $18.4 \%(n=449)$ were Black; and 17.2\% $(n=420)$ were of Hispanic origin. See Table 12.

Regarding marital status at the time of injury, most participants $(89.0 \%, n=$ $2,165)$ were single (never married); and 7.4\% $(n=181)$ were married. Approximately the same proportion of respondents $(1.7 \%, n=41)$ were divorced or separated $(1.6 \%, n=40)$ at the time of injury. Marital status at injury is presented in Table 13.

Table 13

Marital Status at Time of Injury

\begin{tabular}{|c|c|c|c|c|}
\hline \multicolumn{2}{|c|}{ Marital Status } & \multirow{2}{*}{$\frac{N}{2,165}$} & \multirow{2}{*}{$\frac{\%}{88.9}$} & \multirow{2}{*}{$\frac{\text { Valid \% }}{89.0}$} \\
\hline & Single (Never Married) & & & \\
\hline & Married & 181 & 7.4 & 7.4 \\
\hline & Divorced & 41 & 1.7 & 1.7 \\
\hline & Separated & 40 & 1.6 & 1.6 \\
\hline & Widowed & 4 & 0.2 & 0.2 \\
\hline & Other & 2 & 0.1 & 0.1 \\
\hline & Total & 2,433 & 99.9 & 100.0 \\
\hline \multirow[t]{3}{*}{ Missing } & Unknown & 2 & 0.1 & \\
\hline & System & 1 & 0.0 & \\
\hline & Total & 3 & 0.1 & \\
\hline Total & & 2,436 & 100.0 & \\
\hline
\end{tabular}

At follow-up five years later, most participants $(86.4 \%, n=1,716)$ were single (never married); and 7.9\% $(n=156)$ were married. The number of divorced participants $(3.1 \%$, $n=61)$ slightly exceeded the respondents who were separated $(2.2 \%, n=43)$. Marital status at follow-up is presented in Table 14. 
Table 14

Marital Status at Follow-Up

\begin{tabular}{|c|c|c|c|c|}
\hline \multicolumn{2}{|c|}{$\underline{\text { Marital Status }}$} & $N$ & $\%$ & Valid \% \\
\hline & Single (Never Married) & 1,716 & 70.4 & 86.4 \\
\hline & Married & 156 & 6.4 & 7.9 \\
\hline & Divorced & 61 & 2.5 & 3.1 \\
\hline & Separated & 43 & 1.8 & 2.2 \\
\hline & Widowed & 6 & 0.2 & 0.3 \\
\hline & Other & 5 & 0.2 & 0.3 \\
\hline & Total & 1,987 & 81.6 & 100.0 \\
\hline \multirow[t]{3}{*}{ Missing } & Unknown & 5 & 0.2 & \\
\hline & System & 444 & 18.2 & \\
\hline & Total & 449 & 18.4 & \\
\hline Total & & 2,436 & 100.0 & \\
\hline
\end{tabular}

Forty-eight percent $(n=1,173)$ of participants were living with their parents at the time of injury; $12.9 \%(n=313)$ were living with roommates or friends; and $10.8 \%(n=$ 262) were living with their significant others. Respondents also reported living alone $(9.5 \%, n=231)$, with their spouses $(7.2 \%, n=174)$, and other relatives or adult children $(6.2 \%, n=150)$, which represented $94.7 \%$ of the sample. Person living with at time of injury is presented in Table 15 . 
Table 15

Person Living with At Time of Injury: Primary

\begin{tabular}{llccc}
\hline Person Living with at Injury & $n$ & $\%$ & Valid \% \\
\hline Alone & 231 & 9.5 & 9.5 \\
Spouse & 174 & 7.1 & 7.2 \\
Parent(s) & 1,173 & 48.2 & 48.2 \\
Sibling(s) & 77 & 3.2 & 3.2 \\
Child/Children & 29 & 1.2 & 1.2 \\
Other Relative(s) or Adult Child/Children & 150 & 6.2 & 6.2 \\
& Roommate(s) or Friend(s) & 313 & 12.8 & 12.9 \\
& Significant Other & 262 & 10.8 & 10.8 \\
& Other Patients & 3 & 0.1 & 0.1 \\
& Other Residents & 12 & 0.5 & 0.5 \\
& Personal Care Attendant & 1 & 0.0 & 0.0 \\
& Other & 7 & 0.3 & 0.3 \\
& Total & 2,432 & 99.8 & 100.0 \\
Missing & Unknown & 3 & 0.1 & \\
& System & 1 & 0.0 & \\
& Total & 4 & 0.2 & \\
\hline
\end{tabular}

Sixty-six percent $(n=1,605)$ of participants were living with their parents after discharge; $9.4 \%(n=228)$ were living with other patients; and 5.8\% $(n=142)$ were living with their other relatives or adult children. Respondents also reported living with their spouses $(5.5 \%, n=134)$, with their significant others $(5.0 \%, n=122)$, and siblings $(3.3 \%$, $n=81$ ), which represented $95.2 \%$ of the sample. Person living with after discharge is presented in Table 16. 
Table 16

Person Living with After Discharge

\begin{tabular}{llccc}
\hline Person Living with After Discharge & $n$ & $\%$ & Valid \% \\
\hline Alone & 22 & 0.9 & 0.9 \\
Spouse & 134 & 5.5 & 5.5 \\
Parent(s) & 1,605 & 65.9 & 66.1 \\
Sibling(s) & 81 & 3.3 & 3.3 \\
Child/Children & 4 & 0.2 & 0.2 \\
Other Relative(s) or Adult Child/Children & 142 & 5.8 & 5.8 \\
& Roommate(s) or Friend(s) & 43 & 1.8 & 1.8 \\
& Significant Other & 122 & 5.0 & 5.0 \\
& Other Patients & 228 & 9.4 & 9.4 \\
& Other Residents & 39 & 1.6 & 1.6 \\
& Personal Care Attendant & 2 & 0.1 & 0.1 \\
& Other & 6 & 0.2 & 0.2 \\
& Total & 2,428 & 99.7 & 100.0 \\
Missing & 1 & 0.0 & \\
& Unknown & 7 & 0.3 & \\
& System & 8 & 0.3 & \\
Total & 2,436 & 100.0 & \\
\hline
\end{tabular}

Regarding residence at injury, most participants $(98.8 \%, n=2,406)$ were living in private residences. The remaining $1.2 \%(n=29)$ were homeless, lived in adult homes, correctional institutions, hospitals, hotels/motels, and other places. Residence at injury is presented in Table 17. 
Table 17

\begin{tabular}{|c|c|c|c|c|}
\hline \multicolumn{2}{|c|}{ Residence at Injury } & \multirow{2}{*}{$\frac{n}{2,406}$} & \multirow{2}{*}{$\frac{\%}{98.8}$} & \multirow{2}{*}{$\frac{\text { Valid \% }}{98.8}$} \\
\hline & Private Residence & & & \\
\hline & Adult Home & 1 & 0.0 & 0.0 \\
\hline & Correctional Institution & 2 & 0.1 & 0.1 \\
\hline & Hotel/Motel & 4 & 0.2 & 0.2 \\
\hline & Homeless & 6 & 0.2 & 0.2 \\
\hline & Hospital: Rehabilitation & 2 & 0.1 & 0.1 \\
\hline & Hospital: Other & 1 & 0.0 & 0.0 \\
\hline & Other & 13 & 0.5 & 0.5 \\
\hline & Total & 2,435 & 100.0 & 100.0 \\
\hline Missing & System & 1 & .0 & \\
\hline Total & & 2,436 & 100.0 & \\
\hline
\end{tabular}

After discharge from rehab, most participants $(88.6 \%, n=2,151)$ were living in private residences. Less than $3 \%(2.9 \%, n=71)$ were discharged to subacute care facilities after rehab; $2.4 \%(n=58)$ were discharged to rehabilitation hospitals; and $2.1 \%(n=51)$ were discharged to acute care hospitals after rehab. Residence after rehab discharge is presented in Table 18. 
Table 18

Residence After Rehab Discharge

\begin{tabular}{llccc}
\hline Residence After Rehab Discharge & $n$ & $\%$ & Valid \% \\
\hline Private Residence & 2,151 & 88.3 & 88.6 \\
Nursing Home & 34 & 1.4 & 1.4 \\
Adult Home & 37 & 1.5 & 1.5 \\
Correctional Institution & 3 & 0.1 & 0.1 \\
Hotel/Motel & 4 & 0.2 & 0.2 \\
Homeless & 1 & 0.0 & 0.0 \\
& Hospital: Acute care & 51 & 2.1 & 2.1 \\
& Hospital: Rehabilitation & 58 & 2.4 & 2.4 \\
& Hospital: Other & 10 & 0.4 & 0.4 \\
& Subacute care & 71 & 2.9 & 2.9 \\
& Other & 7 & 0.3 & 0.3 \\
Missing & Total & 2,427 & 99.6 & 100.0 \\
& Unknown & 1 & 0.0 & \\
& System & 8 & 0.3 & \\
& Total & 9 & 0.4 & \\
& & 2,436 & 100.0 & \\
\hline \multirow{5}{*}{ Total } & & & & \\
& & &
\end{tabular}

Relative to current residence, most participants $(93.5 \%, n=1,905)$ were living in private residences. The remaining 6.5\% $(n=132)$ were homeless, lived in adult homes, correctional institutions, hospitals, hotels/motels, and other places. Current residence at is presented in Table 19. 
Table 19

\begin{tabular}{|c|c|c|c|c|}
\hline \multicolumn{2}{|c|}{ Current Residence } & \multirow{2}{*}{$\frac{n}{1,905}$} & \multirow{2}{*}{$\frac{\%}{78.2}$} & \multirow{2}{*}{$\frac{\text { Valid \% }}{93.5}$} \\
\hline & Private Residence & & & \\
\hline & Nursing Home & 21 & 0.9 & 1.0 \\
\hline & Adult Home & 14 & 0.6 & 0.7 \\
\hline & Correctional Institution & 43 & 1.8 & 2.1 \\
\hline & Hotel/Motel & 3 & 0.1 & 0.1 \\
\hline & Homeless & 7 & 0.3 & 0.3 \\
\hline & Hospital: Acute care & 1 & 0.0 & 0.0 \\
\hline & Hospital: Rehabilitation & 17 & 0.7 & 0.8 \\
\hline & Hospital: Other & 4 & 0.2 & 0.2 \\
\hline & Subacute Care & 15 & 0.6 & 0.7 \\
\hline & Other & 7 & 0.3 & 0.3 \\
\hline & Total & 2,037 & 83.6 & 100.0 \\
\hline \multirow[t]{3}{*}{ Missing } & Unknown & 1 & 0.0 & \\
\hline & System & 398 & 16.3 & \\
\hline & Total & 399 & 16.4 & \\
\hline Total & & 2,436 & 100.0 & \\
\hline
\end{tabular}

Regarding school participation, $64.6 \%(n=1,556)$ were not attending college at follow-up and $35.4 \%(n=854)$ were attending college. This means that $64.6 \%$ were drop-outs and the remaining $35.4 \%$ persisted. At injury $31.8 \%(n=773)$ had less than a high school diploma; $27.9 \%(n=677)$ had high school diplomas, and the remaining $59.7 \%(n=979)$ were either working toward college degrees or had obtained college degrees. Years of education at injury are presented in Table 20. 
Table 20

Years of Education at Injury

\begin{tabular}{|c|c|c|c|c|c|}
\hline Years of & Education & $n$ & $\%$ & Valid \% & Cumulative \% \\
\hline & 1 Year or Less & 6 & 0.2 & 0.2 & 0.2 \\
\hline & 2 Years & 2 & 0.1 & 0.1 & 0.3 \\
\hline & 3 Years & 1 & 0.0 & 0.0 & 0.4 \\
\hline & 4 Years & 1 & 0.0 & 0.0 & 0.4 \\
\hline & 5 Years & 6 & 0.2 & 0.2 & 0.7 \\
\hline & 6 Years & 20 & 0.8 & 0.8 & 1.5 \\
\hline & 7 Years & 15 & 0.6 & 0.6 & 2.1 \\
\hline & 8 Years & 58 & 2.4 & 2.4 & 4.5 \\
\hline & 9 Years & 102 & 4.2 & 4.2 & 8.7 \\
\hline & 10 Years & 172 & 7.1 & 7.1 & 15.8 \\
\hline & 11 or 12 Years: No diploma & 390 & 16.0 & 16.1 & 31.8 \\
\hline & HS Diploma & 677 & 27.8 & 27.9 & 59.7 \\
\hline & Work Toward Associates & 314 & 12.9 & 12.9 & 72.6 \\
\hline & Associates Degree & 97 & 4.0 & 4.0 & 76.6 \\
\hline & Work Toward Bachelors & 364 & 14.9 & 15.0 & 91.6 \\
\hline & Bachelor's Degree & 150 & 6.2 & 6.2 & 97.8 \\
\hline & Work Toward Masters & 23 & 0.9 & 0.9 & 98.7 \\
\hline & Master's Degree & 20 & 0.8 & 0.8 & 99.5 \\
\hline & Work Toward Doctoral Level & 4 & 0.2 & 0.2 & 99.7 \\
\hline & Doctoral Level Degree & 5 & 0.2 & 0.2 & 99.9 \\
\hline & Other & 2 & 0.1 & 0.1 & 100.0 \\
\hline & Total & 2,429 & 99.7 & 100.0 & \\
\hline Missing & Unknown & 6 & 0.2 & & \\
\hline & System & 1 & 0.0 & & \\
\hline & Total & 7 & 0.3 & & \\
\hline Total & & 2,436 & 100.0 & & \\
\hline
\end{tabular}

At follow-up, 25.2\% $(n=499)$ had less than a high school diploma, as compared to $31.8 \%(n=390)$ five years prior. However, $27.5 \%(n=545)$ had high school diplomas, and the remaining $47.3 \%(n=937)$ were either working toward college degrees or had obtained college degrees. Years of education at follow-up are presented in Table 21. 
Table 21

Years of Education at Follow-Up

\begin{tabular}{|c|c|c|c|c|c|}
\hline \multicolumn{2}{|c|}{ Years of Education } & \multirow{2}{*}{$\frac{n}{2}$} & \multirow{2}{*}{$\frac{\%}{0.1}$} & \multirow{2}{*}{$\begin{array}{c}\text { Valid \% } \\
0.1\end{array}$} & \multirow{2}{*}{$\frac{\text { Cumulative \% }}{0.1}$} \\
\hline & 1 Year or Less & & & & \\
\hline & 2 Years & 1 & 0.0 & 0.1 & 0.2 \\
\hline & 3 Years & 1 & 0.0 & 0.1 & 0.2 \\
\hline & 4 Years & 1 & 0.0 & 0.1 & 0.3 \\
\hline & 5 Years & 3 & 0.1 & 0.2 & 0.4 \\
\hline & 6 Years & 11 & 0.5 & 0.6 & 1.0 \\
\hline & 7 Years & 4 & 0.2 & 0.2 & 1.2 \\
\hline & 8 Years & 44 & 1.8 & 2.2 & 3.4 \\
\hline & 9 Years & 51 & 2.1 & 2.6 & 6.0 \\
\hline & 10 Years & 107 & 4.4 & 5.4 & 11.4 \\
\hline & 11 or 12 years: No diploma & 274 & 11.2 & 13.8 & 25.2 \\
\hline & HS Diploma & 545 & 22.4 & 27.5 & 52.7 \\
\hline & Work Toward Associates & 291 & 11.9 & 14.7 & 67.4 \\
\hline & Associates Degree & 72 & 3.0 & 3.6 & 71.0 \\
\hline & Work Toward Bachelors & 382 & 15.7 & 19.3 & 90.3 \\
\hline & Bachelor's Degree & 132 & 5.4 & 6.7 & 97.0 \\
\hline & Work Toward Masters & 24 & 1.0 & 1.2 & 98.2 \\
\hline & Master's Degree & 21 & 0.9 & 1.1 & 99.2 \\
\hline & Work Toward Doctoral Level & 9 & 0.4 & 0.5 & 99.7 \\
\hline & Doctoral Level Degree & 6 & 0.2 & 0.3 & 100.0 \\
\hline & Total & 1,981 & 81.3 & 100.0 & \\
\hline \multirow[t]{3}{*}{ Missing } & Unknown & 8 & 0.3 & & \\
\hline & System & 447 & 18.3 & & \\
\hline & Total & 455 & 18.7 & & \\
\hline Total & & 2,436 & 100.0 & & \\
\hline
\end{tabular}

Participants who were or had been attending school spent one hour to more than 35 hours per week studying. For instance, $5.3 \%(n=104)$ spent 35 or more hours studying, whereas $3.9 \%(n=77)$ spent $1-9$ hours. Time spent studying is presented in Table 22 . 
Table 22

Time Spent Studying

\begin{tabular}{llcccc}
\hline Time Spent Studying & $n$ & $\%$ & Valid \% & Cumulative \% \\
\hline \multirow{6}{*}{ None } & 1,556 & 63.9 & 79.3 & 79.3 \\
& 1-9 hours & 77 & 3.2 & 3.9 & 83.2 \\
& 10-19 hours & 117 & 4.8 & 6.0 & 89.1 \\
& 20-34 hours & 109 & 4.5 & 5.6 & 94.7 \\
& 35 or more hours & 104 & 4.3 & 5.3 & 100.0 \\
& Total & 1,963 & 80.6 & 100.0 & \\
Missing & System & 473 & 19.4 & & \\
\hline
\end{tabular}

At injury, 33.8\% $(n=819)$ of participants were not employed, whereas $66.2 \%(n$ $=1,601)$ were employed. At follow-up, $67.2 \%(n=1,400)$ were not employed, whereas $32.8 \%(n=684)$ were employed. Employment status at injury and follow-up is presented in Table 23.

Table 23

Employment Status at Injury at Follow-Up

\begin{tabular}{llccc}
\hline Employment at Injury & $n$ & $\%$ & Valid \% \\
\hline & Not Employed & 819 & 33.6 & 33.8 \\
& Employed & 1,601 & 65.7 & 66.2 \\
Total & 2,420 & 99.3 & 100.0 \\
Missing & System & 16 & 0.7 & \\
Total & & 2,436 & 100.0 & \\
& & & & \\
Employment at & Follow-Up & & & \\
& Not Employed & 1,400 & 57.5 & 67.2 \\
& Employed & 684 & 28.1 & 32.8 \\
& Total & 2,084 & 85.6 & 100.0 \\
Missing & System & 352 & 14.4 & \\
Total & & 2,436 & 100.0 & \\
\hline
\end{tabular}


Participants worked 0-100 hours per week at injury $(M=37.84, S D=13.74)$ with a median of 40 hours per week. At follow-up, participants worked 0-99 hours per week $(M=33.99, S D=14.44)$ with a median of 40 hours a week. Regarding annual earnings at injury, 31.2\% $(n=504)$ earned less than $\$ 10,000$ annually; $61.2 \%(n=989)$ earned $\$ 10,000$ to $\$ 49,999$; and $7.6 \%(n=123)$ earned more than $\$ 50,000$ annually. Annual earnings at injury are presented in Table 24.

Table 24

\section{Annual Earnings at Injury}

\begin{tabular}{|c|c|c|c|c|c|}
\hline \multicolumn{2}{|c|}{$\underline{\text { Earnings at Injury }}$} & \multirow{2}{*}{$\frac{n}{504}$} & \multirow{2}{*}{$\frac{\%}{20.7}$} & \multirow{2}{*}{$\frac{\text { Valid } \%}{31.2}$} & \multirow{2}{*}{$\frac{\text { Cumulative \% }}{31.2}$} \\
\hline & $\$ 9,999$ or less & & & & \\
\hline & $\$ 10,000-\$ 19,999$ & 378 & 15.5 & 23.4 & 54.6 \\
\hline & $\$ 20,000$ - \$29,999 & 303 & 12.4 & 18.8 & 73.3 \\
\hline & $\$ 30,000$ - \$39,999 & 196 & 8.0 & 12.1 & 85.5 \\
\hline & $\$ 40,000-\$ 49,999$ & 112 & 4.6 & 6.9 & 92.4 \\
\hline & $\$ 50,000$ - $\$ 59,999$ & 44 & 1.8 & 2.7 & 95.1 \\
\hline & $\$ 60,000$ - $\$ 69,999$ & 32 & 1.3 & 2.0 & 97.1 \\
\hline & $\$ 70,000$ - $\$ 79,999$ & 17 & 0.7 & 1.1 & 98.1 \\
\hline & $\$ 80,000$ - $\$ 89,999$ & 12 & 0.5 & 0.7 & 98.9 \\
\hline & $\$ 90,000$ - $\$ 99,999$ & 6 & 0.2 & 0.4 & 99.3 \\
\hline & $\$ 100,000$ or More & 12 & 0.5 & 0.7 & 100.0 \\
\hline & Total & 1,616 & 66.3 & 100.0 & \\
\hline \multirow{5}{*}{ Missing } & Refused & 36 & 1.5 & & \\
\hline & Not Applicable & 704 & 28.9 & & \\
\hline & Unknown & 77 & 3.2 & & \\
\hline & System & 3 & 0.1 & & \\
\hline & Total & 820 & 33.7 & & \\
\hline Total & & 2,436 & 100.0 & & \\
\hline
\end{tabular}

At follow-up, 30.8\% $(n=190)$ earned less than $\$ 10,000$ annually. However, $60.5 \%(n=$ 373 ) earned $\$ 10,000$ to $\$ 49,999$; and $8.8 \%(n=54)$ earned more than $\$ 50,000$ annually. Annual earnings at follow-up are presented in Table 25. 
Table 25

Annual Earnings at Follow-Up

\begin{tabular}{|c|c|c|c|c|c|}
\hline \multicolumn{2}{|c|}{ Earnings at Follow-Up } & \multirow{2}{*}{$\frac{n}{190}$} & \multirow{2}{*}{$\frac{\%}{7.8}$} & \multirow{2}{*}{$\frac{\text { Valid } \%}{30.8}$} & \multirow{2}{*}{$\frac{\text { Cumulative \% }}{30.8}$} \\
\hline & $\$ 9,999$ or less & & & & \\
\hline & $\$ 10,000$ - \$19,999 & 137 & 5.6 & 22.2 & 53.0 \\
\hline & $\$ 20,000-\$ 29,999$ & 117 & 4.8 & 19.0 & 72.0 \\
\hline & $\$ 30,000-\$ 39,999$ & 71 & 2.9 & 11.5 & 83.5 \\
\hline & $\$ 40,000-\$ 49,999$ & 48 & 2.0 & 7.8 & 91.2 \\
\hline & $\$ 50,000$ - \$59,999 & 18 & 0.7 & 2.9 & 94.2 \\
\hline & $\$ 60,000-\$ 69,999$ & 15 & 0.6 & 2.4 & 96.6 \\
\hline & $\$ 70,000$ - \$79,999 & 9 & 0.4 & 1.5 & 98.1 \\
\hline & $\$ 80,000$ - $\$ 89,999$ & 1 & 0.0 & 0.2 & 98.2 \\
\hline & $\$ 90,000$ - \$99,999 & 1 & 0.0 & 0.2 & 98.4 \\
\hline & $\$ 100,000$ or More & 10 & 0.4 & 1.6 & 100.0 \\
\hline & Total & 617 & 25.3 & 100.0 & \\
\hline \multirow[t]{5}{*}{ Missing } & Refused & 12 & 0.5 & & \\
\hline & Not Applicable & 1,333 & 54.7 & & \\
\hline & Unknown & 27 & 1.1 & & \\
\hline & System & 447 & 18.3 & & \\
\hline & Total & 1,819 & 74.7 & & \\
\hline Total & & 2,436 & 100.0 & & \\
\hline
\end{tabular}

Familial and social support at follow-up are presented in Table 26 (this

information was not available at injury. Although $81.5 \%(n=1,581)$ had a close friend to confide in, only $16.4 \%(n=323)$ were living with a spouse or significant other. Yet, $91.6 \%(n=1,774)$ reported socializing with friends, $97.2 \%(n=1,891)$ socialized with friends and family, and 40.7\% $(n=787)$ were in an ongoing intimate relationship. 
Table 26

Familial and Social Support

\begin{tabular}{llcc}
\hline Variable & Description & $n$ & $\%$ \\
\hline Socialize with Friends & No & 163 & 8.4 \\
& Yes & 1,774 & 91.6 \\
& Total & 1,937 & 100.0 \\
Socialize with Family and & No & 54 & \\
Relatives & Yes & 1,891 & 2.8 \\
& Total & 1,945 & 97.2 \\
Living with Spouse or & & & 100.0 \\
Significant Other & No & 1,645 & 83.6 \\
& Yes & 323 & 16.4 \\
Involved in Ongoing Intimate & Total & 1,968 & 100.0 \\
Relationship & No & 1,148 & \\
& Yes & 787 & 59.3 \\
& Total & 1,935 & 40.7 \\
Have Close Friend to Confide In & No & 359 & 100.0 \\
& Yes & 1,581 & 18.5 \\
& Total & 1,940 & 81.5 \\
& & & 100.0 \\
\hline
\end{tabular}

*Note percentages are valid percentages.

\section{Research Question One/Hypothesis One}

Is there a relationship among gender, socioeconomic status, time spent studying, age at onset of injury, employment, years of education and persistence in postsecondary education among emerging adults with TBI? Research Question One/Hypothesis One was tested with binary logistic regression. It was initially proposed that the independent/predictor variables were gender, socioeconomic status, time spent studying, age at onset of injury, employment, and years of education. When the analysis was conducted, however, the inclusion of employment and time spent studying yielded invalid results. To address this issue, the decision was made to use hours worked in the 
analysis instead of employment status and to analyze time spent studying separately using a chi-square analysis. The dichotomous, dependent variable was persistence with two categories [persistence $=1$, or dropout $=0$ ]. There was a total of 473 complete sets of data; thus, the full logistic regression model was run on this data. The full model significantly predicted persistence (Omnibus $X^{2}=151.54, d f=10, p<.001$ ). The model accounted for between $27.4 \%$ and $43.7 \%$ of the variance in predicted persistence with $96.1 \%$ of the participants who dropped out successfully predicted. However, only $50 \%$ of the predictions for the group that persisted were accurate. Overall, $87.1 \%$ of the predictions were accurate. Table 27 provides coefficients and the Wald statistic and the associated degrees of freedom and probability values for each of the predictor variables. The table shows that age, hours worked at follow-up, annual earnings at injury, years of education at injury, and years of education at follow-up reliably predicted persistence. The values of the coefficients revealed that an increase in one year of age was associated with a decrease in the odds of persistence by a factor of 0.82 (95\% CI: 0.73-0.92), $p=$ .001. An increase in one hour of work per week at follow-up was associated with a decrease in the odds of persistence by a factor of 0.95 (95\% CI: $0.92-0.97), p<.001$. Regarding annual earnings at injury, participants who earned between $\$ 10,000-\$ 49,999$ had reduced odds of persisting by a factor of 0.47 (95\% CI: 0.24-.91) compared to participants who earned $\$ 9,999$ or less at injury, $p=.025$. The values of the coefficients revealed that an increase in one year of education at injury was associated with a decrease in the odds of persistence by a factor of 0.73 (95\% CI: $0.58-0.96), p=.022$. However, an increase in one year of education at follow-up was associated with an increase in the odds of persistence by a factor of 1.84 (95\% CI: 1.40-2.42), $p<.001$. 
Table 27

Coefficients for Logistic Regression Model for Research Hypothesis One

95\% C.I.for $\operatorname{EXP}(B)$

\begin{tabular}{|c|c|c|c|c|c|c|c|c|}
\hline Variable & $B$ & S.E. & Wald & $d f$ & $p$ & $\operatorname{Exp}(B)$ & Lower & Upper \\
\hline Gender & -.272 & .313 & .757 & 1 & .384 & .762 & .412 & 1.41 \\
\hline Age $^{* *}$ & -.198 & .058 & 11.50 & 1 & .001 & .820 & .732 & .920 \\
\hline $\begin{array}{l}\text { Employment: Hours Worked } \\
\text { At Injury }\end{array}$ & -.023 & .013 & 3.11 & 1 & .078 & .977 & .952 & 1.00 \\
\hline $\begin{array}{l}\text { Employment: Hours Worked } \\
\text { At Follow-Up*** }\end{array}$ & -.054 & .014 & 15.14 & 1 & .000 & .947 & .922 & .974 \\
\hline Annual Earnings: At Injury* & & & 6.10 & 2 & .047 & & & \\
\hline$\$ 10,000-\$ 49,999 *$ & -.763 & .339 & 5.05 & 1 & .025 & .466 & .240 & .907 \\
\hline$\$ 50,000$ or more & -1.96 & 1.28 & 2.34 & 1 & .126 & .141 & .012 & 1.73 \\
\hline $\begin{array}{l}\text { Annual Earnings: At Follow- } \\
\text { Up }\end{array}$ & & & 3.12 & 2 & .210 & & & \\
\hline$\$ 10,000-\$ 49,999$ & .557 & .384 & 2.10 & 1 & .147 & 1.75 & .822 & 3.71 \\
\hline$\$ 50,000$ or more & -.659 & 1.31 & .251 & 1 & .616 & .517 & .039 & 6.80 \\
\hline $\begin{array}{l}\text { Years of Education: At } \\
\text { Injury* }\end{array}$ & -.297 & .129 & 5.27 & 1 & .022 & .743 & .576 & .957 \\
\hline $\begin{array}{l}\text { Years of Education: At } \\
\text { Follow-Up*** }\end{array}$ & .608 & .140 & 19.00 & 1 & .000 & 1.84 & 1.40 & 2.42 \\
\hline Constant & 1.75 & 1.37 & 1.62 & 1 & .203 & 5.75 & & \\
\hline
\end{tabular}

Note. . Dependent Variable = Persistence: 1=Persistence, $0=$ Drop-out; Gender: 1=Male, $0=$ Female; Annual Earnings At Injury: The reference category is $\$ 9,999$ or less; Annual Earnings At Follow-Up: The reference category is $\$ 9,999$ or less; $* * * p<.001, * * p<$ $.01, * p<.05$.

A 2 X 5 chi-square test for independence was conducted between time spent studying and persistence to determine if there was an association between the variables. There was a significant association between time spent studying and persistence, $X^{2}(4, N=1963)=$ 1963.0, $p<.001$. A contingency table is presented in Table 28. 
Table 28

School Participation by Time Spent Studying

\begin{tabular}{|c|c|c|c|c|c|c|c|c|}
\hline & & & & Tim & Spent & udying & & \\
\hline & & & None & $\begin{array}{c}1-9 \\
\text { hours }\end{array}$ & $\begin{array}{l}10-19 \\
\text { hours }\end{array}$ & $\begin{array}{l}20-34 \\
\text { hours }\end{array}$ & $\begin{array}{l}35 \text { or } \\
\text { more } \\
\text { hours }\end{array}$ & Total \\
\hline School & Drop-Out & Count & 1,556 & 0 & 0 & 0 & 0 & 1,556 \\
\hline Participation & & $\%$ within & $100.0 \%$ & $0.0 \%$ & $0.0 \%$ & $0.0 \%$ & $0.0 \%$ & $100.0 \%$ \\
\hline & & School & & & & & & \\
\hline & & Participation & & & & & & \\
\hline & & $\%$ of Total & $79.3 \%$ & $0.0 \%$ & $0.0 \%$ & $0.0 \%$ & $0.0 \%$ & $79.3 \%$ \\
\hline & Persistence & Count & 0 & 77 & 117 & 109 & 104 & 407 \\
\hline & & $\%$ within & $0.0 \%$ & $18.9 \%$ & $28.7 \%$ & $26.8 \%$ & $25.6 \%$ & $100.0 \%$ \\
\hline & & School & & & & & & \\
\hline & & Participation & & & & & & \\
\hline & & $\%$ of Total & $0.0 \%$ & $3.9 \%$ & $6.0 \%$ & $5.6 \%$ & $5.3 \%$ & $20.7 \%$ \\
\hline Total & & Count & 1,556 & 77 & 117 & 109 & 104 & 1,963 \\
\hline & & $\%$ within & $79.3 \%$ & $3.9 \%$ & $6.0 \%$ & $5.6 \%$ & $5.3 \%$ & $100.0 \%$ \\
\hline & & School & & & & & & \\
\hline & & Participation & & & & & & \\
\hline & & $\%$ of Total & $79.3 \%$ & $3.9 \%$ & $6.0 \%$ & $5.6 \%$ & $5.3 \%$ & $100.0 \%$ \\
\hline
\end{tabular}

Ho1 stated that there is no significant relationship among gender, socioeconomic status, time spent studying, age at onset of injury, employment, and years of education (independent variables) and persistence among emerging adults with TBI in postsecondary education. There was no significant relationship among gender and persistence among emerging adults with TBI in postsecondary education, $p=.384$.

However, there were significant relationships between socioeconomic status $(p=.047$ at injury), time spent studying ( $p<.001)$, age at onset of injury $(p=.001)$, employment (at follow-up, $p<.001$ ), and years of education (independent variables) [at injury, $p=.022$, at follow-up, $p<.001]$ and persistence among emerging adults with TBI in postsecondary 
education. Therefore, the null hypothesis was partially rejected. In plain language, the first research hypothesis was partially supported.

\section{Research Question Two/Hypothesis Two}

Is there a relationship between familial support and persistence in postsecondary education among emerging adults with traumatic brain injury? Research Question

Two/Hypothesis Two was tested with another logistic regression model. The independent variables were the five aspects of familial support; socialized with friends, socialized with family and relatives, living with spouse or significant other, involved in an intimate or ongoing relationship, and having a close friend to confide in. The dichotomous, dependent variable was persistence with two categories [persistence $=1$, or dropout $=0$ ] . A total of 1,910 cases were analyzed, and the full model significantly predicted persistence (Omnibus $\left.X^{2}=93.33, d f=5, p<.001\right)$. The model accounted for between $4.8 \%$ and $7.5 \%$ of the variance in predicted persistence with $100 \%$ of the participants who dropped out successfully predicted. However, $0 \%$ of the predictions for the group that persisted were accurate. Overall, $79.4 \%$ of the predictions were accurate. Table 29 provides coefficients and the Wald statistic and the associated degrees of freedom and probability values for each of the predictor variables. The table shows that socializing with friends, living with spouse or significant other, and having a close friend to confide in reliably predicted persistence. Participants who socialized with friends were 3.21 times more likely to persist than participants who did not socialize with friends (95\% CI: 1.58 $6.49, p=.001)$. Participants who lived with their spouses or significant others had reduced odds of persisting by a factor of 0.29 compared to participants who did not live with their spouses or significant others (95\% CI: $0.18-0.45, p<.001)$. Participants who 
had a close friend to confide in were 2.23 times more likely to persist than participants who did not have a close friend to confide in (95\% CI: 1.53-3.26, $p<.001)$. Socializing with family/relatives was not a significant predictor of persistence, $p=.210$. Being involved in an intimate ongoing relationship was not a significant predictor of persistence, $p=.242$.

Table 29

Coefficients for Logistic Regression Model for Research Hypothesis Two 95\% C.I.for $\operatorname{EXP}(\mathrm{B})$

Variable $B \quad$ S.E. Wald $d f \quad p \quad \operatorname{Exp}(\mathrm{B})$ Lower Upper

Socialize with friends**

$\begin{array}{llllllll}1.17 & .360 & 10.49 & 1 & .001 & 3.21 & 1.58 & 6.49\end{array}$

Socialize with family/relatives $.677 \quad .540$ $\begin{array}{lllllll}-1.25 & .226 & 30.54 & 1 & .000 & .29\end{array}$

0.68

5.68

Living with spouse/significant other***

Involved in intimate ongoing .152 .130 1.37 1.242

relationship

$\begin{array}{lllllllll}\text { Having a close friend to confide } & .804 & .194 & 17.20 & 1 & .000 & 2.23 & 1.53 & 3.26\end{array}$ in***

Constant $\begin{array}{llllll}-3.71 & 609 & 37.18 & 1 & .000 & .02\end{array}$

Note. . Dependent Variable $=$ Persistence: $1=$ Persistence, $0=$ Drop-out; Socialize with friends: $1=$ Yes, $0=\mathrm{No}$; Socialize with family/relatives: $1=\mathrm{Yes}, \mathrm{No}=0$; Living with spouse/significant other: $1=$ Yes, $0=\mathrm{No}$; Involved in intimate ongoing relationship: $1=$ Yes, $0=$ No; Having a close friend to confide in: $1=$ Yes, $0=\mathrm{No} ; * * *<.001, * * p<.01$.

$\mathbf{H}_{02}$ stated that there is no significant relationship between familial support and persistence among emerging adults with TBI in postsecondary education. The full model significantly predicted persistence (Omnibus $X^{2}=93.33, d f=5, p<.001$ ). Therefore, the null hypothesis was rejected. Again, in plain language, the second research hypothesis was supported. The hypotheses and outcomes are provided in Table 30. 
Table 30

Summary of Hypotheses and Outcomes

\begin{tabular}{|c|c|c|}
\hline Hypotheses & Significance & Outcome \\
\hline $\begin{array}{l}\mathrm{H}_{01} \text { : There is no significant relationship } \\
\text { among gender, socioeconomic status, time } \\
\text { spent studying, age at onset of injury, } \\
\text { employment, and years of education } \\
\text { (independent variables) and persistence } \\
\text { among emerging adults with TBI in } \\
\text { postsecondary education }\end{array}$ & $\begin{array}{l}\text { Gender: } p=.384 \\
\text { Socioeconomic Status: } p=.025 \\
\text { Time spent studying: } p<.001 \\
\text { Age: } p=.001 \\
\text { Employment: } p<.001 \\
\text { Years of education: } p<.001\end{array}$ & $\begin{array}{l}\text { Null } \\
\text { Partially } \\
\text { Rejected. }\end{array}$ \\
\hline $\begin{array}{l}\mathrm{H}_{02} \text { : There is no significant relationship } \\
\text { between familial support and persistence } \\
\text { among emerging adults with TBI in } \\
\text { postsecondary education }\end{array}$ & $p<.001$ & $\begin{array}{l}\text { Null } \\
\text { Rejected. }\end{array}$ \\
\hline
\end{tabular}

\section{Summary of Results}

Two research questions and related hypotheses were formulated for investigation.

Age, hours worked at follow-up, annual earnings at injury, years of education at injury, and years of education at follow-up reliably predicted persistence. An increase in age was associated with a decrease in the odds of persistence. An increase in hours worked per week at follow-up was associated with a decrease in the odds of persistence.

Participants who earned between $\$ 10,000-\$ 49,999$ at injury had reduced odds of persisting compared to participants who earned $\$ 9,999$ or less at injury. An increase in years of education at injury was associated with a decrease in the odds of persistence. However, an increase in years of education at follow-up was associated with an increase in the odds of persistence. Gender was not a significant predictor of persistence.

Socializing with friends, living with spouse or significant other, and having a close friend 
to confide in reliably predicted persistence. Participants who socialized with friends were more likely to persist than participants who did not socialize with friends. Participants who lived with their spouses or significant others had reduced odds of persisting compared to participants who did not live with their spouses or significant others. Participants who had a close friend to confide in were more likely to persist than participants who did not have a close friend to confide in. Socializing with family/relatives was not a significant predictor of persistence. Being involved in an intimate ongoing relationship was not a significant predictor of persistence. Recommendations and implications will be discussed in Chapter Five. 


\section{CHAPTER V \\ DISCUSSION}

The purpose of this study was to examine the role of demographic and sociopsychological factors associated with predicting persistence in postsecondary education among emerging adults with traumatic brain injury (TBI). The predictor variables employed in this study were: (a) gender, (b) socioeconomic status (SES), (c) employment, (d) years of education; (e) age at onset of injury, (f) existence of familial capital/parental involvement, and (g) hours spent studying for a class. Although there is limited published corroboration on the direct effect of the above stated predictor variables on persistence in postsecondary education, particularly among emerging adults with TBI, the researcher sought to explore the possible connection between the previously stated predicting variables, and persistence in postsecondary education among emerging adults with TBI.

The secondary dataset used in this research was collected from the Traumatic Brain Injury Model Systems National Data and Statistical Center longitudinal database (Craig Hospital, 2017). In 1998, the U.S. Department of Education, National Institute on Disability and Rehabilitation Research (NIDRR) funded the Craig Hospital brain injury program and designated it as a TBI Model System.

This chapter summarizes the study findings as indicated by responses to the two research questions, and the two accompanying hypotheses that were tested. As the concluding chapter, it also proposes implications for practice, and makes recommendations for future research. 
The following research questions and accompanying hypotheses guided this study:

RQ1: Is there a relationship among gender, socioeconomic status, time spent studying, age at onset of injury, employment, years of education and persistence in postsecondary education among emerging adults with TBI?

H1: There is a significant relationship among gender, socioeconomic status, time spent studying, age at onset of injury, employment, and years of education (independent variables) and persistence among emerging adults with TBI in postsecondary education.

H01: There is no significant relationship among gender, socioeconomic status, time spent studying, age at onset of injury, employment, and years of education (independent variables) and persistence among emerging adults with TBI in postsecondary education.

RQ2: Is there a relationship between familial support and persistence in postsecondary education among emerging adults with traumatic brain injury?

H2: There is a significant relationship between familial support and persistence among emerging adults with TBI in postsecondary education.

Ho2: There is no significant relationship between familial support and persistence among emerging adults with TBI in postsecondary education.

Data obtained from the secondary dataset were analyzed using SPSS 23 for Windows. Binary logistic regression was the statistical model/strategy used to test the two separate research questions and hypotheses. 


\section{Significant Findings Related to Research Questions and Hypotheses}

\section{Research Question Two/Hypothesis Two}

RQ1: Is there a relationship among gender, socioeconomic status, time spent studying, age at onset of injury, employment, years of education and persistence in postsecondary education among emerging adults with TBI?

$\boldsymbol{H}_{1}$ : There is a significant relationship among gender, socioeconomic status, time spent studying, age at onset of injury, employment, and years of education (independent variables) and persistence among emerging adults with TBI in postsecondary education.

A binary logistic regression analysis was conducted to determine the relationship among gender, socioeconomic status, time spent studying, age at onset of injury, employment, years of education and persistence in postsecondary education among emerging adults with TBI. The inclusion of employment as hours spent working and time spent studying were analyzed separately with chi square analysis, yielding valid results. The dichotomous, dependent variable was persistence with its categories identified as [persistence $=1$, or dropout $=0$ ]. A total of 473 cases were analyzed, and the full model significantly predicted persistence (Omnibus $X^{2}=151.54, d f=10, p<.001$ ). The model accounted for between $27.4 \%$ and $43.7 \%$ of the variance in predicted persistence, and successfully predicted the outcome for $96.1 \%$ of the participants who became dropouts.

\section{Gender/Sex}

This study revealed no significant relationship between gender and persistence. This finding is consistent with previous studies (Baker \& Velez, 1996; Liu \& Liu, 2000; Wiggam, 2004), that observed no statistically significant relationship between gender and 
persistence. It should be noted that the emerging adults participating in Baker and Velez, Liu and Liu and Wiggam's studies were not described as emerging adults with TBI.

In contrast however, researchers such as Tinto (1993), Feldman (1993) and DuBrock and Fenske (2000) contend that gender does have a significant effect on academic persistence. Agnew (2014) further suggests that gender appears to function as a controlling variable that possibly influences the relationship and strength of the dependent variable of academic performance and persistence. Further studies concerning the reliability of gender in predicting academic persistence among emerging adults with TBI is needed.

\section{Socioeconomic Status}

The findings of this study noted that socioeconomic status at injury had a significant relationship with persistence. Participants whose annual earnings at injury, was between $\$ 10,000-\$ 49,999$ had reduced odds of persisting by a factor of 0.47 (95\% CI: 0.24-.91) compared to participants who earned $\$ 9,999$ or less at injury, $p=.025$. These conclusions which can be interpreted as, socioeconomic status impactpmg the odds of academic persistence, is aligned with the findings of previous studies (Allan, 2016; Moschetti and Hudley, 2015). This finding was also supported by other studies that claimed that socioeconomic background may not be as important at developing persistence, if one has a salient goal of a successful future and an optimistic mindset on their ability to climb the socioeconomic ladder through education (Browman et al., 2017; Davidai \& Gilovich, 2015; Eagan et al., 2014; Kraus \& Tan, 2015; Oyserman et al., 2015). Soria et al. (2014) based the findings of her study to make the claim that while low SES for emerging adults may persist on a longer-term basis, they are also more likely 
to make decisions that can negatively impact postsecondary persistence. It is of note that these studies were conducted among emerging adults in postsecondary settings, and not among the specific constituency of emerging adults with TBI in postsecondary settings.

There are several factors that have the potential to negatively affect academic persistence among emerging adults with TBI. As noted by researchers such as, Allan (2016), Amato (1996), Fuller et al (2015), and Harackiewicz et al (2014), issues such as classism, imposter syndrome, identity crisis among others, have been documented as a negative factor linked with low socioeconomic status. Innovative interventions such as socioeconomic mobility approaches (Eagan et al., 2014; Oyserman et a., 2015), are needed to offset the potential negative factors that can negatively impact academic persistence among emerging adults with TBI.

Age at Onset of Injury

This study, revealed significant relationship between age at onset of injury and persistence, by a factor of 0.82 (95\% CI: $0.73-0.92), p=.001 .$. This study showed that an increase in age was associated with a decrease in the odds of persistence. This finding is supported by prior investigations (Himanen et al., 2006; Kolb, Forgie, Gibb, Gorny, \& Rowntree, 1998; Nudo 2013; Ransom et al., 2015) suggesting that age at onset of injury can influence postsecondary persistence.

Previous studies have reported mixed findings of the association of age at onset of injury and academic persistence. Few researchers contend that younger age at onset of injury has more deleterious effects on persistence than older individuals such as emerging adults (Ewing-Cobb, 2012; Kraver et al., 2012). Several published studies however, agree with the findings of this study that individuals who experienced TBI at an older 
age, have a higher risk for cognitive challenges. Consequently, this study concurs with other findings which emphasize the increased need for available support for emerging adults with TBI in a postsecondary setting.

\section{Employment/Hours Spent Working}

In this study, an increase in hours worked per week at follow-up was associated with a decrease in the odds of persistence, by a factor of 0.95 (95\% CI: 0.92-0.97), $p<$ .001. Earlier research postulates various theories regarding the relationship between employment and postsecondary persistence. While some researchers (Drummond et al., 2012; Laberge et al., 2011; Lammers et al., 2001; Martin et al., 2012; Miller et al, 2008; Staff et al., 2010; Steinburg \& Cauffman, 1996) predict a decrease in postsecondary persistence because of participation in employment, while pursuing postsecondary education, others suggest that emerging adults engaging in part-time employment $(\leq 20$ hours per week) at school have a $30 \%$ lower predictive probability of postsecondary persistence, as compared to students who studied full-time (Therriault \& Krivoshey, 2014).

Further investigations suggested that intensive employment $(\geq 20$ hours per week, resulted in poor academic performance, while working manageable hours (10 -19 hours per week), resulted in higher academic performance (Choi, 2018; Dundes and Marx, 2006; Lammers et al., 2001; Manthei and Gilmore, 2005; Miller et al., 2008; Staff et al., 2010). Some previous studies contend that time and amount of work students are engaged in, has little significant impact on postsecondary performance and persistence (Body, Bonnal, \& Giret, 2014; Darolia, 2014; Triventi, 2014). All these studies addressed emerging adults without TBI, in a postsecondary setting. 
In this study, hours worked were analyzed as continuous and not segmented.

Consequently, the findings did not determine the effect of full time (>20 hours/week) and part-time ( $\leq 20$ hours/week) employment on persistence. Further studies are needed to investigate the relationship of segmented hours (part-time and full time hours) and persistence among emerging adults with TBI.

\section{Hours Spent Studying}

A 2 X5 chi-square test for independence was conducted between time spent studying and persistence to determine if there was an association between the variables. There was a significant association between time spent studying and persistence, $X^{2}(4, N$ $=1963)=1963.0, p<.001$.

Although the postsecondary emerging adults participating in Foshnacht, McCormick and Lerma (2018) study were not identified with TBI, their results supported the findings of this study. Foshnacht et al.'s (2018) study revealed that postsecondary students spend approximately 3 hours per day attending classes and studying. Low socioeconomic students, especially those receiving Pell grants are reported as spending $\geq$ 3 hours per day studying, as compared to their more socially advantaged counterparts (Foshnacht et al., 2018; Goldrick-Rab, 2016; Pell Institute, 2015). Some investigators however speculate that although students reporting study time of at least 3 hours per day experienced positive impacts on academic persistence, self-regulating quality of study time rather than the quantity of study time was beneficial in determining academic persistence (Bush et al., 2011; Helms \& Libertz, 2014; Field, Sarver, \& Shaw, 2003; Peng 2012; Zimmerman, 2013). 
The examined hours spent studying were not segmented in this investigation, consequently, it is difficult to determine if the specific number of hours, such as 3 hours per day, as suggested by Foshnacht (2018), played a role in the outcome findings. Contrary to our findings, some researchers (Darolia, 2014; Helms and Libertz, 2014; Nonis and Hudson, 2006; Todis and Glang, 2008), posits that time spent studying has no relationship to academic persistence. Further studies on self-regulation study strategies, among emerging adults with TBI, are currently needed to determine if there are other contributing factors associated with time spent studying and academic persistence.

\section{Education at Injury and Education at Follow-up}

The values of the coefficients revealed that an increase in one year of education at injury was associated with a decrease in the odds of persistence by a factor of 0.73 (95\% CI: $0.58-0.96), p=.022$. However, an increase in one year of education at follow-up was associated with an increase in the odds of persistence by a factor of 1.84 (95\% CI: $1.40-$ 2.42), $p<.001$.

A few studies have been done particularly among students with TBI. So far, research has suggested an increased risk of complications from TBI when it has occurred during lower educational levels. Velikonja, Warriner and Brum (2010) noted increased self-reported behavior associated with lower education level prior to the injury, validating previous researchers' findings of fewer behavioral problems associated with higher education levels and higher socioeconomic status. Moreover, lower levels of education at the time of injury were significantly associated with poor cognitive outcomes (Finnanger et al., 2015). 
Some related studies have been conducted on the postsecondary persistence of emerging adults without TBI. Finnanger et al (2015), found that greater executive dysfunction was also associated with lower education level at onset of injury. Despite these findings, however, research is still generally inconclusive regarding the relationship between educational level at injury and persistence.

Numerous studies revealed significant relationship between years of education and persistence. However, not all studies reviewed, supported the findings in this study. Finnanger et al. (2015) and Velikonja et al. (2010) declared that lower levels of education at the onset of injury, were significantly linked with poor cognitive outcomes. Conversely, other researchers insisted that persistence may not depend soley on certain educational levels, instead the existence of other protective factors such as social and academic support, may be more instrumental in impacting academic persistence (Hall, 2017; Neumann \& Finaly-Neumann, 1989; Tovar, 2015; Walsh \& Robinson, 2016).

The literature emphasized a few possible contributing factors to their findings, such as anxiety, rapport with educators, feelings of belongingness, self-recognition and self-confidence. Additional studies are needed that will further refine the investigation of predicting variables such as anxiety, interactions with educators, self-confidence, selfrecognition and their relationship with persistence among emerging adults with TBI.

\section{Research Question Two/Hypothesis Two}

RQ2: Is there a relationship between familial support and persistence in postsecondary education among emerging adults with traumatic brain injury?

Research Question Two/Hypothesis Two was tested with a logistic regression model. The independent variables were the five aspects of familial support; socialized 
with friends, socialized with family and relatives, living with spouse or significant other, involved in an intimate or ongoing relationship, and having a close friend to confide in. The dichotomous, dependent variable was persistence with the categories of [persistence $=1$, or dropout $=0$ ].

A total of 1,910 cases were analyzed, and the full model significantly predicted persistence (Omnibus $\left.X^{2}=93.33, d f=5, p<.001\right)$. The model accounted for between $4.8 \%$ and $7.5 \%$ of the variance in predicted persistence with $100 \%$ of the participants who dropped out successfully predicted. However, $0 \%$ of the predictions for the group that persisted were accurate. Overall, $79.4 \%$ of the predictions were accurate.

Socializing with friends, living with spouse or significant other, and having a close friend to confide in reliably predicted persistence. Participants who socialized with friends were 3.21 times more likely to persist than participants who did not socialize with friends (95\% CI: 1.58-6.49, $p=.001$ ). Participants who lived with their spouses or significant others had reduced odds of persisting by a factor of 0.29 compared to participants who did not live with their spouses or significant others (95\% CI: 0.18-0.45, $p<.001)$. Participants who had a close friend to confide in were 2.23 times more likely to persist than participants who did not have a close friend to confide in (95\% CI: $1.53-$ $3.26, p<.001)$. Socializing with family/relatives was not a significant predictor of persistence, $p=.210$. Being involved in an intimate ongoing relationship was not a significant predictor of persistence, $p=.242$.

Numerous researchers support the findings of this study that socializing with friends, living with spouse or significant other, and having a close friend to confide in reliably predicted persistence. Social support from peers, friends, faculty members and 
family members, significantly predicts self-efficacy and academic performance of students (Galambos, Barker \& Krahn, 2006; Masten, 2004; Lent et al., 2015). Findings indicated that socializing with family/relatives was not a significant predictor of persistence, in this study. Kenny (1987) and Kenney et al., (2003) stated that parental and social support play an integral role in postsecondary persistence, only if the care is converted to actions consistent to the needed support.

As reported by Finnanger (2015), TBI has significant impact on familial infrastructure due to challenges such as economical and emotional strain. The mind set of familial support changes to a survival mode, economically, and emotionally. Low parental and professional expectations of the educational pursuits of emerging adults with TBI, now becomes the norm. Brown et al. (2013) revealed in his findings that parents of individuals with TBI reportedly distanced themselves from their offsprings to cope with their situation, which resulted in more negative long-term outcomes among the emerging adult with TBI.

"Traumatic brain injury presents outcomes which both strengthen and compromise family systems" (Degeneffe, Gagne\& Tucker, 2013, p. 32). Financial disarray, family dysfunction, family disorientation, family dissolution, social isolation, personality and executive function changes of individual with TBI, emotional chaos, insufficient community support and resources, are reported factors affected by TBI (Degeneffe et al., 2013; Degeneffe and Tucker, 2014; Tucker and Degeneffe, 2013). Family members are unprepared, mentally, socially, financially, emotionally and physically, for the new roles that they now have to assume, due to a lack of, or ineffective community-based resources and support (Degeneffe \& Tucker, 2014). 


\section{Implications for Theory}

The conceptual framework that guided this study is a combination of Emerging Adulthood (2014) and Persistence (Tinto, 1993) theories. This study is divided into three themes: (a) traumatic brain injury, (b) emerging adult and persistence, and (c) predicting factors or variables of persistence among emerging adults with TBI. Due to the limited knowledge regarding the postsecondary persistence and functionality of emerging adults with TBI (Rosema et al., 2014), this overarching framework was selected. This research enriched emerging adulthood theory in that it had not been used to undergird research on emerging adult students with TBI in postsecondary settings previously. New insights that emerging adults, despite having TBI, still engaged in postsecondary educational endeavors (roughly 35\%) is encouraging. Nonetheless, Arnett (2014) suggested that the majority (60\%) of emerging adults tend to be engaged in postsecondary education, demonstrating how profound an impact TBI has had on the participants in this study. This work provided new knowledge and meaning related to Tinto's (1993) and Arnett's theories, in that it was useful for guiding this research as well, despite being developed primarily for traditional undergraduare students. Having a knowledge of the emerging adults mindset, coupled with the addition of TBI can provide valuable insight on how to increase persistence among this targeted population with the appropriate manipulation of predicting variables.

The predicting variables discussed in this investigation were all relevant to the emerging adults quest for identity separate from close family and relatives' connections. As theorized by Arnett (2014), the emerging adults are more self-focused and tend to delay significant adult responsibilities, in an effort to explore and find themselves. As 
noted in the findings of this study, age at onset of injury, socioeconomic status, employment, years of education, time spent studying and familial support were all significantly linked with academic persistence. Further indepth form of investigation, other than the usage of a secondary dataset, is necessary to refine and provide more meaning and clarification to the findings of this study.

\section{Implication of Practice}

This study brings increased awareness of the lack of and need for further studies surrounding the emerging adult with TBI participating in postsecondary education. Although several studies have been published regarding the challenges of the pediatric population with TBI, there is still limited research available on the emerging adult with TBI. Emerging adults are faced with several inner challenges such as, low self-esteem and uncertainty, while trying to fit in, during their quest for self-independence, financial independence, and self-decision making (Arnett, 2014).

The combination of TBI and emerging adulthood can present the perfect challenge/storm for the individual attending college. The search of the emerging adult for (a) the ability to make independent decisions, (b) the ability to be self-responsible (independent), and (c) the ability to be financially independent (Arnett, 2014) is completely challenged when combined with TBI. Arnett's description of the emerging adult's characteristics, sheds some light on possible rational on the findings of this study, (The values of the coefficients revealed that an increase in one year of age was associated with a decrease in the odds of persistence by a factor of 0.82 (95\% CI: 0.73-0.92), $p=$ 
.001). The combination of emerging adults characteristics and TBI presents the perfect storm for decreasing the odds of persistence.

The present investigation revealed a significant relationship between familial support and postsecondary education $(95 \% \mathrm{CI}: 0.18-0.45, p<.001)$. However, there was reduced odds of persistance among emerging adults with TBI living with spouses and significant others by a factor of 0.29 compared to emerging adults with TBI who did not live with their spouses or significant others. The reduced odds of postsecondary persistence among emerging adults with TBI, living with spouses and significant others, is of significant concern. To manage this dilemma, empowerment of families; spouses and significant others is essential. Deliberate, strategic placements of TBI information channels are crucial in empowering families, such as spouses, significant others and other caregivers, with education, financial resources and customized interventions to handle identified deficiencies.

Additional recommended strategies to address this dilemma, created by the combination of the emerging adult and the existence of TBI, school administration needs to equip their staff with the necessary skills and resources needed to address and encourage openness among the emerging adults with TBI. Developing a coaching or buddy mentoring system that will act as a navigating resource would seem prudent, realizing that persistence is motivation driven and is crafted by the student's major experiences and intense desire to stay in college and graduate (Baran \& Kiliç, 2015; Tinto, 2016). Educators should strive then to foster development of intrinsic motivation and self-efficacy among emerging adults with TBI. 
Socioeconomic status plays a role in the emerging adult's pursuit of academic goals. As noted in this study, participants who earned between $\$ 10,000-\$ 49,999$ had reduced odds of persisting by a factor of 0.47 (95\% CI: 0.24-.91) compared to participants who earned $\$ 9,999$ or less at injury, $p=.025$. Increasing access to financial resource and making access to financial resources available to individuals with TBI and their family appears to be a necessary step to help ensure a successful and productive transition for emerging adults with TBI. As an example, the federal Department of Education could make a significant positive impact by extending the years allowed to emerging adults with TBI to complete their bachelor's degree. Additionally, increased counselling can provide a vital and needed benefit not only for the emerging adults with TBI, but also for their families. 


\section{Limitations}

While the usage of secondary database set in a study offers many appealing benefits referring to saving time and costs, especially for longitudinal datasets such as this, but there were limitations, as with any research. First, there was a lack of researcher control over data quality, observations and the types of measures used in data collection. The researcher was unable to ascertain if certain minor demographic questions were mutually exclusive. Still, each of the researchers were trained to ensure the fidelity of the data collection protocols. In addition, each of the measures used were well-studied and validated for use with those with TBI. Second, this was a tremendously complex dataset with many other variables beyond the scope of this research being examined. The researcher was fortunate to be able though to access this national dataset to test her hypotheses. Third, because this was a longitudinal study, there was participant attrition that might introduce bias into the study. Upon comparing the gender of those who left versus those who remained, however, there was no evidence of systematic differences between the groups. Fourth, as this was a nonexperimental U.S. study where causality could not be inferred, the results should be not be applied to settings beyond the U.S.

\section{Recommendations for Future Research}

Inasmuch as gender was not found to be a significant predictor of persistence with this group of emerging adult students with TBI, it would be useful to design research to help explain why. It may be that gender interacts with some other variable (e.g., resilience, intrinsic motivation) to produce an effect. Further, age at injury was found to negatively predict persistence, which may be related to the characteristics associated with 
emerging adults with TBI. Consequently, further testing is needed to clarify questions developed from these research findings.

Future research could be designed to examine if possible issues related to being an emerging TBI adult with increased personal and professional responsibilities could alter persistence systematically from those who do not have TBI. Working had a negative impact on persistence, as much of the prior research suggests, but barely so. Follow-up research should examine if this pattern holds and should be compared with those who do not have TBI. Additional studies should also be done to investigate segmented hours worked for full time or part-time, instead of the measurement of continuous hours, to determine what other factors may be influencing the outcome.

One of the more interesting results from this research was that socializing with family and being engaged in intimate ongoing relationships did not significantly predict persistence. Yet, socializing with friends, being with a spouse or signficant other and having a close friend to confide in did. Clearly, both familial and social support matter, but a more sensitive measure may be needed to tease out these notions further.

Time spent studying was also a significant positive predictor of persistence. Future research should also get at specific self-regulatory strategies that comprise studying for additional information to aid advisors with evidence of those studying practices that have the most impact for those with TBI. Further investigation of time spent studying should be conducted, using segmented measurement instead of continuous hours, which can be beneficial in providing valuable knowledge of the associated factors linking time spent studying with persistence. 
Finally, because this was a U.S. study, it would be best to replicate this research in other international settings. It is possible that the familial and social support variables, for example, may be stronger predictors of persistence with emerging adults with TBI in countries with collectivist cultures like those prevalent in Asia (e.g., India and China). Conducting further research to obtain more indepth and meaningful information on the variables used in this investigation, can be beneficial in enriching and refining the findings of this study.

\section{Conclusions}

The needs of the emerging adult with TBI have not been adequately addressed in the available literature. Hence, the need for this study which focused on the emerging adult with TBI and the variables which enhanced or inhibited their zeal to persist at the postsecondary education level. To acquire new knowledge regarding the predicting variables impacting postsecondary persistence among emerging adults with TBI a secondary data set of longitudinal data was used. It was the intent of this researcher to add valuable accurate and pertinent information to the scholarly peer review journals.

With the newly acquired knowledge of predicting factors of postsecondary persistence among emerging adult with TBI, it is imperative to incorporate all resources and microsystems that interact with emerging adults with TBI in a postsecondary setting, and make them available to emerging adults with TBI and their families. Based on the findings of this study, collegiate administrators and policy makers can be more specific in addressing the needs of this marginalized population, with the goal of increasing the odds of postsecondary persistence among emerging adults with TBI. 


\section{REFERENCES}

Abdelhamid, S. E., Kuhlman, C. J., Marathe, M. V., Ravi, S. S., \& Reid, K. (2016). Agent-/based modeling and simulation of depression and its impact on student success and academic retention. Paper presented at the American Society for Engineering Education (ASEE). $123^{\text {rd }}$ International Conference Exposition, New Orleans, LA.

Agnew, J. A. (2014). From political methodology to geographical social theory? A critical review of electoral geography, 1960c87. In R. Johnston, F. Shelley, \& P. Taylor (Eds.), Developments in electoral geography (pp. 15-21). Abingdon, UK: Routledge.

Albert, P. R. (2015). Why is depression more prevalent in women? Journal of Psychiatry \& Neuroscience: JPN, 40, 219.

Alexandrino-Silva, C., Wang, Y. P., Viana, M. C., Bulhões, R. S., Martins, S. S., \& Andrade, L. H. (2013). Gender differences in symptomatic profiles of depression: results from the Sao Paulo Megacity Mental Health Survey. Journal of Affective Disorders, 147, 355-364.

Allan, B. A., Garriott, P. O., \& Keene, C. N. (2016). Outcomes of social class and classism in first-and continuing-generation college students. Journal of Counseling Psychology, 63, 487.

Allen, J., Robbins, S.B., Casillas, A., \& Oh, I. (2008). Third-year college retention and transfer: effects of academic performance, motivation, and social connectedness. Research in Higher Education, 49, 647-664.

Amato, P. R. (1996). Explaining the intergenerational transmission of divorce. Journal of Marriage and the Family, 21, 628-640.

Amen, D. G., Raji, C. A., Willeumier, K., Taylor, D., Tarzwell, R., Newberg, A., \& Henderson, T. A. (2015). Functional neuroimaging distinguishes posttraumatic stress disorder from traumatic brain injury in focused and large community datasets. PLoS One, 10, e0129659.

Amzat, I. H., Don, Y., Fauzee, S. O., Hussin, F., \& Raman, A. (2017). Determining motivators and hygiene factors among excellent teachers in Malaysia: An experience of confirmatory factor analysis. International Journal of Educational Management, 31, 78-97.

Andelic, N., Stevens, L. F., Sigurdardottir, S., Arango-Lasprilla, J. C., \& Roe, C. (2012). Associations between disability and employment 1 year after traumatic brain injury in a working age population. Brain Injury, 26, 261-269.

Arnett, J. J. (2000). Emerging adulthood: A theory of development from the late teens through the twenties. American Psychologist, 55, 469-480. 
Arnett, J. J. (2004). Emerging adulthood: The winding road from the late teens through the twenties. New York, NY: Oxford University Press.

Arnett, J. J. (2011). Debating emerging adulthood: Stage or process? New York, NY: Oxford University Press.

Arnett, J. J. (2014). Emerging adulthood: The winding road from the late teens through the twenties. New York, NY: Oxford University Press.

Aud, S., Fox, M. A., \& KewalRamani, A. (2010). Status and trends in the education of racial and ethnic groups (NCES 2010-015). Washington, DC: US Department of Education. National Center for Education Statistics.

Aud, S., KewalRamani, A., \& Frohlich, L. (2011). America's Youth: Transitions to Adulthood. NCES 2012-026. National Center for Education Statistics.

Axler, M. S. (2008). Achievement goals and academic internalization: The role of perceived autonomy support, perceived academic competence, gender and grade level in influencing academic motivation and performance. State University of New York at Albany.

Babcock, P., \& Marks, M. (2011). The falling time cost of college: Evidence from half a century of time use data. Review of Economics and Statistics, 93, 468-478.

Baguley, I. J., Cooper, J., \& Felmingham, K. (2006). Aggressive behavior following traumatic brain injury: how common is common? The Journal of Head Trauma Rehabilitation, 21, 45-56.

Baker, T. L., \& Velez, W. (1996). Access to and opportunity in postsecondary education in the United States: A review. Sociology of Education, 44, 82-101.

Bandura, A. (1989). Human agency in social cognitive theory. American Psychologist, 44, 1175-1184.

Bandura, A. 2010. Self-efficacy. In Corsini Encyclopedia of Psychology. (Vol.4, pp.1-3). Hoboken, New Jersey: Wiley and Sons.

Bandura, A. (2011). Social cognitive theory. Handbook of Social Psychological Theories, 2012, 349-373. Newbury Park, California: SAGE Publishers.

Baoyan, Y., \& Minggang, W. (2015). How Father's Education and Economic Capital Impact Academic Performance-An Analysis Based on the Mediating Effect and Moderating Effect. Chinese Education \& Society, 48, 412-432.

Baran, B., \& Kiliç, E. (2015). Applying the CHAID algorithm to analyze how achievement is influenced by university students' demographics, study habits, and technology familiarity. Journal of Educational Technology \& Society, 18, 323 336

Barron, K. E., \& Hulleman, C. S. (2015). Expectancy-value-cost model of motivation. Psychology, 84, 261-271. 
Barry, A. E., Whiteman, S. D., \& MacDermid Wadsworth, S. M. (2012). Implications of posttraumatic stress among military-affiliated and civilian students. Journal of American College Health, 60, 562-573.

Barry, A. E., Whiteman, S. D., \& MacDermid Wadsworth, S. (2014). Student service Members/Veterans in higher education: A systematic review. Journal of Student Affairs Research and Practice, 51, 30-42.

Batista, S., Zivadinov, R., Hoogs, M., Bergsland, N., Heininen-Brown, M., Dwyer, M. G., ... \& Benedict, R. H. (2012). Basal ganglia, thalamus and neocortical atrophy predicting slowed cognitive processing in multiple sclerosis. Journal of Neurology, 259, 139-146.

Bertisch, H., Rivara, F. P., Kisala, P. A., Wang, J., Yeates, K. O., Durbin, D., . . Tulsky, D. S. (2017). Psychometric evaluation of the pediatric and parent-proxy patientreported outcomes measurement information system and the neurology and traumatic brain injury quality of life measurement item banks in pediatric traumatic brain injury. Quality of Life Research, 26, 1887-1899.

Bessette, A., Morkos, B., \& Sangelkar, S. (2016, August). Motivational differences between senior and freshman engineering design students: A multi-institution study. In ASME 2016 International Design Engineering Technical Conferences and Computers and Information in Engineering Conference (pp. V003T04A014V003T04A014). American Society of Mechanical Engineers.

Blinn-Pike, L., Worthy, S. L., Jonkman, J. N., \& Smith, G. R. (2008). Emerging adult versus adult status among college students: examination of explanatory variables. Adolescence, 43, 577-592.

Body, K. M. D., Bonnal, L., \& Giret, J. F. (2014). Does student employment really impact academic achievement? The case of France. Applied Economics, 46, 30613073.

Browman, A. S., \& Destin, M. (2016). The effects of a warm or chilly climate toward socioeconomic diversity on academic motivation and self-concept. Personality and Social Psychology Bulletin, 42, 172-187.

Browman, A. S., Destin, M., Carswell, K. L., \& Svoboda, R. C. (2017). Perceptions of socioeconomic mobility influence academic persistence among low socioeconomic status students. Journal of Experimental Social Psychology, 72, 45-52.

Brown, F. L., Whittingham, K., Sofronoff, K., \& Boyd, R. N. (2013). Parenting a child with a traumatic brain injury: Experiences of parents and health professionals. Brain injury, 27, 1570-1582.

Bush, E., Hux, K., Zickefoose, S., Simanek, G., Holmberg, M., \& Henderson, A. (2011). Learning and study strategies of students with traumatic brain injury: A mixed method study. Journal of Postsecondary Education and Disability, 24, 231-250. 
Calderwood, C., \& Gabriel, A. S. (2017). Thriving at school and succeeding at work? A demands-resources view of spillover processes in working students. Journal of Vocational Behavior, 103, 1-13.

Carey, K. (2016). The end of college: Creating the future of learning and the university of everywhere. Riverhead, NY: Riverhead Books.

Cella, D., Lai, J. S., Nowinski, C. J., Victorson, D., Peterman, A., Miller, D., ... \& Reder, A. T. (2012). Neuro-QOL: brief measures of health-related quality of life for clinical research in neurology. Neurology, 78, 1860-1867.

Centers for Disease Control and Prevention. (2017). Traumatic brain injury in the United States: Fact. Centers for Disease Control and Prevention.

Chan, D., \& Schmitt, N. (2004). An agenda for future research on applicant reactions to selection procedures: A construct-oriented approach. International Journal of Selection and Assessment, 12, 9-23.

Chellman, C. C., Crook, D., Holod, A., Schwartz, A. E., \& Stiefel, L. (2011). At-risk at college: Differing paths to success for disadvantaged students in higher education. Working paper). Retrieved from CUNY Office of Policy Research website: http://www. cuny. edu/about/administration/offices/ira/opr/paper2. Pdf

Chen, M., \& Zheng, B. (2014). Axon plasticity in the mammalian central nervous system after injury. Trends in Neurosciences, 37, 583-593.

Chevignard, M., Francillette, L., Toure, H., Brugel, D., Meyer, P., Vannier, A. L., ... \& Watier, L. (2016). Academic outcome, participation and health-related quality of life following childhood severe traumatic brain injury: results of a prospective longitudinal study: the seven-year follow-up of the TGE cohort. Annals of Physical and Rehabilitation Medicine, 59, e133.

Chiang, C. C., Guo, S. E., Huang, K. C., Lee, B. O., \& Fan, J. Y. (2016). Trajectories and associated factors of quality of life, global outcome, and post-concussion symptoms in the first year following mild traumatic brain injury. Quality of Life Research, 25, 2009-2019.

Choi, Y. (2018). Student employment and persistence: Evidence of effect heterogeneity of student employment on college dropout. Research in Higher Education, 59, 88107.

Clance, P. R., \& Imes, S. A. (1978). The imposter phenomenon in high achieving women: Dynamics and therapeutic intervention. Psychotherapy: Theory, Research \& Practice, 15(3), 241.

Convertino, C. (2017). State disinvestment, technologies of choice and 'fitting in': neoliberal transformations in US public education. Journal of Education Policy, $32,832-854$. 
Coronado VG, Haileyesus T, Cheng TA, Bell JM, Haarbauer-Krupa J, Lionbarger MR, Flores-Herrera J, McGuire LC, Gilchrist J. (2015). Trends in sports- and recreation-related traumatic brain injuries treated in US emergency departments: The National Electronic Injury Surveillance System-All Injury Program (NEISSAIP) 2001-2012. The Journal of Head Trauma Rehabilitation, 30, 185-197.

Cramer, E. D., Pellegrini-Lafont, C., \& Gonzalez, L. (2014). Towards Culturally Responsive and Integrated Instruction for All Learners: The Integrated Learning Model. Interdisciplinary Journal of Teaching and Learning, 4, 110-124.

Crisp, G., Taggart, A., \& Nora, A. (2015). Undergraduate Latina/o students: A systematic review of research identifying factors contributing to academic success outcomes. Review of Educational Research, 85, 249-274.

Cubeta, J. F., Travers, N. L., \& Sheckley, B. G. (2001). Predicting the academic success of adults from diverse populations. Journal of College Student Retention: Research, Theory \& Practice, 2, 295-311.

Darolia, R. (2014). Working (and studying) day and night: Heterogeneous effects of working on the academic performance of full-time and part-time students. Economics of Education Review, 38, 38-50.

Davidai, S., \& Gilovich, T. (2015). Building a more mobile America-One income quintile at a time. Perspectives on Psychological Science, 10, 60-71.

Degeneffe, C. E., Gagne, L. M., \& Tucker, M. (2013). Family systems changes following traumatic brain injury: Adult sibling perspectives. Journal of Applied Rehabilitation Counseling, 44(3), 32.

Degeneffe, C. E., \& Tucker, M. (2014). Community-based support and unmet needs among families of persons with brain injuries: A mixed methods study with the Brain Injury Association of America state affiliates. In Military deployment and its consequences for families (pp. 293-313). Springer, New York, NY.

Deidrick, K. K. M., \& Farmer, J. E. (2005). School reentry following traumatic brain injury. Preventing School Failure, 49, 23-33.

Denney, S. C., \& Daviso, A. W. (2012). Self-determination: A critical component of education. American Secondary Education, 34, 43-51.

D'Lima, G. M., Winsler, A., Kitsantas, A., 2014, Ethnic and gender differences in firstyear college students' goal orientation, self-efficacy, and extrinsic and intrinsic motivation. Journal of Educational Research, 107, 341-356

Dortch, C. (2014). The Post-9/11 Veterans Educational Assistance Act of 2008 (Post9/11 GI Bill): Primer and issues. Washington, DC: Congressional Research Service.

Douglass, C. B. (2007). From duty to desire: Emerging adulthood in Europe and its consequences. Child Development Perspectives, 1, 101-108. 
DuBrock, C. P., \& Fenske, R. H. (2000, May). Financial aid and college persistence: A five-year longitudinal study of 1993 and 1994 beginning freshmen students. In Association for Institutional Research Forum Paper.

Drummond, S. P., Anderson, D. E., Straus, L. D., Vogel, E. K., \& Perez, V. B. (2012). The effects of two types of sleep deprivation on visual working memory capacity and filtering efficiency. Plo one, 7, e35653.

Dundes, L., \& Marx, J. (2006). Balancing work and academics in college: Why do students working 10 to 19 hours per week excel? Journal of College Student Retention: Research, Theory \& Practice, 8, 107-120.

Durante, F., Tablante, C. B., \& Fiske, S. T. (2017). Poor but warm, rich but cold (and competent): Social classes in the stereotype content model. Journal of Social Issues, 73, 138-157.

Dweck, C. S. (2007). Boosting achievement with messages that motivate. Education Canada, 47, 6-10.

Eagan, K., Stolzenberg, E. B., Ramirez, J. J., Aragon, M. C., Suchard, M. R., \& Hurtado, S. (2014). The American freshman: National norms fall 2014. Los Angeles: Higher Education Research Institute, UCLA.

Eccles, J. S., \& Wigfield, A. (1995). In the mind of the actor: The structure of adolescents' achievement task values and expectancy-related beliefs. Personality and Social Psychology Bulletin, 21, 215-225.

Edwards, K. E., \& McKelfresh, D. A. (2002). The Impact of a Living Learning Center on Students' Academic Success and Persistence. Journal of College Student Development, 43, 395-402.

Erikson, E. H. (1968). Identity, psychosocial. In International Encyclopedia of the Social Sciences, (Vol.7, pp. 61-65). Oxford, UK: Elsevier

Faul, M., Xu, L., Wald, M. M., \& Coronado, V. G. (2010). Traumatic brain injury in the United States. Atlanta, GA: Centers for Disease Control and Prevention, National Center for Injury Prevention and Control.

Feldman, M. J. (1993). Factors associated with one-year retention in a community college. Research in Higher Education, 34, 503-512.

Field, S., \& Hoffman, A. (1994). Development of a model for self-determination. Career Development for Exceptional Individuals, 17, 159-169.

Field, S., Sarver, M. D., \& Shaw, S. F. (2003). Self-determination: A key to success in postsecondary education for students with learning disabilities. Remedial and Special Education, 24, 339-349.

Figlio, D., Karbownik, K., Roth, J., \& Wasserman, M. (2016). School quality and the gender gap in educational achievement. American Economic Review, 106, 289295. 
Finnanger, T. G., Olsen, A., Skandsen, T., Lydersen, S., Vik, A., Evensen, K. A. I., ... \& Indredavik, M. S. (2015). Life after adolescent and adult moderate and severe traumatic brain injury: self-reported executive, emotional, and behavioural function 2-5 years after injury. Behavioural Neurology, 61, 2015.

Flake, J. K., Barron, K. E., Hulleman, C., McCoach, B. D., \& Welsh, M. E. (2015). Measuring cost: The forgotten component of expectancy-value theory. Contemporary Educational Psychology, 41, 232-244.

Frank-Stromberg, M. (1988). Instruments for clinical nursing research. Norwalk, CT: Appleton \& Lange.

Friedman, I. A. (2003). Self-efficacy and burnout in teaching: The importance of interpersonal-relations efficacy. Social Psychology of Education, 6, 191-215.

Fuller-Rowell, T. E., Evans, G. W., Paul, E., \& Curtis, D. S. (2015). The role of poverty and chaos in the development of task persistence among adolescents. Journal of Research on Adolescence (Wiley-Blackwell), 25, 606-613.

Galambos, N. L., Barker, E. T., \& Krahn, H. J. (2006). Depression, self-esteem, and anger in emerging adulthood: Seven-year trajectories. Developmental Psychology, $42,350-365$.

Gbollie, C., \& Keamu, H. P. (2017). Student academic performance: The role of motivation, strategies, and perceived factors hindering Liberian junior and senior high school students learning. Education Research International, 2017, 1-11.

Gershon, R. C., Lai, J. S., Bode, R., Choi, S., Moy, C., Bleck, T., . . Cella, D. (2012). Neuro-QOL: Quality of life item banks for adults with neurological disorders: Item development and calibrations based upon clinical and general population testing. Quality of Life Research, 21, 475-86.

Ghauri, P.N. and Grønhaug, K. (2005). Research methods in business studies: A practical guide, (3rd ed.). Upper Saddle River, NJ: Prentice-Hall.

Ghosh, C. (2012). The politics of the American dream: Democratic inclusion in contemporary American political culture. New York, NY: Springer.

Goldin, C., Katz, L. F., \& Kuziemko, I. (2006). The homecoming of American college women: The reversal of the college gender gap. Journal of Economic perspectives, 20, 133-156.

Goldrick-Rab, S. (2016). Paying the price: College costs, financial aid, and the betrayal of the American dream. Chicago, IL. University of Chicago Press.

Griffin, R., MacKewn, A., Moser, E., \& VanVuren, K. W. (2013). Learning skills and motivation: Correlates to superior academic performance. Business Education \& Accreditation, 5, 53-65. 
Grossman, E. J., Ge, Y., Jensen, J. H., Babb, J. S., Miles, L., Reaume, J., ... \& Inglese, M. (2012). Thalamus and cognitive impairment in mild traumatic brain injury: a diffusional kurtosis imaging study. Journal of Neurotrauma, 29, 2318-2327.

Haddad, S. H., \& Arabi, Y. M. (2012). Critical care management of severe traumatic brain injury in adults. Scandinavian Journal of Trauma, Resuscitation and Emergency Medicine, 20, 12.

Hall, D. L. (2017). Overcoming barriers to college graduation: The sophomore student experience with academic integration, retention and persistence (Doctoral dissertation, Hampton University).

Harackiewicz, J. M., Canning, E. A., Tibbetts, Y., Giffen, C. J., Blair, S. S., Rouse, D. I., \& Hyde, J. S. (2014). Closing the social class achievement gap for first-generation students in undergraduate biology. Journal of Educational Psychology, 106, 115.

Harris, V. (2017). The effect of the sophomore slump on students' persistence (Doctoral dissertation). Retrieved from https://search-proquestcom.ezproxy.fiu.edu/docview/2029385808/3DC32BA456244D9PQ/1 ?accountid= $\underline{10901}$ (10623939).

Hartley, R. F. (2011). Management mistakes and successes. Hoboken, NJ: Wiley.

Hattie, J., \& Timperley, H. (2007). The power of feedback. Review of Educational Research, 77, 81-112.

Hearn, J. C., \& Rosinger, K. O. (2014). Socioeconomic diversity in selective private colleges: An organizational analysis. The Review of Higher Education, 38, 71104.

Helms, K. T., \& Libertz, D. (2014). When service members with traumatic brain injury become students: Methods to advance learning. Adult Learning, 25, 11-19.

Hendricks, D. J., Sampson, E., Rumrill, P., Leopold, A., Elias, E., Jacobs, K., ... \& Stauffer, C. (2015). Activities and interim outcomes of a multi-site development project to promote cognitive support technology use and employment success among postsecondary students with traumatic brain injuries. NeuroRehabilitation, 37, 449-458.

Herbert, J. T., Hong, B. S., Byun, S. Y., Welsh, W., Kurz, C. A., \& Atkinson, H. A. (2014). Persistence and graduation of college students seeking disability support services. Journal of Rehabilitation, 80, 22-32.

Himanen, L., Portin, R., Isoniemi, H., Helenius, H., Kurki, T., \& Tenovuo, O. (2006). Longitudinal cognitive changes in traumatic brain injury A 30-year follow-up study. Neurology, 66, 187-192. 
Hoge, C. W., McGurk, D., Thomas, J. L., Cox, A. L., Engel, C. C., \& Castro, C. A. (2008). Mild traumatic brain injury in US soldiers returning from Iraq. New England Journal of Medicine, 358, 453-463.

Holland, J. N., \& Schmidt, A. T. (2015). Static and dynamic factors promoting resilience following traumatic brain injury: A brief review. Neural Plasticity, 20151-8. doi: $10.1155 / 2015 / 902802$

Howell, D. C. (2012). Statistical methods of psychology ( $8^{\text {th }}$ ed.). Belmont, CA: Wadsworth Publishing Company.

Hyder, A. A., Wunderlich, C. A., Puvanachandra, P., Gururaj, G., \& Kobusingye, O. C. (2007). The impact of traumatic brain injuries: a global perspective. NeuroRehabilitation-An Interdisciplinary Journal, 22, 341-354.

Jacobs, J. E., Lanza, S., Osgood, D. W., Eccles, J. S., \& Wigfield, A. (2002). Changes in children's self-competence and values: Gender and domain differences across grades one through twelve. Child Development, 73, 509-527.

Jury, M., Smeding, A., Stephens, N. M., Nelson, J. E., Aelenei, C., \& Darnon, C. (2017). The experience of low-SES students in higher education: Psychological barriers to success and interventions to reduce social-class inequality. Journal of Social Issues, 73, 23-41.

Kalenkoski, C. M., \& Pabilonia, S. W. (2012). Time to work or time to play: The effect of student employment on homework, sleep, and screen time. Labour Economics, $19,211-221$.

Karver, C. L., Wade, S. L., Cassedy, A., Taylor, H. G., Stancin, T., Yeates, K. O., \& Walz, N. C. (2012). Age at injury and long-term behavior problems after traumatic brain injury in young children. Rehabilitation Psychology, 57, 256-265.

Keiser, H. N., Sackett, P. R., Kuncel, N. R., \& Brothen, T. (2016). Why women perform better in college than admission scores would predict: Exploring the roles of conscientiousness and course-taking patterns. Journal of Applied Psychology, $101,569-581$.

Keniston, K. (1978). All our children. Across the Board, 15, 61-8.

Kenny, M. E. (1987). The extent and function of parental attachment among first-year college students. Journal of Youth and Adolescence, 16, 17-29.

Kenny, M. E., Blustein, D. L., Chaves, A., Grossman, J. M., \& Gallagher, L. A. (2003). The role of perceived barriers and relational support in the educational and vocational lives of urban high school students. Journal of Counseling Psychology, $50,142-149$.

Kennedy, M. R., \& Coelho, C. (2005). Self-regulation after traumatic brain injury: A framework for intervention of memory and problem solving. Strategies, 12, 13. 
Kennedy, M. R., \& Krause, M. O. (2011). Self-regulated learning in a dynamic coaching model for supporting college students with traumatic brain injury: Two case reports. The Journal of Head Trauma Rehabilitation, 26, 212-223.

Kennedy, M. R., Krause, M. O., \& O’Brien, K. H. (2014). Psychometric properties of the college survey for students with brain injury: Individuals with and without traumatic brain injury. Brain Injury, 28, 1748-1757.

Kennedy, M. R., Krause, M. O., \& Turkstra, L. S. (2008). An electronic survey about college experiences after traumatic brain injury. NeuroRehabilitation, 23, 511520 .

Kernie, S. G., Erwin, T. M., \& Parada, L. F. (2001). Brain remodeling due to neuronal and ast ocytic proliferation after controlled cortical injury in mice. Journal of Neuroscience Research, 66, 317-326.

Khattab, N. (2015). Students' aspirations, expectations and school achievement: What really matters? British Educational Research Journal, 41, 731-748.

King, G. A. (2004). The meaning of life experiences: Application of a meta-model to rehabilitation sciences and services. American Journal of Orthopsychiatry, 74, 72-88.

Kishimoto, N., Shimizu, K., \& Sawamoto, K. (2012). Neuronal regeneration in a zebrafish model of adult brain injury. Disease Models and Mechanisms, 5, 200209.

Kolb, B., Forgie, M., Gibb, R., Gorny, G., \& Rowntree, S. (1998). Age, experience and the changing brain. Neuroscience \& Biobehavioral Reviews, 22, 143-159.

Komarraju, M., \& Nadler, D. (2013). Self-efficacy and academic achievement: Why do implicit beliefs, goals, and effort regulation matter? Learning and Individual Differences, 25, 67-72.

Kraus, M. W., \& Tan, J. J. (2015). Americans overestimate social class mobility. Journal of Experimental Social Psychology, 58, 101-111.

Kuh, G. D., Kinzie, J., Buckley, J. A., Bridges, B. K., \& Hayek, J. C. (2011). Piecing together the student success puzzle: Research, propositions, and recommendations: ASHE higher education report (vol. 116). Hoboken, NJ: John Wiley \& Sons.

Laberge, M., \& Ledoux, E. (2011). Occupational health and safety issues affecting young workers: A literature review. Work, 39, 215-232.

Lammers, W. J., Onweugbuzie, A. J., \& Slate, J. R. (2001). Academic success as a function of gender, class, age, study habits, and employment of college students. Research in the Schools, 8, 71-81.

Lane, J. A. (2013). The impact of attachment working models and social support on the subjective and psychological wellbeing of emerging adults in transition: Testing a 
theoretical mediation model (Order No. 10306194). Available from ProQuest Dissertations \& Theses A\&I; ProQuest Dissertations \& Theses Global. (1857876854). Retrieved from http://ezproxy.fiu.edu/login?url=https://searchproquest-com.ezproxy.fiu.edu/docview/1857876854?accountid=10901

Lane, J. A. (2014). Counseling emerging adults in transition: Practical applications of attachment and social support research. The Professional Counselor, 5, 30-42

Lazzeroni, L. C., \& Ray, A. (2012). The cost of large numbers of hypothesis tests on power, effect size and sample size. Molecular Psychiatry, 17, 108-14.

Lee, C., \& Gramotnev, H. (2007). Life transitions and mental health in a national cohort of young Australian women. Developmental Psychology, 43, 877-884.

Lent, R. W., Miller, M. J., Smith, P. E., Watford, B. A., Hui, K., \& Lim, R. v H. (2015). Social cognitive model of adjustment to engineering majors: Longitudinal test across gender and race/ethnicity. Journal of Vocational Behavior, 86, 77-85.

Levett-Jones, T., \& Lathlean, J. (2008). Belongingness: A prerequisite for nursing students' clinical learning. Nurse Education in Practice, 8, 103-111.

Levinson, D. J. (1978). The seasons of a man's life. Westminster, MD: Random House Digital, Inc.

Lopez, J. D. (2018). Factors influencing American Indian and Alaska Native postsecondary persistence: AI/AN millennium falcon persistence model. Research in Higher Education, 59, 792-811.

Liu, R., \& Liu, E. (2000). Institutional Integration: An Analysis of Tinto's Theory. Retrieved from Eric Database. (ED445629)

Lorenzetti, J.P. (2009). Student satisfaction and retention: Understanding the year-by year relationship. Recruitment and Retention in Higher Education, 23, 5-6.

Lott, B. (2012). The social psychology of class and classism. American Psychologist, 67, 650-659.

Lythgow, K. T., Hudson, G., Andras, P., \& Chinnery, P. F. (2011). A critical analysis of the combined usage of protein localization prediction methods: Increasing the number of independent data sets can reduce the accuracy of predicted mitochondrial localization. Mitochondrion, 11, 444-449.

Mallya, S., Sutherland, J., Pongracic, S., Mainland, B., \& Ornstein, T. J. (2015). The manifestation of anxiety disorders after traumatic brain injury: a review. Journal of Neurotrauma, 32, 411-421.

Manthei, R. J., \& Gilmore, A. (2005). The effect of paid employment on university students' lives. Education+ Training, 47, 202-215.

Markle, G. (2015). Factors influencing persistence among nontraditional university students. Adult Education Quarterly, 65, 267-285. 
Martin, J. S., Hébert, M., Ledoux, É., Gaudreault, M., \& Laberge, L. (2012). Relationship of chronotype to sleep, light exposure, and work-related fatigue in student workers. Chronobiology International, 29, 295-304.

Maslow, A. H. (1943). A theory of human motivation. Psychological Review, 50, 370.

Mason, M. P. (2016). Traumatic brain injury basics [Web log Post]. Retrieved from http://www.brainline.org/content/2009/06/tbi-basics_pageall.html.

Masten, A. S., Burt, K. B., Roisman, G. I., Obradović, J., Long, J. D., \& Tellegen, A. (2004). Resources and resilience in the transition to adulthood: Continuity and change. Development and Psychopathology, 16, 1071-1094.

Mau, W. C. J. (2016). Characteristics of US students that pursued a STEM major and factors that predicted their persistence in degree completion. Universal Journal of Educational Research, 4, 1495-1500.

McMahon, P. J., Hricik, A., Yue, J. K., Puccio, A. M., Inoue, T., Lingsma, H. F., ... \& Okonkwo and the TRACK-TBI investigators including, D. O. (2014). Symptomatology and functional outcome in mild traumatic brain injury: results from the prospective TRACK-TBI study. Journal of Neurotrauma, 31, 26-33.

Mezirow, J. (2000). Learning to think like an adult. Learning as Transformation: Critical Perspectives on a Theory in Progress, 24, 3-33.

Mezirow, J., \& Taylor, E. W. (2009). Transformative learning in practice: Insights from community, workplace, and higher education. Hoboken, New Jersey: John Wiley \& Sons.

Miller, K., Danner, F., \& Staten, R. (2008). Relationship of work hours with selected health behaviors and academic progress among a college student cohort. Journal of American College Health, 56, 675-679.

Moschetti, R. V., \& Hudley, C. (2015). Social capital and academic motivation among first-generation community college students. Community College Journal of Research and Practice, 39, 235-251.

Motrenko, A., Strijov, V., \& Weber, G. W. (2014). Sample size determination for logistic regression. Journal of Computational and Applied Mathematics, 255, 743-752.

Mueller, B. K., Mueller, R., \& Schoemaker, H. (2009). Stimulating neuroregeneration as a therapeutic drug approach for traumatic brain injury. British Journal of Pharmacology, 157, 675-685.

National Institute of Health. (n.d.). Neuro QoL [Weblog post]. Retrieved from http://www.healthmeasures.net/explore-measurement-systems/neuro-qol

Ness, B. M., Rocke, M. R., Harrist, C. J., \& Vroman, K. G. (2014). College and combat trauma: An insider's perspective of the post-secondary education experience shared by service members managing neurobehavioral symptoms.

NeuroRehabilitation, 35, 147-158. 
Ness, B. M., \& Vroman, K. (2014). Preliminary examination of the impact of traumatic brain injury and posttraumatic stress disorder on self-regulated learning and academic achievement among military service members enrolled in postsecondary education. The Journal of Head Trauma Rehabilitation, 29, 33-43.

Neumann, Y., \& Finaly-Neumann, E. (1989). Predicting juniors' and seniors' persistence and attrition: A quality of learning experience approach. The Journal of Experimental Education, 57, 129-140.

Nimon, K., \& Reio Jr, T. G. (2011). Measurement invariance: A foundational principle for quantitative theory building. Human Resource Development Review, 10, 198214.

Non, A., \& Tempelaar, D. (2016). Time preferences, study effort, and academic performance. Economics of Education Review, 54, 36-61.

Nonis, S. A., \& Hudson, G. I. (2006). Academic performance of college students: Influence of time spent studying and working. Journal of Education for Business, 81, 151-159.

Nonis, S. A., \& Wright, D. (2003). Moderating effects of achievement striving and situational optimism on the relationship between ability and performance outcomes of college students. Research in Higher Education, 44, 327-346.

Norstrom, M., \& Lubkin, I. (1990). Quality of life. In I. M. Lubkin (Ed.), Chronic illness: Impact and interventions (2nd ed. pp. 134-154). Boston, MA: Jones \& Bartlett.

Nudo, R. J. (2013). Recovery after brain injury: mechanisms and principles. Frontiers in Human Neuroscience, 7, 887-895.

Nuñez, A. M., \& Sansone, V. A. (2016). Earning and learning: Exploring the meaning of work in the experiences of first-generation Latino college students. The Review of Higher Education, 40, 91-116.

O'Neill, S., \& Thomson, M. M. (2013). Supporting academic persistence in low-skilled adult learners. Support for Learning, 28, 162-172.

Ongowo, R. O., \& Hungi, S. K. (2014). Motivational beliefs and self-regulation in biology learning: Influence of ethnicity, gender and grade level in Kenya. Creative Education, 5, 218-224.

Oyserman, D. (2013). Not just any path: Implications of identity-based motivation for disparities in school outcomes. Economics of Education Review, 33, 179-190.

Oyserman, D., Destin, M., \& Novin, S. (2015). The context-sensitive future self: Possible selves motivate in context, not otherwise. Self and Identity, 14, 173-188.

Oyserman, D., Smith, G. C., \& Elmore, K. (2014). Identity-based motivation: Implications for health and health disparities. Journal of Social Issues, 70, 206225. 
Özsoy-Güneş, Z., Güneş, İ., \& Kırbaşlar, M. (2014). Investigation of the relationships between educational internet use self-efficacy beliefs and self-regulated learning skills. Procedia-Social and Behavioral Sciences, 152, 708-713.

Pareja, A. S. The effect of parental employment on children's academic achievement in the context of welfare reform Available from Social Science Premium Collection. (61633474; 200706823). Retrieved from http://ezproxy.fiu.edu/login?url=https://search-proquestcom.ezproxy.fiu.edu/docview/61633474?accountid=10901

Pell Institute. (2015). Time use of full-time college students ages 18 to 242003 to 2014. Postsecondary Education Opportunity, 276.

Peng, C. (2012). Self-regulated Learning Behavior of College Students of Art and Their Academic Achievement. Physics Procedia, 33, 1451-1455.

Perez, T., Cromley, J. G., \& Kaplan, A. (2014). The role of identity development, values, and costs in college STEM retention. Journal of Educational Psychology, 106, 315-324.

Prasad, M. R., Swank, P. R., \& Ewing-Cobbs, L. (2017). Long-term school outcomes of children and adolescents with traumatic brain injury. The Journal of Head Trauma Rehabilitation, 32, E24.

Prat-Sala, M., \& Redford, P. (2010). The interplay between motivation, self-efficacy, and approaches to studying. British Journal of Educational Psychology, 80, 283-305.

Ransom, D. M., Vaughan, C. G., Pratson, L., Sady, M. D., McGill, C. A., \& Gioia, G. A. (2015). Academic effects of concussion in children and adolescents. Pediatrics, $135,1043-1050$.

Reio, T. G., Jr. (2011). Supervisor and coworker incivility: Testing the work frustrationaggression model. Advances in Developing Human Resources, 13, 54-68.

Reio Jr, T. G., Portes, P. R., \& Nixon, C. B. (2014). Differences in identity style and process: Can less be more. New Horizons in Adult Education and Human Resource Development, 26, 26-40.

Resch, J. A., Villarreal, V., Johnson, C. L., Elliott, T. R., Kwok, O. M., Berry, J. W., \& Underhill, A. T. (2009). Trajectories of life satisfaction in the first 5 years following traumatic brain injury. Rehabilitation Psychology, 54, 51-59.

Rosema, S., Muscara, F., Anderson, V., Godfrey, C., Eren, S., \& Catroppa, C. (2014). Agreement on and predictors of long-term psychosocial development 16 years post-childhood traumatic brain injury. Journal of Neurotrauma, 31, 899-905.

Rosenfeld, J. V., Maas, A. I., Bragge, P., Morganti-Kossmann, M. C., Manley, G. T., \& Gruen, R. L. (2012). Early management of severe traumatic brain injury. The Lancet, 380, 1088-1098. 
Ryan, R. M., \& Deci, E. L. (2000). Intrinsic and extrinsic motivations: Classic definitions and new directions. Contemporary Educational Psychology, 25, 54-67.

Salsman, J. M., Lai, J., Hendrie, H. C., Butt, Z., Zill, N., Pilkonis, P. A., . . Cella, D. (2014). Assessing psychological well-being: Self-report instruments for the NIH toolbox. Quality of Life Research, 23, 205-15.

Sanchez, J. E., Lowman, J. L., \& Hill, K. A. (2016). Performance and persistence outcomes of EAR UP students: Leveling the playing field in higher education. Journal of College Student Retention: Research, Theory \& Practice, 44, 1521025116669954.

Sanchez, J. E., \& Smith, J. (2017). Non-US citizen, community college students: Their federal student aid status, gender, achievement, and persistence at an emerging HSI. Journal of Student Financial Aid, 47, 3-12.

Sander, A. M., Kreutzer, J. S., Rosenthal, M., Delmonico, R., Young, M. E. (1996) A multicenter longitudinal investigation of return to work and community integration following traumatic brain injury. Journal of Head Trauma Rehabilitation, 11, 70-84.

Sandhaug, M., Andelic, N., Langhammer, B., \& Mygland, A. (2015). Functional level during the first 2 years after moderate and severe traumatic brain injury. Brain Injury, 29, 1431-1438.

Sariaslan, A., Sharp, D. J., D’Onofrio, B. M., Larsson, H., \& Fazel, S. (2016). Long-term outcomes associated with traumatic brain injury in childhood and adolescence: a nationwide Swedish cohort study of a wide range of medical and social outcomes. PLoS Medicine, 13, e1002103.

Schneider, E. B., Sur, S., Raymont, V., Duckworth, J., Kowalski, R. G., Efron, D. T., \& Stevens, R. D. (2014). Functional recovery after moderate/severe traumatic brain injury A role for cognitive reserve? Neurology, 82, 1636-1642.

Scott, C., McKinlay, A., McLellan, T., Britt, E., Grace, R., \& MacFarlane, M. (2015). A comparison of adult outcomes for males compared to females following pediatric traumatic brain injury. Neuropsychology, 29, 501.

Seibert, P. S., Reedy, D. P., Hash, J., Webb, A., Stridh-Igo, P., Basom, J., \& Zimmerman, C. G. (2002). Brain injury: quality of life's greatest challenge. Brain Injury, 16, $837-848$

Senler, B., \& Sungur-Vural, S. (2014). Pre-service science teachers' use of selfregulation strategies. Procedia-Social and Behavioral Sciences, 152, 551-556.

Soria, K.M. Weiner, B., Lu, E.C. (2014). Financial decisions among undergraduate students from low-income and working-class social class backgrounds. Journal of Student Financial Aid, 44, 2-24. 
Spady, W. G. (1970). Dropouts from higher education: An interdisciplinary review and synthesis. Interchange, 1, 64-85.

Spitzer, R. L., Kroenke, K., Williams, J. B., \& Löwe, B. (2006). A brief measure for assessing generalized anxiety disorder: the GAD-7. Archives of Internal Medicine, 166, 1092-1097.

Staff, J., Schulenberg, J. E., \& Bachman, J. G. (2010). Adolescent work intensity, school performance, and academic engagement. Sociology of Education, 83, 183-200.

Stebleton, M. J., Soria, K. M., \& Huesman, R. L. (2014). First-generation students' sense of belonging, mental health, and use of counseling services at public research universities. Journal of College Counseling, 17, 6-20.

Sternberg, R. J. (1985). Implicit theories of intelligence, creativity, and wisdom. Journal of Personality and Social Psychology, 49, 607.

Steinberg, L., \& Cauffman, E. (1996). Maturity of judgment in adolescence: Psychosocial factors in adolescent decision making. Law and Human Behavior, 20, 249-272.

Stephens, N. M., Brannon, T. N., Markus, H. R., \& Nelson, J. E. (2015). Feeling at home in college: Fortifying school-relevant selves to reduce social class disparities in higher education. Social Issues and Policy Review, 9, 1-24.

Stewart, S., Lim, D. H., \& Kim, J. (2015). Factors influencing college persistence for first-time students. Journal of Developmental Education, 38, 12-20.

Stillman, T. F., \& Lambert, N. M. (2013). The bidirectional relationship of meaning and belonging. In The experience of meaning in life (pp. 305-315). New York, NY: Springer.

Strauss, L. C., \& Volkwein, J. F. (2002). Comparing student performance and growth in 2-and 4-year institutions. Research in Higher Education, 43, 133-161.

Sun, D. (2014). The potential of endogenous neurogenesis for brain repair and regeneration following traumatic brain injury. Neural Regeneration Research, 9, 688.

Tanner, J. L., \& Arnett, J. J. (2011).. Presenting "emerging adulthood": What makes it developmentally distinctive? In J. Arnett, M. Kloep, L. Hendry, J. Tanner (Eds.), Debating emerging adulthood: Stage or process, (pp. 13-30). New York, NY: Oxford University Press.

Taylor, C. A., Bell, J. M., Breiding, M. J., \& Xu, L. (2017). Traumatic Brain InjuryRelated Emergency Department Visits, Hospitalizations, and Deaths-United States, 2007 and 2013. Morbidity and Mortality Weekly Report. Surveillance Summaries (Washington, DC: 2002),66(9), 1-16.

Teasdale, G., Maas, A., Lecky, F., Manley, G., Stocchetti, N., \& Murray, G. (2014). The glasgow coma scale at 40 years: Standing the test of time. The Lancet Neurology, $13,844-854$. 
Therriault, S. B., \& Krivoshey, A. (2014). College persistence indicators research review. American Institutes for Research, 1-19.

Thurlow, M., Quenemoen, R., Altman, J., \& Cuthbert, M. (2008). Trends in the Participation and Performance of Students with Disabilities. Technical Report 50. National Center on Educational Outcomes, University of Minnesota.

Tinto, V. (1973). College proximity and rates of college attendance. American Educational Research Journal, 10, 277-293.

Tinto, V. (1993). Leaving college: Rethinking the causes and cures of student attrition ( $2^{\text {nd }}$ ed.). Chicago, IL: The University of Chicago Press.

Tinto, V. (2016, September 26). From retention to persistence, [Web log post]. Retrieved from https://www.insidehighered.com/views/2016/09/26/how-improve-studentpersistence-and-completion-essay

Todis, B., \& Glang, A. (2008). Redefining success: Results of a qualitative study of postsecondary transition outcomes for youth with traumatic brain injury. The Journal of Head Trauma Rehabilitation, 23, 252-263.

Todis, B., Glang, A., Bullis, M., Ettel, D., \& Hood, D. (2011). Longitudinal investigation of the post-high school transition experiences of adolescents with traumatic brain injury. Journal of Head Trauma Rehabilitation, 26, 138-149.

Tovar, E. (2015). The role of faculty, counselors, and support programs on Latino/a community college students' success and intent to persist. Community College Review, 43, 46-71.

Trainor, A. A. (2008). Using cultural and social capital to improve postsecondary outcomes and expand transition models for youth with disabilities. The Journal of Special Education, 42, 148-162.

Triventi, M. (2014). Does working during higher education affect students' academic progression? Economics of Education Review, 41, 1-13.

Tucker, M., \& Degeneffe, C. E. (2013). Future concerns among families following brain injury in the United States: Views from the Brain Injury Association of America state affiliates. The Australian Journal of Rehabilitation Counselling, 19, 135141.

United States Department of Veterans Affairs. (2018). Traumatic brain injury. MyHealtheVet Veterans Health Library. Washington, DC: U.S. Government Printing Office.

Velikonja, D., Warriner, E., \& Brum, C. (2010). Profiles of emotional and behavioral sequelae following acquired brain injury: cluster analysis of the Personality Assessment Inventory. Journal of Clinical and Experimental Neuropsychology, $32,610-621$. 
Walsh, K. J., \& Robinson Kurpius, S. E. (2016). Parental, residential, and self-belief factors influencing academic persistence decisions of college freshmen. Journal of College Student Retention: Research, Theory \& Practice, 18, 49-67.

Webb, O. J., \& Cotton, D. R. E. (2018). Deciphering the sophomore slump: changes to student perceptions during the undergraduate journey. Higher Education, 44, 118.

Wehman, P. (2013). Life beyond the classroom (5th ed.). Baltimore, MD: Paul H. Brookes Publishing Co.

Weiss, D., Freund, A. M., \& Wiese, B. S. (2012). Mastering developmental transitions in young and middle adulthood: The interplay of openness to experience and traditional gender ideology on women's self-efficacy and subjective well-being. Developmental Psychology, 48, 1774-1788.

Wessel, R. D., Jones, J. A., Markle, L., \& Westfall, C. (2009). Retention and graduation of students with disabilities: Facilitating student success. Journal of Postsecondary Education and Disability, 21, 116-125.

Wigfield, A. (1994). Expectancy-value theory of achievement motivation: A developmental perspective. Educational Psychology Review, 6, 49-78.

Wigfield, A., \& Eccles, J. S. (2000). Expectancy-value theory of achievement motivation. Contemporary Educational Psychology, 25, 68-81.

Wiggam, M. K. (2004). Predicting adult learner academic persistence: Strength of relationship between age, gender, ethnicity, financial aid, transfer credits, and delivery methods (Doctoral dissertation, The Ohio State University).

Willer, B., Rosenthal, M., Kreutzer, J. S., Gordon, W. A., \& Rempel, R. (1993). Assessment of community integration following rehabilitation for traumatic brain injury. The Journal of Head Trauma Rehabilitation, 8, 75-87.

Williamson, M. L., Elliott, T. R., Bogner, J., Dreer, L. E., Arango-Lasprilla, J. C., Kolakowsky-Hayner, S. A., ... \& Perrin, P. B. (2016). Trajectories of life satisfaction over the first 10 years after traumatic brain injury: race, gender, and functional ability. The Journal of Head Trauma Rehabilitation, 31, 167-179.

Yosso, T. J. (2005). Whose culture has capital? A critical race theory discussion of community cultural wealth. Race Ethnicity and Education, 8, 69-91.

Zimmerman, B. J. (2013). Theories of self-regulated learning and academic achievement: An overview and analysis. In Self-regulated learning and academic achievement (pp. 10-45). New York, NY: Routledge. 
VITA

ARDITH CLAYTON-WRIGHT

EDUCATION, PROFESSIONAL AND ACADEMIC EXPERIENCES

$2016-2019$

Instructor (Credentialed)

EDF 1005 Introduction to Education (Hybrid)

EDF 1005 Introduction to Education 05 (Fully Online),

EDP 3004 Educational Psychology

Florida International University

Teaching Assistant

EDP 3004/5053 Educational Psychology

EDF 6211 Educational Psychology

LEI 3001 Introduction to Leisure and Recreation

LEI 3701 Introduction to Recreation Therapy

LEI 4941 Recreation Therapy Internship II

Florida International University

2014-2016

$2013-2019$

Managing Editor, New Horizon Journal AE/HRD

Florida International University

Doctorate in Adult Education/Human Resource Development

Minor in Disability

Florida International University, Miami, Florida

2000

Master of Public Health, concentration in Epidemiology

Research Project: Individuals with Sickle Cell Anemia

(Hemoglobinopathies) Awareness of Available Resources in South FloridaFlorida International University \& University of Miami,

Miami, Florida

1983

Bachelor of Science in Nutrition and Dietetics

Andrews University, Berrien Springs, Michigan

1999-2014

Florida Department of Health. Wellness Coordinator/Senior Public Health Nutritionist

1998-1999

Professional Nutrition Services. Nutrition Consultant

1995-1998

National Healthcare for South Florida. Clinical/Consultant Dietitian

1991-1995

Indian River Memorial Hospital, Vero Beach, Florida. Clinical Dietitian 
Academy of Graduates for Integrative Learning Experiences (AGILE). Florida International University Honor Society: Phi Kappa Phi. DELTA OMEGA honor Society in Public Health: Alpha Omega

\section{PUBLICATIONS AND PRESENTATIONS}

- Clayton-Wright, A. (2006). Nutrition and dietetics promotion among health professionals. Broward Dietetic Association.

- Clayton-Wright, A. (2007). Diabetes and hypertension. Recap of the CSC Youth Summit [MEDIA: WSFL-TV, CW 33. Becon TV]. Children's Services Council of Broward County

- Clayton-Wright, A. (2008). The pie... Which slice is yours? Nuts and bolts of networking. Broward County Dietetic Association, Fort Lauderdale, Florida.

- Clayton-Wright, A. (2010). Tips on grocery shopping for the holidays. Memorial Hospital District Diabetic Support Group.

- McGill, C. M., Heikkila, M. R., \& Clayton-Wright, A. (2015). Program evaluation primer: A review of three evaluations. South Florida Education Research Conference

- Nimblett, D., \& Clayton-Wright, A. (2016). Allegory of Mount Everest. AAACE Conference, Albuquerque, New Mexico.

- Wright, A. (1992). Nutritional care to persons with sickle cell disease. In H. Chen (Ed), Resource manual for hemoglobinopathies: An essential guide for health professionals (pp. 54-65). Columbus, Ohio: Ohio Department of Health Advisory Council on Universal Newborn Screening for Hemoglobinopathies. 